\title{
ESTIMATION OF 3-D REACTIVITIES OF VOLATILE ORGANIC COMPOUNDS USING ADJOINT SENSITIVITY ANALYSIS
}

by

Saba Hajaghassi

A thesis submitted to the Faculty of Graduate and Postdoctoral Affairs in partial fulfillment of the requirements for the degree of

Master of Applied Science in

Environmental Engineering

Carleton University

Ottawa, Ontario

August 2012

(C) 2012, Saba Hajaghassi 
Library and Archives

Canada

Published Heritage

Branch

395 Wellington Street

Ottawa ON K1A ON4

Canada
Bibliothèque et

Archives Canada

Direction du

Patrimoine de l'édition

395 , rue Wellington

Ottawa ON K1A ON4

Canada
Your file Votre référence

ISBN: 978-0-494-93477-7

Our file Notre référence

ISBN: $978-0-494-93477-7$
NOTICE:

The author has granted a nonexclusive license allowing Library and Archives Canada to reproduce, publish, archive, preserve, conserve, communicate to the public by telecommunication or on the Internet, loan, distrbute and sell theses worldwide, for commercial or noncommercial purposes, in microform, paper, electronic and/or any other formats.

The author retains copyright ownership and moral rights in this thesis. Neither the thesis nor substantial extracts from it may be printed or otherwise reproduced without the author's permission.
AVIS:

L'auteur a accordé une licence non exclusive permettant à la Bibliothèque et Archives Canada de reproduire, publier, archiver, sauvegarder, conserver, transmettre au public par télécommunication ou par l'Internet, prêter, distribuer et vendre des thèses partout dans le monde, à des fins commerciales ou autres, sur support microforme, papier, électronique et/ou autres formats.

L'auteur conserve la propriété du droit d'auteur et des droits moraux qui protege cette thèse. $\mathrm{Ni}$ la thèse ni des extraits substantiels de celle-ci ne doivent être imprimés ou autrement reproduits sans son autorisation.
In compliance with the Canadian Privacy Act some supporting forms may have been removed from this thesis.

While these forms may be included in the document page count, their removal does not represent any loss of content from the thesis.
Conformément à la loi canadienne sur la protection de la vie privée, quelques formulaires secondaires ont été enlevés de cette thèse.

Bien que ces formulaires aient inclus dans la pagination, il n'y aura aucun contenu manquant. 
To My Parents 


\section{ABSTRACT}

Ozone formation potential of volatile organic compounds (VOCs) in the troposphere varies significantly among species. This formation potential, referred to as incremental reactivity, is also different for various locations and times. Reactivity of organic compounds was traditionally calculated in box model simulations that do not account for physical variability in the atmosphere. Previous efforts for three-dimensional simulation of organic reactivities have been limited to forward sensitivity analysis methods where responses of ozone at various receptors to uniform changes in source emissions are calculated. This work is focused on quantification of three-dimensional reactivities using adjoint sensitivity analysis tools. The adjoint of CMAQ with SAPRC99 chemistry is used to elucidate location-dependent reactivities of 28 (lumped or explicit) species while preserving source specificity over a North American domain for the summer of 2007. Our results indicate the adjoint method is capable of capturing spatial variability. Measures of temporal variability in reactivity estimations showed rather lower variations as opposed to domain-wide variability. The highest reactivity for summer 2007 was found for Ethene, while less reactive compounds were associated with significant negative sensitivities over the domain. For most of the compounds our 3-D reactivities are comparable to the box model scales but notable (and at times significant) differences exist. Impact of different base mixtures on reactivity calculations is also explored but no significant impact on calculated reactivity scales is observed. 


\section{ACKNOWLEDGMENT}

This thesis would not have been possible without the guidance and help of several individuals who in one way or another contributed and extended their valuable assistance in the preparation and completion of this study. First and foremost, my utmost gratitude to my supervisor, Dr. Amir Hakami, Professor of the Civil and Environmental Engineering Department at Carleton University, who made me believe in myself, and guided me with great sincerity. Professor Hakami has been my inspiration as I hurdled different obstacles in the course of this research. His encouragements and support I shall never forget.

I am truly indebted and thankful to my colleague and friend, Morteza Mesbah, for his help and patience throughout this thesis. I would also like to acknowledge my coworkers in our research team who have been tremendously helpful in various aspects of this work. Furthermore, I owe sincere and earnest gratitude to Payal Chadha, the Graduate Administrator in the department, who until the last day had kind concern and consideration regarding my academic requirements.

Last but not the least, I would like to express my gratitude to my beloved family and friends, especially mom, dad and my sister, back home in Iran or elsewhere in the world, who have been a constant source of love, concern, support and strength all these years. I would like to give a special mention to my dear brother, Alireza Hajaghassi, whose pure love and sacrifice made this journey more desirable for me and more bearable for my family. 


\section{TABLE OF CONTENTS}

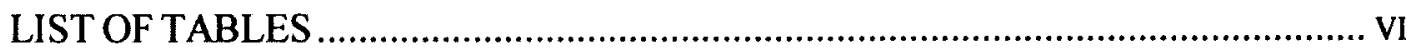

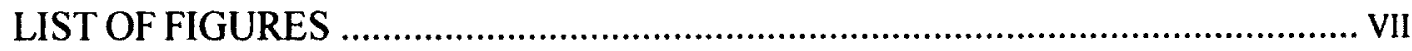

LIST OF ABBREVIATIONS.......................................................................... IX

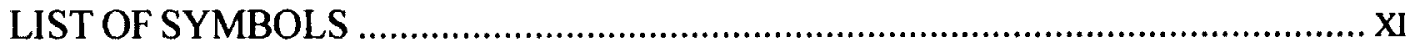

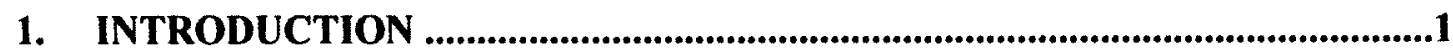

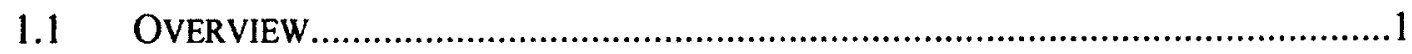

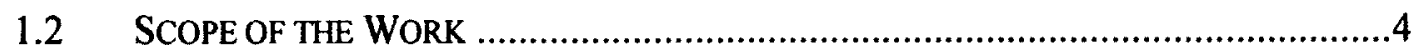

2. OZONE AND VOC REACTIVITY …....................................................................6

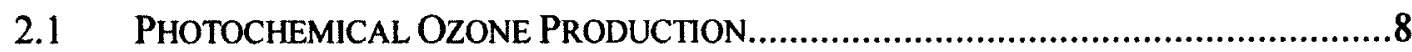

2.2 REACTIVITY OF VOLATILE ORGANIC COMPOUNDS …......................................

2.3 METHODS OF REACTIVITY EVALUATION ..................................................... 18

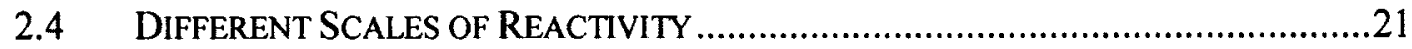

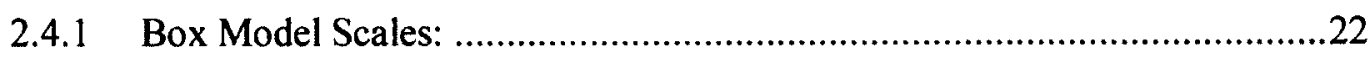

2.4.1.1 Maximum Incremental Reactivity .....................................................23

2.4.1.2 Maximum Ozone Incremental Reactivity (MOIR) ...............................23

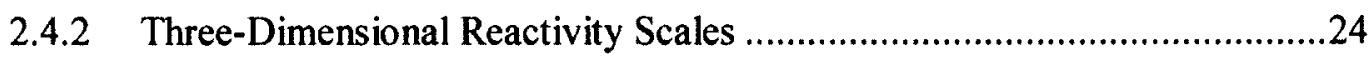

2.4.2.1 Maximum Incremental Reactivity- 3D ...............................................26

2.4.2.2 Peak Ozone Incremental Reactivity- 3D ...........................................26

2.4.2.3 Regional Average Ozone Metric (AV) ...............................................27

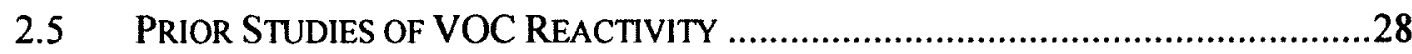

3. SENSITIVITY ANALYSIS IN AIR QUALITY MODELS ....................................33 
3.1 PRESENTATION OF PROCESSES IN MOdELING FRAMEWORK ..............................34

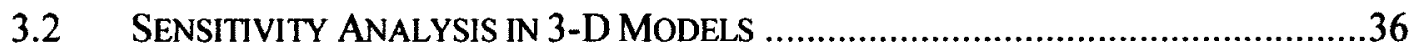

3.3 ANALYTICAL METHODS IN SENSITIVITY ANALYSIS ......................................

3.3.1 Decoupled Direct Method.............................................................40

3.3.2 Adjoint (Backward) Method .........................................................41

3.3.2.1 Prior studies of the adjo int method...........................................44

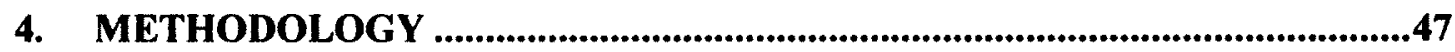

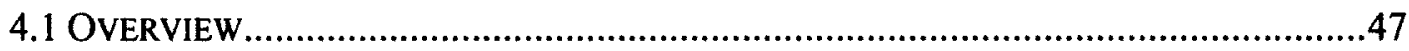

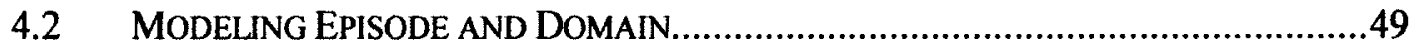

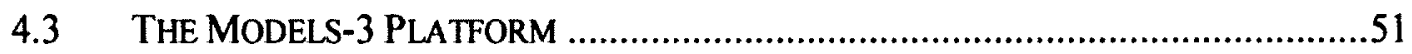

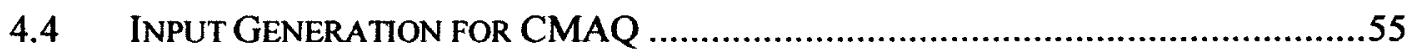

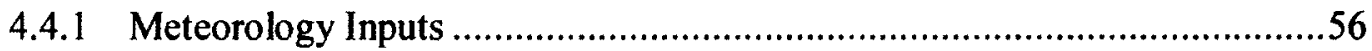

4.4.1.1 WRF Model.....................................................................56

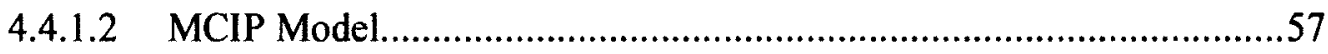

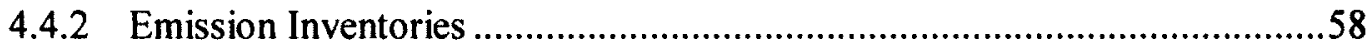

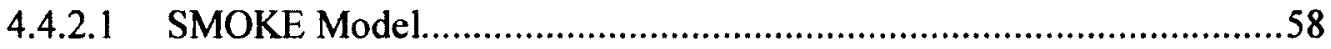

4.5 CMAQ PERFORMANCE EVALUATION ................................................61

4.6 REACTIVITy CALCUlation METHOdology ........................................62

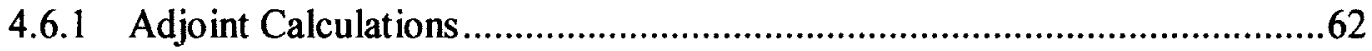

4.6.1.1 Adjoint Cost Function..........................................................64

4.6.1.2 Absolute Incremental Reactivities...........................................65

4.6.2 Base Mixture Specification............................................................66

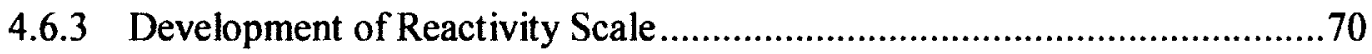


5. RESULTS AND DISCUSSION .............................................................................

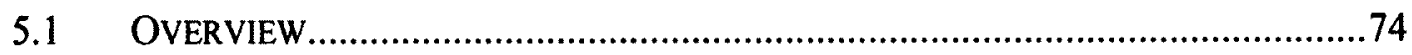

5.2 OZONE PROFILE OVER THE DOMAIN...........................................................

5.3 ABSOLUTE INCREMENTAL REACTIVITIES …….............................................

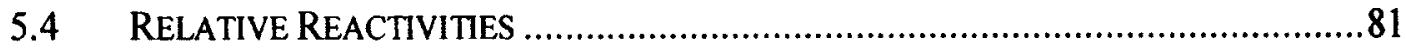

5.5 MEDIAN RELATIVE REACTIVITY (MRR) SCALE ..............................................

5.6 COMPARISON OF RESULTS WITH THE MIR SCALE ……...................................95

5.7 LOCAL BASE MIXTURE MRRS ..................................................................98

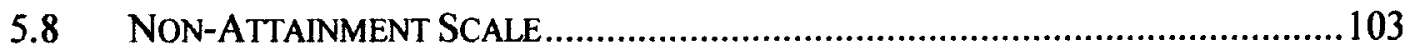

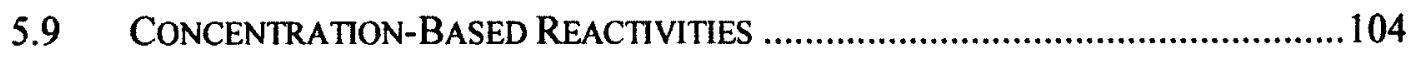

6. CONCLUSIONS AND FUTURE WORK ......................................................107

REFERENCES

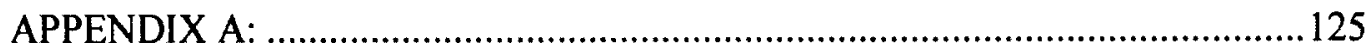

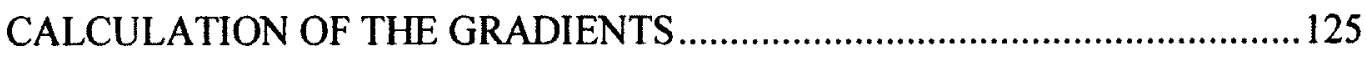

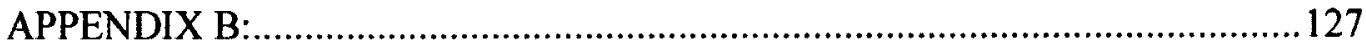

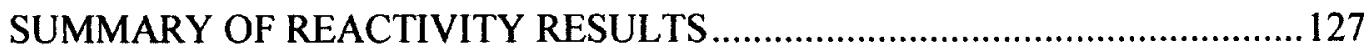




\section{LIST OF TABLES}

Table 4-1 CMAQ Model Specification.........................................................................5

Table 4-2: Monthly Average Emissions Over the Domain.....................................59

Table 4-3: Ozone Performance Statistics......................................................................62

Table 4-4: Base Mixture Composition........................................................68

Table 5-1: Ranking of VOCs with Respect to Median Relative...............................102

Table B-1: Median Relative Reactivities of Adjoint and Box Model Values..................132

Table B-2: Local MRR of Selected Compounds for Different Sites...............................133

Table B-3: MRRs for Concentration-Based and Non-Attainment Scenarios...................134 


\section{LIST OF FIGURES}

Figure 2-1: Ozone Isopleth Diagrams Showing the Nonlinear Response of Ozone to Emissions.

Figure 2-2: U.S. EPA Guideline on The Required Reduction in Hydrocarbon Emission Needed to Achieve the $80 \mathrm{ppb}$ Air-Quality Standard................................................15

Figure 2-3: Comparison of Box Model and 3-D Regional Model Incremental

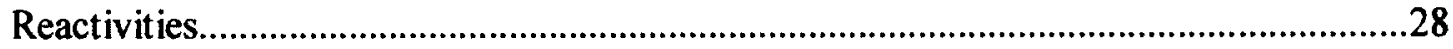

Figure 3-1: Comparison of Forward and Backward (Adjoint) Methods .42

Figure 4-1: Simulation Domain Covering North America: a) With a $36 \mathrm{Km}$ Horizontal Resolution and a) 34 Vertical Layers. .50

Figure 4-2: The Model-3 CMAQ and CMAQ-ADJ Modelling System, CCTM and

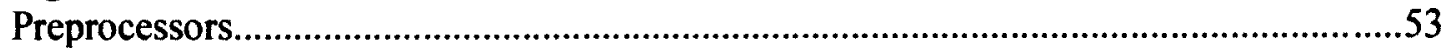

Figure 4-3: Total Emissions over the Episode of Three Months for Each Grid................60

Figure 4-4: Contribution of Each Particular VOC to the Base Mixture Derived from Anthropogenic Emissions........................................................................................ 72

Figure 4-5: Contribution of Each Particular VOC to the Base Mixture Derived from

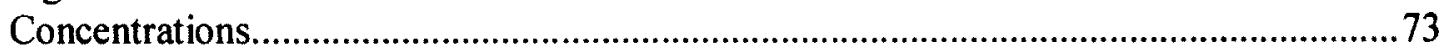

Figure 5-1: $\mathrm{O}_{3}$ Concentration at the Time of the Peak over the Domain...........................77

Figure 5-2: Adjoint Sensitivities of Maximum 8h-Averge Ozone (Absolute VOC Reactivities) For the Middle of summer 2007 .........................................................78

Figure 5-3: Adjoint Absolute Incremental Reactivities of Ethene Integrated for Each

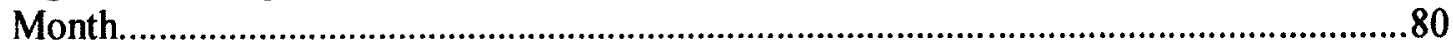

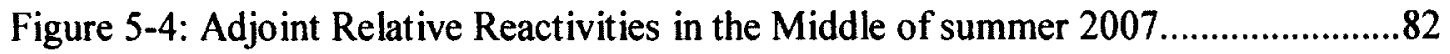

Figure 5-5: Median Metric Relative Reactivities of Ethene for Each Location.................86

Figure 5-6: Median Metric Relative Reactivities of Isoprene for Each Location..............87

Figure 5-7: Median Metric Relative Reactivities of Formaldehyde for Each Location....88

Figure 5-8: Median Metric Relative Reactivities of Methanol for Each Location. .89

Figure5-9: Median Metric Relative Reactivities of Lumped Aromatics for Each Location. . .90 
Figure 5-10: Local Median Relative Reactivity of High Reactive Compounds for Different Sites over the Domain.

Figure 5-11: Local Median Relative Reactivity of Low Reactive Compounds for Different Sites over the Domain.

Figure 5-12: Domain-Wide Median of MRR for the VOCs in the Base Mixture, Isoprene, Piene, and Carbon Monoxide. . .94

Figure 5-13: Comparison of Relative Box Model MIR Scale (Carter 2003) and 3-D Median Relative Reactivity......

Figure 5-14: Comparison of MIR Scale and 3-D Median Relative Reactivity When Species with High Discrepancies Were Removed from the List of Species.

Figure 5-15: Comparison of Median Relative Reactivities with Constant Base Mixture and Location-Wise Base Mixture. 100

Figure 5-16: Comparison of Non-Attainment Median Relative Reactivity with the Case with No Threshold over the Domain. 105

Figure 5-17: Comparison of Emission-Based and Concentration-Based Composition of Base Mixture Scenarios. 106

Figure B-1: Median Metric Relative Reactivities of Acetone for Each Location. 127

Figure B-2: Median Metric Relative Reactivities of Alkenes for Each Location. 128

Figure B-3: Median Metric Relative Reactivities of Banzaldehyde for Each Location..129

Figure B-4: Median Metric Relative Reactivities of Cresols for Each Location. 130

Figure B-5: Median Metric Relative Reactivities of Glyoxal for Each Location. 131 


\section{LIST OF ABBREVIATIONS}

\begin{tabular}{|c|c|}
\hline $\mathrm{ADE}$ & Atmospheric Diffusion Equation \\
\hline $\mathrm{AQM}$ & Air Quality Model \\
\hline AQS & Air Quality System \\
\hline AV & Regional Average Ozone Metric \\
\hline BCON & Boundary Condition PreProcessor \\
\hline $\mathrm{BF}$ & Brute-Force \\
\hline CAA & Clean Air Act \\
\hline CARB & California Air Resources Board \\
\hline CCTM & CMAQ Chemical Transport Model \\
\hline CMAQ & Community Multiscale Air Quality model \\
\hline CMAQ-ADJ & CMAQ Adjoint \\
\hline CTM & Chemical Transport Model \\
\hline CWS & Canada-Wide Standards \\
\hline DDM-3D & Decoupled Direct Method in Three Dimensions \\
\hline EBIR & Equal Benefit Incremental Reactivity \\
\hline EKMA & Empirical Kinetic Modeling Approach \\
\hline $\mathrm{GCM}$ & General Circulation Model \\
\hline ICON & Initial Condition PreProcessor \\
\hline IR & Incremental Reactivity \\
\hline MCIP & Meteorology Chemistry Interface Processor \\
\hline MFB & Mean Fractional Bias \\
\hline MFE & Mean Fractional Error \\
\hline MIR & Maximum Incremental Reactivity \\
\hline $\mathrm{MNB}$ & Mean Normalized Bias \\
\hline MNE & Mean Normalized Error \\
\hline MOIR & Maximum Ozone Incremental Reactivity \\
\hline MPI & Message Passing Interface \\
\hline MPICH & Message Passing Interface Chameleon \\
\hline MRR & Median Relative Reactivity \\
\hline
\end{tabular}


NAAQS National Ambient Air Quality Standards

NAPS National Air Pollution Surveillance

NEI National Emissions Inventory

$\mathrm{NO}_{\mathbf{x}} \quad$ Nitrogen Oxides

NRC National Research Center

PBL Planetary Boundary Layer

PM Particulate Matter

POIR Peak Ozone Incremental Reactivity

RIR Relative Incremental Reactivity

ROG Reactive Organic Gas

RRWG Reactivity Research Working Group

SAPRC Statewide Air Pollution Research Center

SIP State Implementation Plan

SMOKE Sparse Matrix Operator and Kernel Emissions

TLM Tangent Linear Model

US EPA United States Environmental Protection Agency

VOC Volatile Organic Compound

NMVOC Non Methane Volatile Organic Carbon 


\section{LIST OF SYMBOLS}

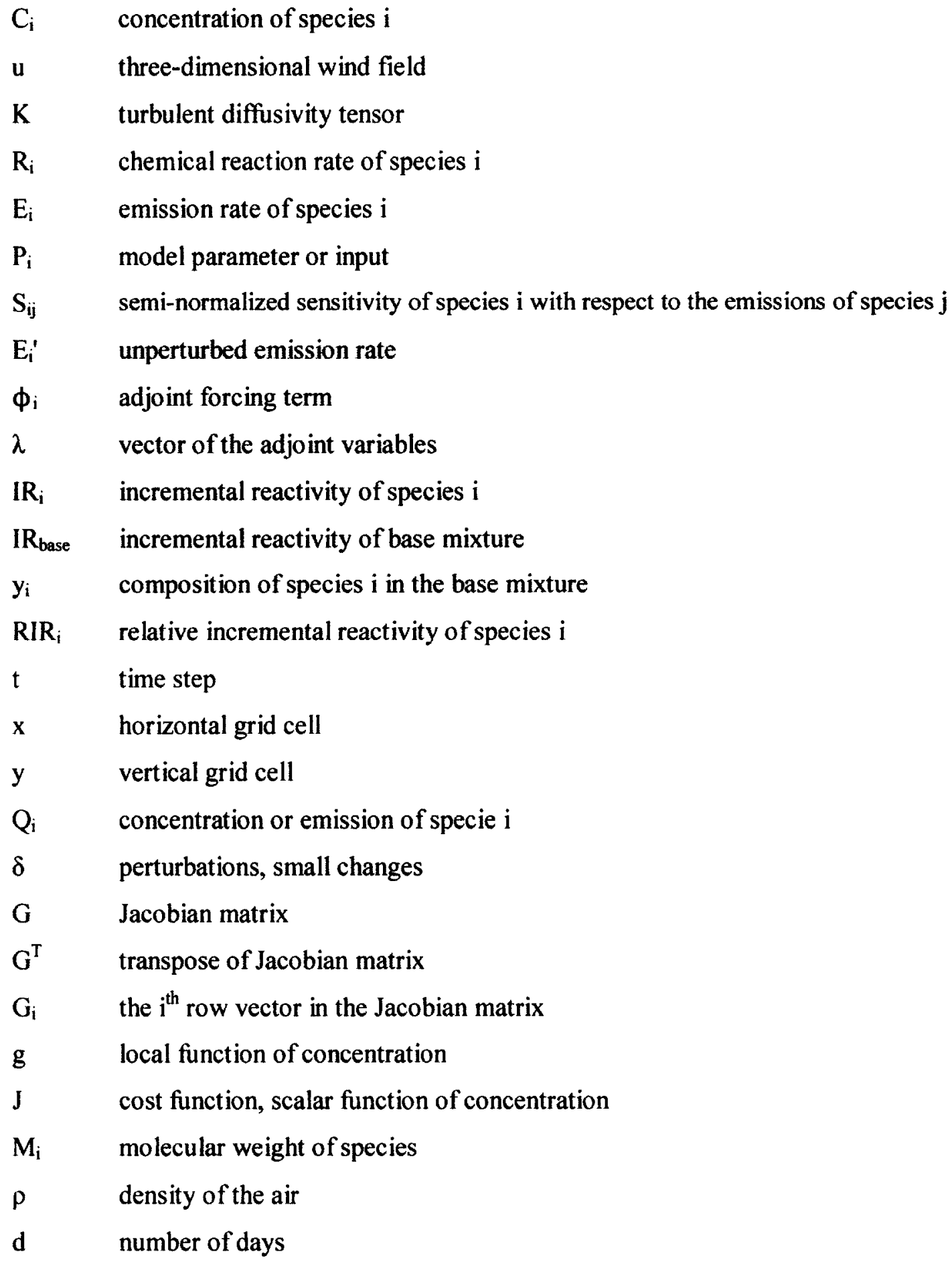




\section{Introduction}

\subsection{Overview}

Over the past decades, many regulations and control strategies have been promulgated and developed to ease the photochemical smog afflicting many urban areas across the nation. Ozone $\left(\mathrm{O}_{3}\right)$ in the troposphere, also referred to as the "ground-level ozone", and particulate matter (PM) are the major constituents of photochemical smog, and have long been a major concern for air quality managers. This is due to significant adverse impacts on human health [Lippmann, 2002] and ecosystems [NRC, 1991]. Ozone also plays an important role in tropospheric photochemistry, and in the formation of other pollutants [Seinfeld \& Pandis, 2006]. Majority of the population in North America live in non-attainment areas, i.e. locations with ozone levels above the standards [Bell et al., $2005]$

Ideally, air quality standards reflect maximum allowable levels for ambient ozone concentrations that ensure the health of population and/or ecosystem. In reality, these standards may also consider feasibility and technological availability. For example, the Canada-Wide Standards (CWS) for $\mathrm{O}_{3}$ is set at 65 parts per billion (ppb) for the average of 8 consecutive hours ( 8 -hour average) by the Environment Canada (2000). Likewise, National Ambient Air Quality Standards (NAAQS), set by the United States Environmental Protection Agency (US EPA), represents the maximum allowable groundlevel ozone concentrations across the United States [US EPA, 2008]. The NAAQS was set to $80 \mathrm{ppb}$ for an 8 -hour average, in 1997. Later on in 2008 , it was changed to more 
stringent threshold of $75 \mathrm{ppb}$. The NAAQS is established through the Clean Air Act (CAA), a set of comprehensive federal laws that regulates emissions of stationary and mobile sources and the ambient air quality.

CAA imposes controls on ozone formation by regulating both Volatile Organic Compounds (VOCs) and Nitrogen Oxide $\left(\mathrm{NO}_{\mathrm{x}}\right)$ emissions, to protect public health and welfare. $\mathrm{NO}_{\mathrm{x}}$ and VOCs are the main precursors of ozone, and reducing the emissions of either, depending on which is the limiting reagent, will result in a reduction in ozone concentration [Dodge, 1987]. The two limiting states are referred to as NOx-limited and VOC-limited (or NOx-saturated) photochemical regimes, where VOC controls and $\mathrm{NO}_{\mathbf{x}}$ controls are effective, respectively. Current regulations of volatile organic compounds are based on total mass of emissions. However, it has been recognized that each VOC have very different impact on the rate and amount of ozone formed in the atmosphere. In recent years, control strategies that encourage the use of less reactive VOCs have been recognized for their potential to provide cost-effective ozone control. This approach, called "selective targeting" or substitution of the VOCs, provides industries with valuable flexibility in meeting ozone attainment, by allowing them to adopt innovative manufacturing techniques and to develop more effective product formulations. By executing a strategy where pollutants with lower ozone forming potential are released to the atmosphere, the VOC emission controls become more cost-effective, and a greater flexibility to the regulated community is achieved. This ozone formation potential of organic compounds is referred to as "reactivity" of VOCs. The EPA continues to update the regulations as part of the California State Implementation Plan (SIP) for ozone as 
amended in 1990. This California regulation adopts a new approach to reducing ozone formation from VOCs [US EPA, 2005].

Traditionally, comprehensive VOC reactivity scales have been calculated using box or trajectory models with a single well-mixed cell representing the pollution scenario. Box model are used so as to represent the many types of VOCs that are of interest. This group of models permit a variety of chemical conditions to be modeled in a computationally efficient manner. However, such models necessarily have highly simplified representations of conditions in actual airsheds, and simulations cannot represent any single reality episode or multi-day effects [Hakami et al., 2004a]. Consequently, the scenarios and methodologies used to develop the current scales do not account for physical variability within the atmosphere and do need an update, which is most effectively achieved through three-dimensional modeling [Carter, 2009].

As a secondary pollutant, regional levels of ozone are governed by the interactions of complex physical and chemical processes; hence the use of Air Quality Models (AQMs); they are the only prognostic tool available to the policy-making community. An additional advantage of AQMs is that their results can be analyzed and presented in numerous ways, including the application of a variety of reactivity metrics and the construction of detailed process budgets. AQMs differ in characterizing chemical and physical processes, choice of numerical solution and adapting the model to the episode of interest. Chemical Transport Models (CTMs) have been widely used for regional 3-D model reactivity metrics. In response to particular emission inputs and meteorological conditions, CTMs calculate concentration of ozone or other pollutants. Previous three-dimensional simulations of reactivities have been limited to forward 
sensitivity, where a source-oriented approach is used to calculate the sensitivities of ozone. A clearer insight on emitters of VOCs is attempted to be reached through adjoint sensitivity analysis which is characterized by source specific information. While there are many benefits to a practical, cost-effective, and enforceable policy based on reactivity of VOCs, there are nonetheless significant hurdles in their implementation of them, and further research is needed to solve these issues.

\subsection{Scope of the Work}

The primary objective of this work is to acquire an indication of whether reactivity-based policies are really as effective in reducing ozone on multiple scales as it is hoped, and if so, what type of reactivity quantification should be used. This purpose is met through quantitative evaluation of three-dimensional reactivities of VOCs conducted over North American domain. Backward sensitivity analysis or Adjoint method is implemented using the US EPA's Community Multiscale Air Quality (CMAQ) model, applied over United States and Canada for reactivity assessment. CMAQ is a widely used and meticulously evaluated regional scale chemical transport model with a fine spatial gridding. We make an effort to take a closer look at the plethora of information available in the form of sensitivity analysis in order to summarize them into applicable reactivity scales. In the current work a backward sensitivity analysis of VOC reactivities are used, where ozone formation is integrated backward in time to get more specificity on the sources of emissions. The following analysis should result in establishment of more robust reactivity evaluation than are currently available. 
The approaches documented in this study can be summarized into four categories:

- Numerical quantification of North America ozone level sensitivity to emission sources of volatile organic compounds everywhere in the domain, which will breed in VOC reactivities.

- Developing an applicable reactivity metric over the domain and episodes of the study.

- Evaluating the validity of the metric with previous studies, and also when the metric is applied to a specific location.

Different air quality metrics of interest are also implemented, which can later be used to set more solid strategies for VOC-based controls. Each approach provides a distinct perspective to the quantification of 3-D reactivities.

The thesis is organized into 5 chapters: In Chapter 2, ozone formation and its nonlinear chemistry is introduced. This section also contains a summary on reactivity scales, and later on discusses and reviews previous studies on reactivity of VOCs. A concise overview of the air quality modelling, methods of sensitivity analysis, and details on adjoint approach is provided in Chapter 3. Chapter 4 characterizes different aspects of this study such as the domain, inputs, and their applications. This chapter also depicts the methodology used to derive the reactivity scales and the metric implemented in this research. Results and their discussion of them are presented in Chapter 5. Chapter 6 concludes this thesis with its key findings, and discusses potential improvements for future studies. 


\section{Ozone and VOC Reactivity}

The troposphere is the lowest layer of the Earth's atmosphere, and extends from the surface up to a height of 7 to $20 \mathrm{~km}$. The lowest part of the troposphere, the planetary boundary layer (PBL), ranges up to 3000 metres. In the PBL horizontal movement of air is affected by the surface friction, and therefore winds are weaker than those in higher altitudes of the free troposphere. However, convective mixing within the PBL results in effective dilution of the pollutants that are emitted at the surface. Since this layer also contains the air that populations are exposed to, the PBL is of greater interest for air quality purposes.

Ozone at high ground level concentrations, is a major constituent of air pollution, and has significant effects on human health. Ambient ozone exposure is of concern due to its effect on the respiratory system, such as causing pulmonary stress in humans. Longterm exposure to ozone can lead to irreversible changes in the lungs, which in turn could lead to premature lung aging and/or chronic respiratory illnesses [Bell et al., 2005; US EPA, 2011]. Ozone is also associated with mortality due to short-term [Bell et al., 2004] and long-term exposures [Jerrett et al., 2009]. Ozone can also significantly impact vegetation, ecosystem, forest growth, and productivity of crops, and can also increase a forest's susceptibility to pest attacks [Emberson et al., 2001].

Ozone in the lower troposphere may be a result of downward intrusion of stratospheric ozone. However, its major source is the photochemical reactions involving $\mathrm{NO}_{\mathrm{x}}$ and a variety of VOCs in the presence of sunlight [Seinfeld \& Pandis, 2006], which can result in ozone formation hundreds of kilometres from the source of the original VOC 
and $\mathrm{NO}_{\mathbf{x}}$ emissions [NRC, 1991]. Ozone is a secondary pollutant, meaning that it is not emitted directly into the atmosphere. Anthropogenic $\mathrm{NO}_{\mathrm{x}}$ is mainly emitted from combustion and through mobile sources and power plants; $\mathrm{NO}_{\mathrm{x}}$ emissions from automobiles consist of approximately $90 \% \mathrm{NO}$ and $10 \% \mathrm{NO}_{2}$. On the other hand, VOCs are released from a wider range of sources, including automobiles, various industrial processes, solvent use, and vegetation. In order to reduce ozone concentrations in the troposphere, the regulations should be applied to the emissions of its precursors, VOCs and $\mathrm{NO}_{\mathbf{x}}$.

Volatile organic compounds are generally regulated on a mass basis. This means they are treated equally mass in the regulatory context, regardless of their unique ability to form ozone in the atmosphere. However, the VOCs emitted into the atmosphere can differ extensively in their effects on ozone formation, due to the wide variety of sources, reaction rates, and reaction pathways for each VOC [Atkinson, 1994; 2000]. The differences in impact on ozone formation, is referred to as the reactivity of the VOCs. Ozone control strategies that take this characterization into account have the potential to be more efficient and cost-effective than those that consider all VOCs evenly. Whereas uncertainties still exist in our understanding of tropospheric photochemistry, the basic sets of ozone-producing reactions have been identified. The set of reactions that leads emissions to ozone formation are usually referred to as the "photochemical smog mechanism" [Seinfeld \& Pandis, 2006]. 


\subsection{Photochemical Ozone Production}

Given that VOCs and $\mathrm{NO}_{\mathbf{x}}$ are precursor compounds for tropospheric ozone formation, it is crucial to understand how changing $\mathrm{VOC}$ and $\mathrm{NO}_{\mathrm{x}}$ levels affect the amount of ozone produced. This section gives a brief overview on the most important processes leading to ozone formation in the troposphere. More complete descriptions of the reaction scheme can be found elsewhere [Atkinson, 1994; Jacob, 1999].

Ozone production is governed by a sequence of reactions involving several important radical species in the atmosphere. The way VOCs react in the atmosphere depends to a large extent on the availability of radicals. Ozone production starts with the photolysis of $\mathrm{NO}_{2}$, which produces the main source of atomic oxygen (in electric ground state, i.e. $\mathrm{O}^{3} \mathrm{P}$ ) without ozone consumption, and forms NO in the lower troposphere (Reaction 2-1). For the reaction above, the source of $\mathrm{NO}_{2}$ is the oxidation of the NO

emitted in combustion processes. Following the photolysis of $\mathrm{NO}_{2}, \mathrm{O}^{3} \mathrm{P}$ can further react with molecular oxygen to form ozone (Reaction 2-2); this is the main reaction that leads to the direct formation of ozone in the atmosphere. At sufficient levels of nitrogen oxides, ozone can be removed through Reaction $2-3$, which can lead to another set of nitrogen dioxide production that could start the sequence of reactions over again. Due to the high reaction rates causing fast conversion of $\mathrm{NO}$ and $\mathrm{NO}_{2}$, an atmospheric photochemical equilibrium is reached between ozone and $\mathrm{NO}_{\mathrm{x}}$ in a relatively short time (minutes to an hour) [Seinfeld \& Pandis, 2006]. The $\mathrm{O}_{3}-\mathrm{NO}_{\mathrm{x}}$ cycle includes the following reactions:

$$
\begin{array}{ll}
\mathrm{NO}_{2}+h v \rightarrow \mathrm{NO}+\mathrm{O}^{3} P & (2-1) \\
\mathrm{O}^{3} \mathrm{P}+\mathrm{O}_{2}+\mathrm{M} \rightarrow \mathrm{O}_{3}+\mathrm{M} & (2-2)
\end{array}
$$




$$
\mathrm{O}_{3}+\mathrm{NO} \rightarrow \mathrm{NO}_{2}+\mathrm{O}_{2}
$$

Observed levels of ozone in a polluted atmosphere cannot be explained solely by the $\mathrm{O}_{3}-\mathrm{NO}_{\mathrm{x}}$ cycle above. The more significant pathway of ozone formation in such environments starts by photolysis of ozone itself that leads to the formation of an oxygen molecule and an excited oxygen atom $\mathrm{O}^{1} \mathrm{D}$ (Reaction 2-4). The excited oxygen atom can either react with water vapour (Reaction 2-5) to generate two hydroxyl radical molecules $(\mathrm{OH})$, or can quench to its ground state on an air molecule (Oxygen or Nitrogen) through Reaction 2-6. The latter pathway results in reproduction of the ozone molecule while the former produces $\mathrm{OH}$ :

$$
\begin{aligned}
& O_{3}+h v \rightarrow O_{2}+O^{1} D \\
& O^{1} D+H_{2} O \rightarrow 2 O H \\
& O^{1} D+M \rightarrow O^{3} P+M
\end{aligned}
$$

Hydroxyl radical and peroxy radical $\left(\mathrm{HO}_{2}\right)$ is known as the cleansing agent of the atmosphere and plays an important catalytic role in photochemical smog formation in the atmosphere. Additional sources of $\mathrm{OH}$ and $\mathrm{HO}_{2}$ in the troposphere are photolysis reactions of other species such as $\mathrm{HONO}, \mathrm{HCHO}, \mathrm{H}_{2} \mathrm{O}_{2}$, and $\mathrm{CH}_{3} \mathrm{CHO}$ (Reactions 2-7 through 2-12):

$$
\begin{array}{ll}
\mathrm{HONO}+h v \rightarrow \mathrm{OH}+\mathrm{NO} & (2-7) \\
\mathrm{HCHO}+h v \rightarrow \mathrm{H}_{2}+\mathrm{CO} & (2-8) \\
\mathrm{H}_{2} \mathrm{O}_{2}+h v \rightarrow 2 \mathrm{OH} & (2-9) \\
\mathrm{CH}_{3} \mathrm{CHO}+h v \rightarrow \mathrm{CH}_{3}+\mathrm{CHO} & (2-10)
\end{array}
$$




$$
\begin{array}{ll}
\mathrm{HCO}+\mathrm{O}_{2} \rightarrow \mathrm{HO}_{2}+\mathrm{CO} & (2-11) \\
\mathrm{H}+\mathrm{O}_{2}+\mathrm{M} \rightarrow \mathrm{HO}_{2}+\mathrm{M} & (2-12) \\
\mathrm{HO}_{2}+\mathrm{NO} \rightarrow \mathrm{NO}_{2}+\mathrm{OH} & (2-13)
\end{array}
$$

Hydroxyl radicals also react with most of the VOCs (denoted with the term RH, with $\mathrm{R}$ representing radical compound), which are emitted to the air from various sources related to human activities (anthropogenic sources) or from vegetation (biogenic sources). VOCs are oxidised in a process including a set of radical species $(\mathrm{OH}, \mathrm{RO}$, $\mathrm{RO}_{2}$, and $\mathrm{HO}_{2}$ ), which is shown by Reactions 2-14 through 2-17:

$$
\begin{array}{ll}
\mathrm{OH}+\mathrm{RH} \rightarrow \mathrm{R}+\mathrm{H}_{2} \mathrm{O} & (2-14) \\
\mathrm{R}+\mathrm{O}_{2} \rightarrow \mathrm{RO}_{2} & (2-15) \\
\mathrm{RO}_{2}+\mathrm{NO} \rightarrow \mathrm{NO}_{2}+\mathrm{RO} & (2-16) \\
\mathrm{RO}+\mathrm{O}_{2} \rightarrow \mathrm{R}^{\prime} \mathrm{CHO}+\mathrm{HO}_{2} & (2-17)
\end{array}
$$

In typical urban conditions, the atmosphere is rich with nitrogen, and these radicals convert $\mathrm{NO}$ to $\mathrm{NO}_{2}$ (Reaction 2-13 and 2-16). These processes oxidise NO to $\mathrm{NO}_{2}$ without consuming ozone, involving the second set of ozone precursors, the volatile organic compounds (VOCs). They are considered a net ozone production reaction and are the major sources of ozone formation in polluted environments. $\mathrm{NO}_{2}$ formed in these reactions will lead to $\mathrm{O}_{3}$ formation through Reactions 2-1 through 2-2, which can be approximated by the rate of Reaction $2-13$ as subsequent $\mathrm{NO}_{2}$-photolysis. Reaction $2-2$ is fast and produces ozone with a near $100 \%$ yield. In general, the presence of VOCs and their reactions with hydroxyl radicals enhances the formation of ozone, as well as leading to formation of new radicals; therefore, they contribute to the radical propagation step. 
Finally, radicals are removed from the atmosphere by their reaction with themselves or with other species such as $\mathrm{NO}_{\mathrm{x}}$ :

$$
\text { Radical }+\mathrm{NO}_{\mathbf{x}} \text { : }
$$

$$
\begin{gathered}
\mathrm{OH}+\mathrm{NO}_{2} \rightarrow \mathrm{HNO}_{3} \\
\mathrm{RO}_{2}+\mathrm{NO} \rightarrow \mathrm{RONO}_{2} \\
\mathrm{RO}_{2}+\mathrm{NO}_{2} \rightarrow \mathrm{ROONO}_{2}
\end{gathered}
$$

Radical + Radical:

$$
\begin{aligned}
& \mathrm{HO}_{2}+\mathrm{HO}_{2} \rightarrow \mathrm{H}_{2} \mathrm{O}_{2}+\mathrm{O}_{2} \\
& \mathrm{RO}_{2}+\mathrm{HO}_{2} \rightarrow \mathrm{ROOH}+\mathrm{O}_{2} \\
& \mathrm{OH}+\mathrm{HO}_{2} \rightarrow \mathrm{H}_{2} \mathrm{O}+\mathrm{O}_{2}
\end{aligned}
$$

Consequently, stable products are formed, and ozone production is ceased; hence these reactions are called "radical termination" reactions. Ozone production is therefore largely determined by the concentration of radicals and $\mathrm{NO}_{\mathbf{x}}$. The day-time termination of ozone is dominated by Reaction 2-18 while the rate of ozone formation will depend on the rate of $\mathrm{NO}$ to $\mathrm{NO}_{2}$ conversion by peroxy radicals (Reactions 2-13 and 2-16). From these reactions, there are two opposing regimes of ozone production, and the relative importance of radical and $\mathrm{NO}_{\mathrm{x}}$ sources, as well as sinks, can be used to explain those different regimes from a qualitative point of view [Kleinman et al., 1997]. At very high $\mathrm{NO}_{\mathrm{x}}$ concentrations, predominance of Reaction 2-18 results in subdued ozone formation. This chemical regime is called VOC-limited, $\mathrm{NO}_{\mathbf{x}}$-inhibited, or radical-limited regime. Conversely, at low $\mathrm{NO}_{\mathrm{x}}$ conditions, the rate of ozone formation is low and controlled by 
Reactions 2-13 and 2-16 and through availability of $\mathrm{NO}_{\mathrm{x}}$. This chemical regime is referred to as $\mathrm{NO}_{\mathrm{x}}$-limited. The dynamics of the $\mathrm{VOC}-\mathrm{OH}-\mathrm{NO}_{\mathrm{x}}$ chemistry explains the division between the $\mathrm{NO}_{\mathrm{x}}$-sensitive and VOC-sensitive regimes which will be discussed in more detail below.

The relation between $\mathrm{O}_{3}, \mathrm{NO}_{\mathrm{x}}$ and $\mathrm{VOC}$ is driven by complex nonlinear photochemistry, and daily maximum hourly average ozone concentrations can be represented by means of an ozone isopleth diagram (Figure 2-1) [NRC, 1991; Seinfeld \& Pandis, 2006]. Isopleths are generated using models that simulate a representation of the atmospheric chemistry, such as the photochemical box model called the Empirical Kinetic Modeling Approach (EKMA) [US EPA, 1983]. The EKMA model was implemented for estimating ozone concentration in urban areas and for developing isopleth plots. These isopleths give valuable information about the expected peak $\mathrm{O}_{3}$ levels as a function of initial VOC and $\mathrm{NO}_{\mathrm{x}}$ concentrations, or the amounts of volumetric emissions of these species added to the system.

The isopleth provides contours of constant ozone concentrations, i.e. the concentration of ozone remains constant along each isopleth line. A diagonal area from the lower left to the upper right corner of the graph is referred to as "the ozone ridge". The $\mathrm{O}_{3}$ ridge responds to the maximum ozone level at given VOC concentrations with changing $\mathrm{NO}_{\mathrm{x}}$ concentrations (with a nearly constant $\mathrm{VOC} / \mathrm{NO}_{\mathrm{x}}$, typically between 4 and 15 depending on the VOC mixture and environmental conditions). The transition from low-NO $\mathrm{N}_{\mathrm{x}}$ to high-NO $\mathrm{N}_{\mathrm{x}}$ chemistry is associated with a specific ratio of VOC to $\mathrm{NO}_{\mathrm{x}}$. In the inferior right area of the ridgeline, $\mathrm{NO}_{\mathbf{x}}$ levels are relatively low, while there is an ample supply of organic compounds and radicals; this leads to rather high $\mathrm{VOC} / \mathrm{NO}_{\mathbf{x}}$ ratios. 
Thus, ozone formation in this region is limited by the availability of $\mathrm{NO}_{\mathrm{x}}$, which means that ozone concentration in the area is sensitive to changes in $\mathrm{NO}_{\mathrm{x}}$ emissions. This expanse is called "NO $\mathrm{x}_{\mathrm{x}}$-limited" regime, where reductions in hydrocarbons have little or no effect on the levels of $\mathrm{O}_{3}$, and somewhat ineffective (ozone is not sensitive to VOCs), hence the horizontal orientation. Sensitivity of ozone to $\mathrm{NO}_{\mathrm{x}}$ in this regime is positive. To the upper left, with lower $\mathrm{VOC} / \mathrm{NO}_{\mathrm{x}}$ ratios than along the ridge, the $\mathrm{O}_{3}$ formation is restricted by the radicals that are generated through oxidation of hydrocarbons. This is caused by the depletion of radicals by higher amounts of $\mathrm{NO}_{\mathbf{x}}$. The isopleths depict a very nonlinear behaviour in this region, with instances where $\mathrm{NO}_{\mathrm{x}}$ reductions are ineffective (not-sensitive), or can even lead to an increase in ozone production (negative sensitivity).

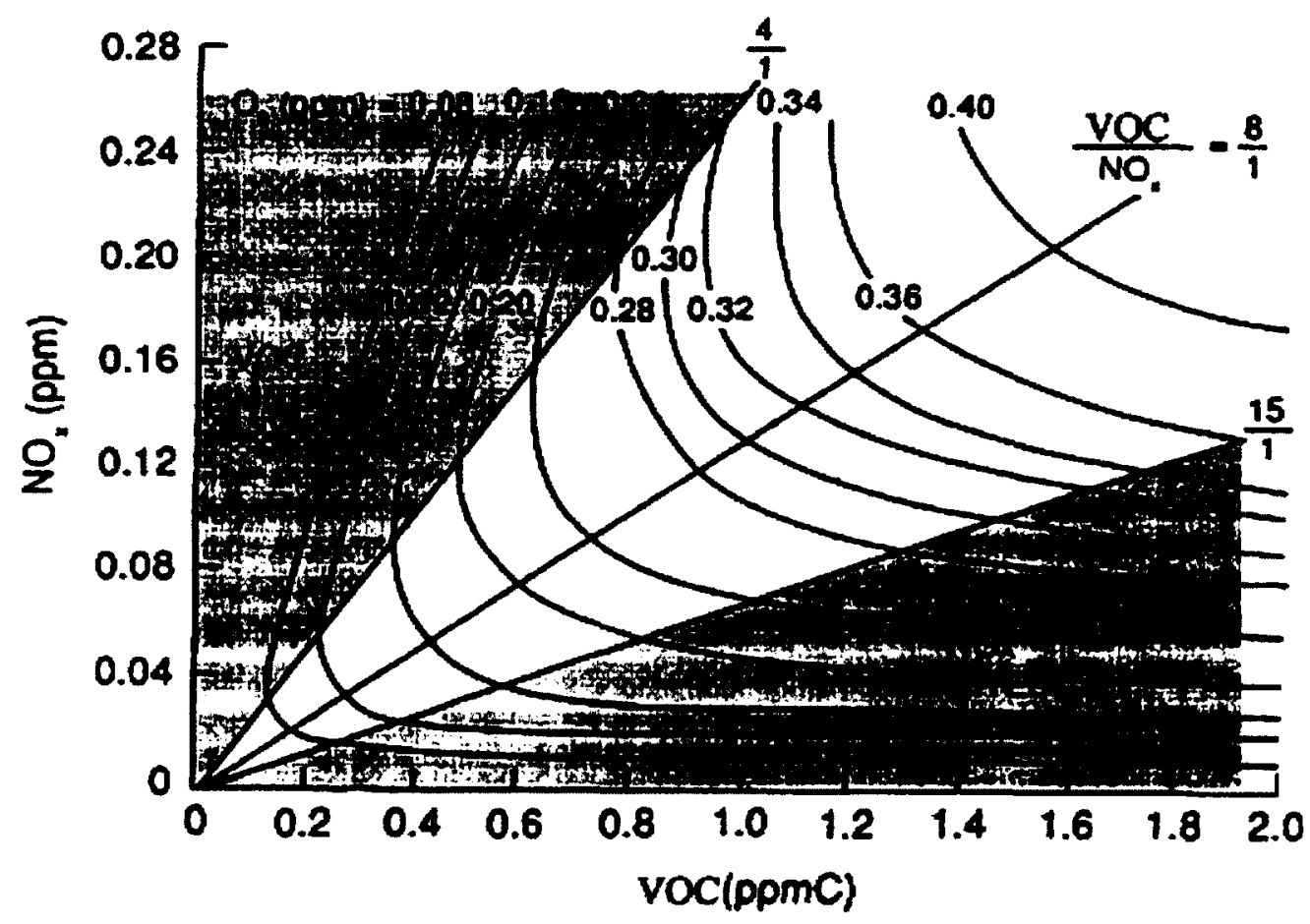

Figure 2-1: Ozone isopleth diagrams showing the nonlinear response of ozone to emissions. The $x$-axis displays increasing concentrations of VOCs. The $y$-axis displays increasing concentrations of NOx. The isopleths - these are $c$-shaped curves in the body of the graph that represent increasing concentrations of ozone from the bottom left corner to the top right corner [National Academy of Sciences, 1991]. 
This is known as the "VOC-limited", "radical-limited", or "NO${ }_{x}$-inhibited" regime. This regime is characteristic of $\mathrm{NO}_{\mathrm{x}}$-rich plumes from urban cores or power plants.

When the ozone concentration in an urban or industrial environment is higher than the regulations specified in NAAQS standards of criteria pollutants, VOC- and $\mathrm{NO}_{\mathrm{x}^{-}}$ based control strategies are explored depending on the prevalent chemical regime. With the passage of the US Federal Clean Air Act in 1990 [US EPA, 2003], the first North American national program for ozone mitigation was established. By that time, it was widely accepted that limiting emissions of VOCs could be effective in controlling ozone in populated regions as such areas were believed to be VOC-limited. Later, this came under question as wide regions in the Southeast U.S. were found to be predominantly NOx-limited due to significant biogenic emissions. However, the US EPA published associated guidance for VOC reductions, on a total VOC mass basis, that must be achieved to attain the 24-hour $\mathrm{O}_{3}$ standard in place at the time. This is shown below in Figure 2-2 from NARSTO 2000 [Russell \& Dennis, 2000].

However, our understanding of atmosphere chemistry has significantly evolved since then, and some amendments were made to the US CAA [US EPA, 2008]. The Clean Air Act is EPA's responsibilities set by the law to protect and improve the US's air quality and the stratospheric ozone layer. Regional controls, as well as local controls, were added because of the transportation of ozone and its precursors. Furthermore, a mix of $\mathrm{NO}_{\mathrm{x}}$ and $\mathrm{VOC}$ mitigations results in a more cost-effective control. Reactivity-based VOC regulations have already been implemented in different regions in the state of California; however, there are a number of scientific and policy issues that need to be 
addressed before reactivity-based regulations are more widely accepted for implementation.

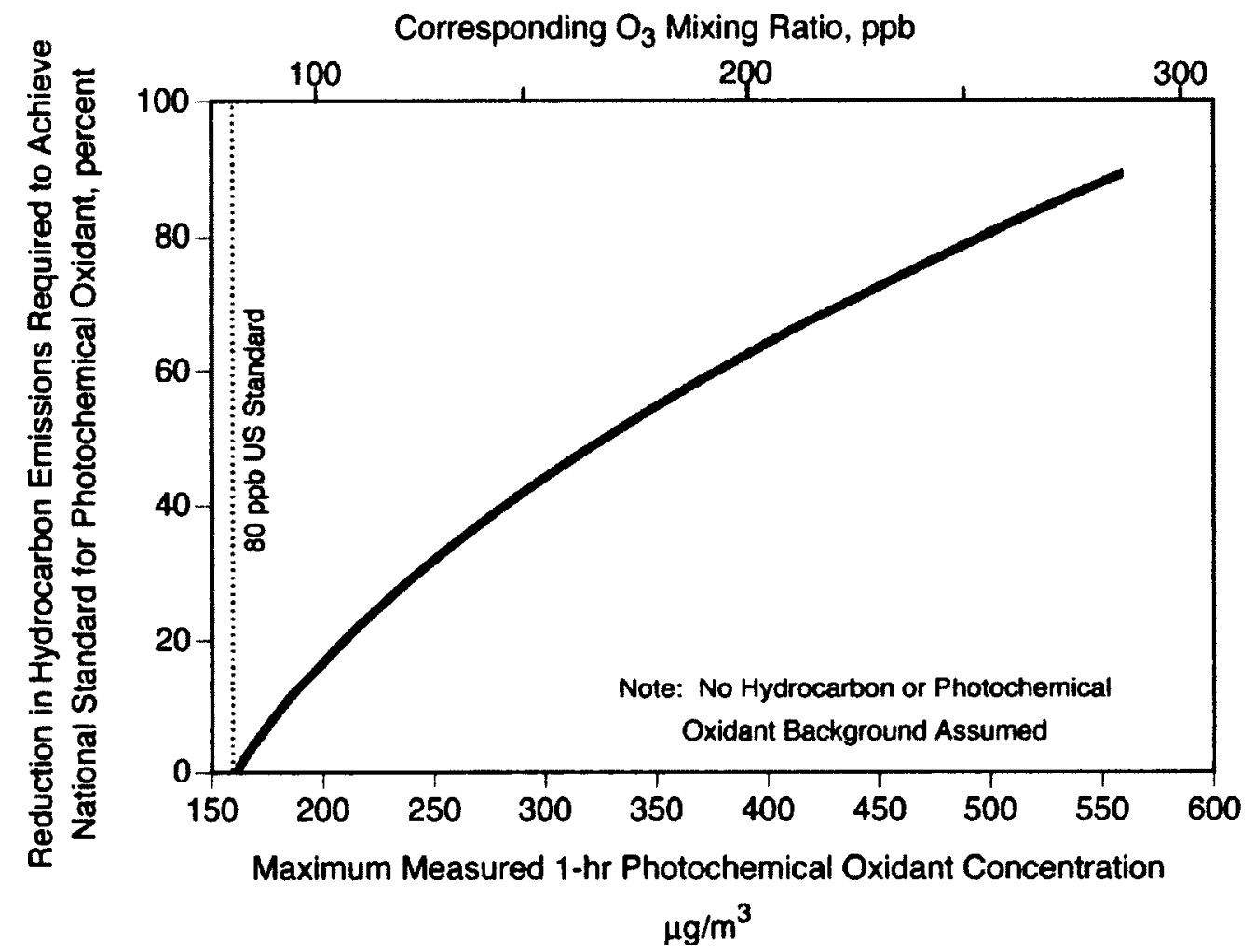

Figure 2-2: U.S. EPA Guideline on the required reduction in hydrocarbon emission needed to achieve the previous 80 ppb Air-Quality Standard [RRWG report to NARSTO, 2000]. 


\subsection{Reactivity of Volatile Organic Compounds}

After the first CAA in the United States in 1990, VOC emissions were reduced by $38 \%$, but the ozone concentrations were not reduced as much as researchers expected [US EPA, 2003], and photochemical air pollution was still a significant environmental problem in many urban areas of the Unites States, where ozone concentrations continued to exceed the NAAQS standards. This practice during the last several decades showed that urban ozone reduction is not always successful as expected [Seinfeld, 1989]. It is believed that part of the reason is the focus of controls on the emissions reduction measured in total mass of VOC, regardless of their difference in photochemical ozone production [Dimitriades, 1999].

Volatile organic compounds are a large number of chemically different compounds that can affect the formation of ozone via the different photochemical reactions illustrated in the previous section. Atkinson (2000) discussed how one VOC can have a very different impact on the rate and amount of ozone formed, or can react at different rates with different reaction mechanisms, branded for each individual VOC as reactivity of that VOC. Depending on how fast the organic species react, as well as the mechanism of formation, a general scale of reactivity toward ozone formation can be determined. Some compounds can cause the formation of 10 or more additional molecules of ozone per carbon atom reacted, either directly or through its effects on other reactions of different compounds. Other compounds can cause almost no ozone formation when they react, or even cause ozone formation to be reduced [Jacob, 1999]. 
Incremental reactivities are distinguished with two aspects; they are considered as being the product of the "kinetic" and the "mechanistic" reactivities to evaluate different aspects of VOC reaction mechanisms [Carter, 1994a]. The kinetic reactivity is the fraction of the emitted VOC which reacts, and depends on the VOC's relevant rate constants and the levels of the species which react with the hydroxyl radical. Mechanistic reactivity is the downstream ozone production through different mechanistic pathways after the VOC oxidation is initiated by the hydroxyl radical. These two components of IR are affected by the representation of the VOC chemistry through the chemical mechanism in use.

In terms of ozone formation, a wide range of approaches to reactivity study has been taken in the literature. The multi-stakeholder Reactivity Research Working Group (RRWG) was established in September 1998 from a coordinated effort between the industry and the EPA to guide and conduct policy relevant research related to VOC reactivity. The group reached a near-term research priority to use existing models to address the effectiveness of reactivity-based rules and substitutions on multiple scales. This was to be done through the use of regional modeling tools and scenarios, a context within which many believe that reactivity effects had not been adequately evaluated [RRWG, 2003]. The California Air Resources Board [CARB, 1990; CARB, 2000] was the first to encourage the implementation of rigorous reactivity-based management strategies, through their use of reactivity adjustment factors for reformulated gasoline in clean-fuel vehicles. This program was initiated in 1990 and last updated in 2000 in the state of California. CARB also introduced similar regulations for VOCs that were emitted from consumer and commercial products in 1991 and last updated in 2010. 


\subsection{Methods of Reactivity Evaluation}

The measurement that is most relevant in quantifying VOC reactivities is the actual change in ozone formation in an airshed resulting from changing the emissions of the VOC. This can be tested in environmental chamber experiments by determining the effect of adding the VOC in simulated photochemical smog experiments. An accurate characterization of atmospheric chemistry is essential for developing reliable simulations of the response of any species of concern to emissions changes. This is usually achieved by representing atmospheric chemistry as chemical mechanisms. As the number of species and reactions involved in atmospheric chemistry is very large (thousands of species and reactions), realistic representation required condensation into a lumped form of these species and reactions. Chemical mechanisms differ in their approach to lumping of species. Chemical mechanisms are in general complex and have many uncertainties; environmental chamber experiments are needed to evaluate the predictive capability of the chemical mechanism (ability to forecast the details of the reactions happening in the atmosphere). VOC reactivity experiments are useful in this regard because they are testing the mechanism under chemical conditions similar to those in the atmosphere [Bergin et al., 1995; Russell, 1997]. It is important to recognize that the purpose of these experiments is not to measure atmospheric reactivities but to provide the data needed to test the ability of a mechanism to accurately calculate reactivity in an atmospheric model. Environmental chamber experiments cannot be assumed to be the same as the quantitative ozone impacts observed in the atmosphere [Carter, 1994b; Carter et al., 1993]. This is because it is not practical to duplicate all of the relevant atmospheric conditions in a chamber experiment. Ambient atmospheric scenarios have dilution, 
variable emissions schedules, entrained and initial pollutants, transport from other regions, and other factors, which are difficult to simulate in a chamber experiment in a controlled manner. Even if it were practical to simulate these ambient conditions, a large number of experiments would be required to assess how VOC reactivities vary with each simulated atmospheric condition.

A more practical way to estimate the reactivities of VOCs in actual atmospheric conditions, is to calculate them using CTMs, i.e. given a model for the airshed conditions, and the chemical mechanism representing the VOCs atmospheric reactions are required [Carter, 2009]. A modeling framework provides flexible means to assess the many factors which affect ozone formation, as well as allowing for the development of VOC reactivity scales [Russell, 1997; Russell \& Dennis, 2000]. CTMs have an additional advantage that their results can be analyzed and presented in numerous ways, including the application of a variety of reactivity metrics and the construction of detailed process budgets. These models are pioneered by the box model [Carter, 1994a]; however, as discussed earlier, the physics of atmosphere transport and mixing as well as spatial variability in precursor emissions and concentrations are not reflected in box model calculations. On the other hand, three-dimensional CTMs incorporate physical details into their calculations and consider temporal as well as the spatial variability of different species, and consequently provide more realistic estimates of organic compounds [Hakami et al., 2004].

Nonetheless, it is costly and time-consuming to develop scenarios, modeling methods, and software for the derivation of comprehensive reactivity scales using 3-D models of actual airsheds. There is a concern that these models may not accurately 
predict the relative VOC reactivities in multi-day or long-range transport scenarios. Moreover, in $\mathrm{NO}_{\mathrm{x}}$-limited regional areas, where $\mathrm{O}_{3}$ formation is of concern, biogenic sources dominate over anthropogenic emissions of VOCs. These conditions might add uncertainties and cause inaccurate predictions from the model. A significant weakness of the models has been in how investigators have addressed, and communicated, such qualms. Studies found that major uncertainties are due to model inputs, such as emissions and meteorology, more so than the model itself [Bergin \& Russell, 1998]. Reaction mechanisms for most VOCs have uncertain data and assumptions, though the level of uncertainty varies considerably from compound to compound [Russell et al., 1995]. It is not apparent how much such uncertainties affect the results and the policies based upon those results. Laboratory studies, such as environmental chamber experiments for reactivities, can reduce these uncertainties. However, for most VOCs, they will not provide the needed information in the time frame that is required for current regulatory applications [Wang et al., 2000a].

RRWG's VOC reactivity science paper [RRWG, 1999] concludes that regionalscale, three-dimensional Eulerian models, that adequately resolve both the boundary layer and the free troposphere, are presently the only tools that can realistically simulate the long-range impacts of VOCs. It further recommends that the use of such models in reactivity assessments be expanded. More detailed discussion of air quality models, types, application, advantages, and disadvantages is given in Chapter 3. 


\subsection{Different Scales of Reactivity}

Various metrics can be used to derive reactivity scales calculated for a variety of conditions. As discussed by Carter et al., (2003) these can include weighing all regions equally, regardless of the sensitivity of ozone to VOCs. Other alternatives are weighing cells by population exposure to ozone, minimizing ozone differences caused by reactivity-based substitutions, including only cells where ozone exceeds the air quality or cells that are sensitive to VOC controls, or using other criteria [Carter et al., 2003; Hakami et al., 2004a]. The fact that reactivities depend on environmental conditions means that no single scale can provide a complete picture under all conditions. This causes more challenges in developing reactivity scales that are applicable and useful for policy purposes.

In a particular episode, the effect of a VOC on ozone formation can be determined from its Incremental Reactivity (IR). Incremental reactivities depend significantly on the environmental conditions, specifically on the relative availability of $\mathrm{NO}_{\mathbf{x}}[$ Carter, 1989]. $\mathrm{NO}_{\mathrm{x}}$ availability has traditionally been measured by the ratio of total emissions of VOCs, also called, reactive organic gases (ROG) to the total emissions of $\mathrm{NO}_{\mathrm{x}}$. Other aspects of the environment in which the VOC is emitted, such as the nature of the other organics emitted into the airshed, can also be important in affecting VOC reactivities, though investigations in to these aspects are more limited. IRs have been investigated in a number of computer modeling studies, which apply different sensitivity analysis techniques [Carter et al., 2003; Hakami et al., 2004b; Russell et al., 1995]. Some of the reactivity scales developed to address the recent reactivity policy issues are discussed next. 


\subsubsection{Box Model Scales:}

Carter (1994a) developed a series of box model scenarios to derive reactivity metrics. The IR value of an organic compound is defined as the amount of ozone produced per unit mass of VOC added to an organic mixture [Carter, 1994a]:

$$
I R_{i}=\lim _{\Delta V O C_{i \rightarrow 0}}\left(\frac{\Delta C_{O_{3}}}{\Delta V O C_{i}}\right)
$$

where $\Delta$ represents the change in the parameter. In essence, incremental reactivities represent sensitivities of $\mathrm{O}_{3}$ concentrations $\left(C_{O_{3}}\right)$ (or mixing ratios) to some sensitivity parameter, which is usually a measure of the "target" VOC in question $\left(\mathrm{VOC}_{i}\right)$ that is an input to the model. Primarily, the input is initial concentration; however, depending on the particular reactivity calculation, it can also arise from emissions or from a combination of emissions and initial concentrations [Yang et al., 1995].

The first scale is the Maximum Incremental Reactivity (MIR) which is the most sensitive IR to VOC emissions. Other alternatives are the maximum ozone incremental reactivity (MOIR) scale, which is calculated for the lower $\mathrm{NO}_{\mathrm{x}}$ levels (most favorable for ozone formation) at conditions that are conducive to maximum ozone concentrations, or the Equal Benefit Incremental Reactivity (EBIR) scale that is calculated for the lowest $\mathrm{NO}_{\mathrm{x}}$ levels, for conditions where VOC and $\mathrm{NO}_{\mathrm{x}}$ controls have the same relative effects on ozone. MIR and MOIR are the most widely used box model reactivity scales (also called Carter scales), and are discussed further below. 


\subsubsection{Maximum Incremental Reactivity}

The maximum incremental reactivity scale is the primary reactivity scale used in VOC-control regulations for gasoline vehicles and aerosol coatings in California [CARB , 1990, 2000], and is developed using a box model. In box model calculations [Carter, $1994 a], \mathrm{NO}_{\mathrm{x}}$ levels are adjusted to result in the highest incremental reactivity at the end of simulation:

$$
M I R_{i}=\max \left[\frac{\Delta C_{O_{3}}}{\Delta V O C_{i}}\right]
$$

MIRs are typically observed at relatively low $\mathrm{VOC} / \mathrm{NO}_{\mathrm{x}}$ ratios (about 4-6 ppmC/ppm) [Wang et al., 2000b]. This is appropriate for regulatory applications because it reflects the conditions where VOC controls are the most effective for reducing ozone; this tends to represent highly polluted, urban, and densely populated areas. That is why this scale is of high practical significance. MIR values are also appropriate to quantify relative ozone impacts of VOCs, especially if the objective is to assess the maximum adverse impacts of the emissions of the compounds under consideration [Martien et al., 2002]. The MIR scales do not reflect conditions where the highest $\mathrm{O}_{3}$ forms, since this is generally at lower $\mathrm{NO}_{\mathrm{x}}$ levels than with the MIR scale [Carter, 2009].

\subsubsection{Maximum Ozone Incremental Reactivity (MOIR)}

Using the same box model calculations as the MIR scale, the Maximum Ozone Incremental Reactivity scale [Carter, 1994a] is developed with lower $\mathrm{NO}_{\mathrm{x}}$ levels such that maximum ozone concentration is achieved at the end of box model simulation: 


$$
M O I R_{i}=\left[\frac{\Delta\left(\max C_{O_{3}}\right)}{\Delta V O C_{i}}\right]
$$

MOIR values are defined as the difference in peak ozone obtained throughout the simulations, with base and increased $\mathrm{VOC}$ emissions at the $\mathrm{NO}_{\mathrm{x}}$ conditions leading to the highest ozone levels, referred to as peak ozone. Conditions leading to the MOIR are calculated to occur at higher $\mathrm{VOC} / \mathrm{NO}_{\mathrm{x}}$ ratios (about $7-8 \mathrm{ppmC} / \mathrm{ppm}$ ) [Wang et al., $2000 \mathrm{~b}$; it is more typical of aged urban air masses. MOIR scales can be developed based on instantaneous, 1-hour average, or 8-hour average box model ozone concentrations.

\subsubsection{Three-Dimensional Reactivity Scales}

For control strategy design purposes, IR of a given VOC, relative to others, may be of greater significance than the incremental reactivities themselves. This is the case, because from an industry perspective, improvement is the result of substitution of more reactive VOCs with less reactive ones. Therefore, it is the relative magnitude of IRs that is of practical importance from decision making point of view. Additionally, Carter's reactivity scales are given in units of $\mathrm{gO}_{3} / \mathrm{gVOC}$; this is possible since a box model is used. However, in a three-dimensional framework, the overall domain acts as emission sources and concentration receptors, and therefore impacts from individual sources on a single receptor cannot be isolated. In 3-D models, the reactivity scale is meant to be the aggregate measure of VOC behaviour across various locations and times. Also, 3-D reactivities are often normalized to that of a base mixture that is representative of VOC concentrations or emissions. 3-D Relative Incremental Reactivity (RIR) is shown to have less variability in time and space [Hakami et al., 2004b]: 


$$
R I R_{i}=\frac{I R_{3 D i}}{\overline{I R}_{\text {Base }}}
$$

where $I R_{3 D i}$ is the absolute reactivity of species $i$ (in units of $p p m O_{3} / g m V O C$ ) and is calculated through the sensitivity analysis of the three-dimensional modelling:

$$
I R_{3 D i}=\frac{\partial C_{O_{3}}}{\partial E_{V O C i}}
$$

where $C_{\mathrm{O}_{3}}$ is the ozone concentration in ppm, and $E_{V O c_{i}}$ is the mass emission of each individual VOC. $I R_{B a s e}$ is the reactivity of a normalized VOC mixture:

$$
\overline{I R}_{\text {Base }}=\sum_{j=1}^{N}\left(y_{j} I R_{j}\right)
$$

where $\mathrm{N}$ is the total number of VOCs in the mixture and $y_{j}$ is the mole fraction (per mole of carbon of the base mixture) for each organic compound. The base mixture composition is usually chosen to represent an average mixture of organic compounds based on a source or receptor profile. In the context of three-dimensional modelling, reactivity scales are evaluated over all the ground level grid cells and times for each day. Several studies have used three-dimensional photochemical models to calculate the reactivity scales for certain compounds in various conditions of $\mathrm{NO}_{\mathrm{x}}$ availability. Hakami et al., [Hakami et al., 2004a;Hakami et al., 2004b] used a 3-D regional model, and a detailed chemical mechanism, leading to the creation of relative reactivity scales for 31 VOCs over the Eastern US. This study introduced a new set of 3-D scales, which later on were further developed by Carter [Carter, 2005, 2009]. 


\subsubsection{Maximum Incremental Reactivity- 3D}

Maximum Incremental Reactivity (MIR-3D) metric is defined as the RIR of each species, at the time and location where the base mixture has its daily maximum reactivity:

$$
M I R_{3 D i}=\left.\frac{I R_{V O C_{i}}}{\overline{I R}_{\text {Base }}}\right|_{\max \left(\overline{I R}_{\text {Base }}\right)}
$$

The $M I R_{3 D}$ scale is defined for conditions that maximize the overall incremental reactivity of the base mixture reactivity.

\subsubsection{Peak Ozone Incremental Reactivity-3D}

Another metric, $P O I R_{3 D}$, represents the incremental reactivity associated with peak ozone concentration for a given VOC mixture [Hakami et al., 2004b]. It is defined as the RIR of each species at the time and location of the daily peak ozone concentration:

$$
\operatorname{POIR}_{3 D i}=\left.\frac{I R_{V O C_{i}}}{\overline{I R}_{\text {Base }}}\right|_{\max \left[c_{O_{3}}\right]}
$$

MIR-3D is expected to behave similarly to the MIR box model. However, POIR will not necessarily correspond to the box model MOIR scale where the ozone sensitivity to $\mathrm{NO}_{\mathrm{x}}$ emissions is zero (i.e. located on the ozone ridge). Therefore POIR-3D makes a distinction between theoretical maximum ozone and the peak ozone in the 3-D domain. $\mathrm{MIR}_{3 \mathrm{D}}$ and POIR $3 \mathrm{D}$ metrics are calculated from the values of a single cell in an averaging period. A somewhat similar scale will be used in this research, and is discussed in greater details in Section 4.6. 


\subsubsection{Regional Average Ozone Metric (AV)}

To assess the effects of VOCs on ozone formation, the Carter studies, (2005; 2003) defined another metric known as the "Regional Average Ozone Metric (AV)". It is defined as the average of incremental reactivities (absolute $\mathrm{O}_{3}$ impacts) throughout the entire domain. The metric reflects the effect of the VOC on the average ozone in all locations (domain-wide).

A comparison between the 3-D scale and box model values conducted by Carter (2009) is shown in Figure 2-3. The vertical axis is showing the measures derived from 3D reactivity analysis of Hakami et al. (2004a), whereas the horizontal axis is illustrating the average of MIR and MOIR scales of Carter (2003). Despite some minor differences, the results are well correlated, and for most cases reactivities are predicted in the same range (Figure 2-3). Two major factors to be considered in a 3-D reactivity assessment are the different methods to derive single reactivity scales (MIR, MOIR, etc.), and averaging times for receptor concentrations (1-hour or 8-hour). An alternative method includes reactivity assessment for locations and times that $\mathrm{O}_{3}$ is over the air quality standard [Carter, 2005]. Ozone impacts can also be quantified in terms of the effects of VOCs on ozone population exposure. In practical terms, the 3-D MIR scale is widely used for qualitative reactivity assessments, and for VOC rankings in the United States. It is believed that because the MIR scale results in consistent rankings with other scales, its continued use is adequate at present, however, improvements could also be helpful in this matter. 


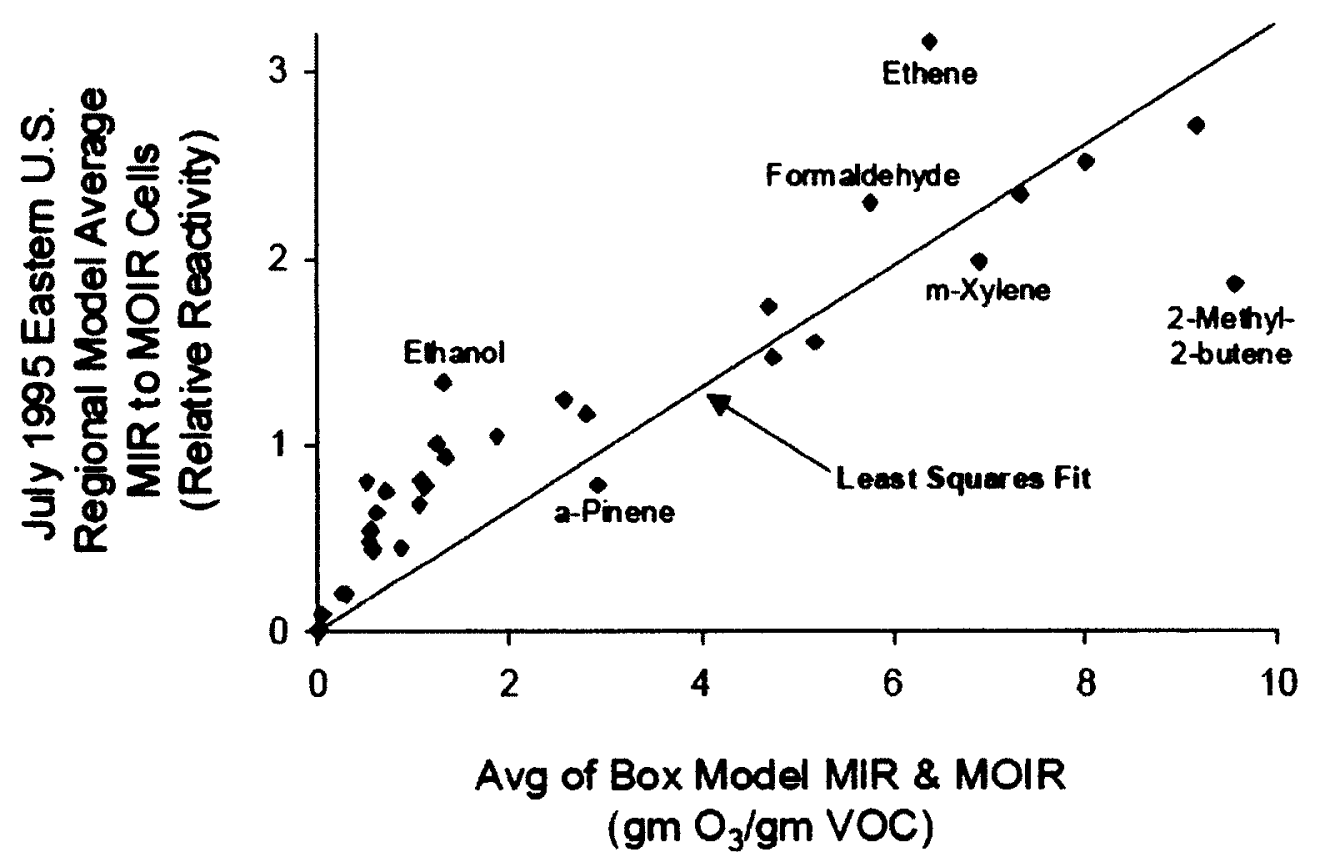

Figure 2-3: Comparison of box model and 3-D regional model incremental reactivities, calculated using the SAPRC-99 mechanism for comparable conditions. Regional model reactivities are relative to the mixture used in the box model to represent reactive VOC [Carter, 2009].

\subsection{Prior Studies of VOC Reactivity}

In the past two decades, a number of studies have been carried to inform reactivity-based policy making. Carter \& Atkinson (1987) modeled reactivities of a variety of VOCs using a box model with detailed chemistry. Shortly thereafter, Carter (1989) developed a series of scales quantifying VOC reactivity under different conditions, again using a box model. Following this, Carter (1994a) used single day simulations in box and trajectory models. However, a concern developed around the similar results observed between the box and trajectory models for the less-reactive compounds, with the potential to be carried over during multi-day smog episodes. Later 
on, Carter developed and evaluated a detailed atmospheric photochemical mechanism, the Statewide Air Pollution Research Center (SAPRC) mechanism, which had previously been used in model calculations. This study was conducted for developing ozone reactivity scales for VOCs by comparing its predictions with measurements of reactivities in an environmental chamber system [Carter, 1994a; Carter et al., 1993].

Around the same time, the relative reactivity (that is, the ratio of the reactivity of the one substituted species to the reactivity of a base mixture of VOCs) was investigated by McNair et al (1992) for alternative fuels, and by Bergin et al., (1995) for individual organics. While there were some differences, it was generally found that the relative reactivity did not differ significantly in the Carnegie/California Institute of Technology (CIT) airshed model simulations, from the results obtained with the box model. In a follow-up from the work of Carter, Russell et al. (1995) proposed an ozone control strategy based on relative reactivity, instead of total VOC emission rate. They used both a box model and an airshed model to look at the extent of variability and uncertainties in chemical rate parameters. The impact on the calculated reactivities was evaluated with almost the same reactivity scales, with few improvements. Carter also carried out experiments to calculate different scales of reactivities using a box model and the SAPRC99 (version 1999) mechanism [Carter, 1999].

In addition to the studies of the reactivity metrics discussed above, threedimensional air quality models have been applied to the areas of Los Angeles, Swiss plateau, Eastern U.S., and Mexico City, in both urban and regional scales. Spatial variability of relative reactivities of various VOCs were assessed in these studies [Khan \& Yang, 1999]. For North American urban "averaged conditions", Derwent et al., (2001) 
did a comprehensive description of the ozone forming potentials of organic compounds using a detailed master chemical mechanism, and a simple air parcel trajectory model. While the reactivities of most of the 86 compared organic compounds fell within a consistent range, significant discrepancies were found for exceptions.

Carter et al. (2003) used the Comprehensive Air quality Model with extensions (CAMx) 3-D model of the Eastern United States to calculate ozone impacts of VOC model species in a condensed chemical mechanism, varying both spatially and temporally within the model domain. A companion study was then carried out by Hakami et al (2004b), using a similar domain but a different airshed model, the Urban-to-Regional Multiscale (URM) model, as well as a more detailed chemical mechanism, SAPRC99. They found that despite the fact that the absolute reactivities varied through time and space, relative reactivities were fairly constant. Different metrics were compared between the 3-D and box models, and these comparisons showed consistency for different episodes, scenarios, and domains. It was also found that including the biogenic VOC emissions in the perturbation pattern has little effect on the results. The results of the calculations by Carter et al (2003) were then used to derive a number of different reactivity scales, which differed depending on how ozone impacts were quantified. In order to investigate the regional model reactivity metrics developed by Carter et al (2003) using a more detailed chemical mechanism, Hakami et al (2004) analyzed previous data from Hakami et al (2003) to derive metrics comparable to those of Carter et al (2003), this time using the Multiscale Air Quality SImulation Platform (MAQSIP) and central California as the modeling domain. Overall, ozone reactivity metrics (with the exception of those based on daily peak ozone) are fairly robust and consistent between different 
episodes or emission scenarios. A detailed and comprehensive documentation of the procedures and algorithms for the calculation of 3-D reactivity metrics of interest to the RRWG was provided by Carter (2005), using regional models. In another work by Arunachalam et al., [RRWG, 2003], the effectiveness of various VOC substitution scenarios were evaluated using modeling analysis to develop new metrics for Eastern United States, and South Eastern United States. Key findings were that reduction of ozone levels resulted from reactivity-based substitution, yet the responses of domains dominated by biogenic VOCs were moderate. Scales of reactivities varied both temporally and spatially, and in general high versus low reactivity strategy were beneficial in reducing both 1-hour and 8-hour average ozone EPA guidelines.

In more recent studies, Steiner et al., (2008) examined the reactivity of VOCs in Central California using the CMAQ model and ground-based measurements. Classifying VOCs into different categories, and comparing VOC kinetic reactivities using updated metrics, illustrated that in the urban areas, the model under-predicts $\mathrm{NO}_{\mathrm{x}}$ and VOC concentrations. At all other locations the model was consistent with previous observations of the relative contributions of each VOC. With a different target, Stroud et al., (2008) calculated OH-reactivity of VOCs in urban and rural sites across Canada. Observationally-derived $\mathrm{OH}$ reactivity for VOCs was compared to predictions from Environment Canada A Unified Regional Air-quality Modelling System (AURAMS). Total OH-reactivity was predicted within a factor of two for most sites; however, in the case of different individual model VOC species, the contributions were commonly larger and offsetting. In a similar study, Czader, et al., (2008) investigated the reactivity of individual organic compounds in Houston-Galveston region. The CMAQ model and an 
extended version of SAPRC99 mechanism were used and variations of incremental reactivities with respect to the differences in the air compositions between urban and industrial areas as well as meteorological conditions were found. With a focus on the North Eastern United States, Capps et al., (2010) used the CMAQ model and SAPRC99 chemical mechanism for different solvent substitution test scenarios to investigate possible transport effects of using VOC reactivity scales for air quality management purposes. The effects of reactivity-based substitutions were analysed downwind of the area in which the replacements are applied. Also, different reactivity scales were discussed based on the ozone transport between multiple cities.

The EPA believes that more research is needed before reactivity-based regulations should be implemented [Carter, 2009]. As can be appreciated from the above discussion, these regulations have the disadvantages of higher complexity and interpretive difficulty, as well as their dependency on uncertain model calculations. However, the use of 3-D reactivity scales is currently considered the state-of-the-art approach for estimating individual VOC influences on ozone. 


\section{Sensitivity Analysis in Air Quality Models}

Making more effective environmental regulations requires a better understanding of the relationship between the emission and distribution of primary and secondary species in the atmosphere. As discussed in the previous section, as a result of complicated interrelations between different processes occurring in the atmosphere, mathematical and computational models play an important role in air quality. Regional- and global-scale CTMs predict the effects of the interactions between transport, emissions, chemical kinetics or transformations, and deposition processes in an integrated framework. As a result, they provide information on the concentration of primary and secondary pollutants formed as a result of these interactions. They also show the response of the pollutant distributions to system perturbations, and link pollutant distributions to environmental effects [Russell, 1997]. This relationship is defined as the sensitivity of the pollution observed (e.g. ozone concentration) at a receptor (e.g. Ottawa, or North America) to the reduction of emissions of a particular species at a source (e.g. VOC emissions). Such contributions are often approximated through first-order sensitivity coefficients (derivatives) while ignoring nonlinearities in presence of large perturbations [Cohan et al., 2005]. In that sense, sensitivity analysis, when applied to VOC emissions, can be regarded as an inherent incremental reactivity assessment method.

In this chapter, the general structure of CTMs used in previous reactivity studies and specifics regarding the air quality model chosen for this study are reviewed. Furthermore, sensitivity analysis methods and their application in 3-D reactivity studies are given. 


\subsection{Presentation of Processes in Modeling Framework}

Various numerical modeling approaches have been adopted in reactivity assessments, based on their treatment of physical and chemical processes. They range from zero dimensional box models and trajectory methods [Carter, 1994, 1999; Wang et al., 2000; Yang et al., 1995] to grid-based, three dimensional models [Bergin et al., 1995; Carter et al., 2003; Hakami et al., 2004a; 2004b]. The former is chemically detailed but physically simplified, yet the latter approach has the least number of limitations in formulation, but can be computationally intensive.

Box models characterize the simulated area as a stationary box, which takes different factors such as emissions, chemical transformation, and flow in and out of the box into account; this model includes the assumption that air in the box is well mixed. Therefore, it does not provide detailed spatial distributions of pollutants, and transport processes are very simplified and lacking physical realism. On the other hand, these models account for a large number of explicit species using detailed chemical mechanisms, [Russell \& Dennis, 2000]. The next generation of models used for urban or long-range transport of pollutants are the trajectory or Langrangian models. The plume of interest is represented as a column that moves with the speed of wind. Along the way, no mass exchange between the column and its surroundings is taken into account, except the emissions that are injected to the airshed. These types of models found applications in simulating source-receptor relationship [Derwent et al., 1998; Yang et al., 1995]. These, box and trajectory models use very simplified initial conditions. 
Currently, more sophisticated grid-based models are the Eulerian or 3-D CTMs ("emission-based models"). The simulated area is divided into many small grid cells in both the horizontal and vertical directions. The mass of the pollutant is exchanged between these cells, but may also leave the domain [Dennis et al., 1996; Derwent, 2004]. These models make simulation possible on urban and regional scales, thanks to their detailed spatial treatment of emissions and meteorological parameters. These models are considered to be the more accurate for simulating ozone formation over wide regions, while using highly condensed mechanisms [Sillman, 1999]. On the other hand, they are computationally costly and their development requires larger effort. CTMs are powerful tools for assessing and designing control strategies but their results are subject to significant uncertainty [Russell, 1997]. Confidence in CTMs will come at the expense of significant evaluation, corroborative evidence, and diagnoses of the results.

The two major inputs into air quality models are the emissions and meteorological parameters. CTMs often take into account many processes such as pollutant diffusion and advection, chemical transformation, aerosol processes, and representation of sub-grid processes like plume dilution and clouds. But due to a large number of chemical species in the air, and the fact that hundreds of reactions may be included in each oxidation, the explicit treatment of atmospheric chemistry in an Eulerian model is difficult to manage. This is further aggravated since the oxidation mechanisms of certain species are not well understood [Russell \& Dennis, 2000]. Because of this, the chemical mechanisms employed in 3-dimensional AQMs are condensed. The reduction of the number of chemical species is done by lumping together organic species that have either the same chemical structure or properties [Dodge 2000]. Calculation of reactivity scales using 
CTMs is feasible but expensive, and it has only been done for a limited number of compounds. The early 3-D models addressed individual pollution problems separately, such as urban airshed model (UAM) [Morris \& Myers, 1990]; while more recent ones were developed based on a more general approach of the atmosphere, e.g. the CMAQ model [Byun \& Ching, 1999; Byun \& Schere, 2006]. CMAQ is the most widely used Eulerian photochemical model that simulates the emissions, transport, and chemical transformations of gases and particles in the troposphere. The CMAQ model was employed in this study and more detailed information about the model and its configuration is provided in Chapter 4 and elsewhere [US-EPA, 1999].

\subsection{Sensitivity Analysis in 3-D Models}

Most air quality studies have assessed how changing various parameters and inputs could impact the predictions of the main variable of interest, ozone concentration [Russell, 1997]. This is achieved by calculating, directly or indirectly, the first-order sensitivity coefficient or derivatives of concentrations with respect to input parameters of concern. The study of the response of the model outputs to changes in the model inputs, parameters, or even its structure and underlying assumptions, is defined as "sensitivity analysis". The first-order sensitivity coefficients evaluate the responsiveness of pollutant concentration to infinitesimal perturbations of model inputs, while the second order sensitivity coefficients quantify the nonlinearity of the pollutant concentration response. For instance, the contribution from various emission sources to the pollution observed in a certain location can be assessed through sensitivity analysis [Cohan et al., 2005]. Sensitivity analyses are useful because they can identify the parameters that have the 
largest influence on the results of the simulation [Russell \& Dennis, 2000]. The applications of sensitivity analysis are wide-ranging: from the development and evaluation of control strategies, to more limited applications for data assimilation, or source apportionment [Bergin et al., 2007; Dunker et al., 2002]. Furthermore, sensitivity analysis can aid in the development of uncertainty estimates about a model's predictions, due to the uncertainties inherent in the inputs (such as the emissions). In the following section, some of the important sensitivity analysis methods used, and particularly the "adjoint method" used in this study, are discussed in greater detail.

\subsection{Analytical Methods in Sensitivity Analysis}

Sensitivity analysis is traditionally done through "brute force" method where each input or model parameter is perturbed one at a time. The first order sensitivity coefficient is estimated as the ratio of the change in the model output to the change in the input. Although this method is easy to implement, it requires a multitude of simulations for larger numbers of sensitivity parameters [Cohan et al., 2005]. Historically, box model reactivity scales are calculated by a brute-force approach, where the response of ozone to a change in the initial amount of an individual VOC is estimated at the end of the simulation. Three-dimensional reactivities have also been estimated by this method, i.e. one-at-a-time changes in VOC emissions. The brute-force method is straightforward and simple to implement for few VOCs, but as the number of VOCs increases, the method becomes cumbersome and computationally expensive. More importantly, in the bruteforce method, a large perturbation can change the original characteristics of the mixture; 
while a small perturbation may introduce numerical noise in model calculations [Russell \& Dennis, 2000].

Nevertheless, $t$ is important to carry out the sensitivity calculations for the Eulerian chemical transport models. CTMs usually follow the time evolution of pollutants by solving the Atmospheric Diffusion Equation (ADE) [Seinfeld \& Pandis, 2006], which governs the transportation and transformation of pollutants in the pathway from the source to the receptor:

$$
\frac{\partial C_{i}}{\partial t}=-\nabla \cdot\left(\boldsymbol{u} C_{i}\right)+\frac{1}{\rho} \nabla \cdot\left(\rho \mathbf{K} \nabla C_{i}\right)+R_{i}+E_{i}
$$

In the equation above, $C_{i}$ is the concentration or mixing ratio of species $i$, $\mathbf{u}$ is a vector of wind field, $\mathbf{K}$ is the diffusivity tensor, $\rho$ is the air density, the term $E_{i}$ represents elevated emissions, and $R_{i}$ is the net rate of production of species $i$ by chemical reactions. Equation 3-1 is solved subject to specified initial and boundary conditions explained elsewhere [Seinfeld \& Pandis, 2006].

The local sensitivity of a model output to a single parameter can be calculated as the partial derivative of the output with respect to that parameter while other parameters are held constant [Yang, Wilkinson, \& Russell, 1997]:

$$
s_{i j}=\frac{\partial C_{i}(t)}{\partial p_{j}}
$$

Here, $S_{i j}$ is a sensitivity coefficient, and $p_{j}$ is a model parameter or input. This is the definition of the slope of the response surface produced by the model in the direction of the parameter of concern. Due to the spatial and temporal variability in the magnitudes 
and units of different parameters of concern, semi-normalized sensitivity coefficients are defined by normalizing the absolute coefficient:

$$
S_{i j}=P_{j} \frac{\partial C_{i}(t)}{\partial p_{j}}=P_{j} \frac{\partial C_{i}(t)}{\partial\left(\epsilon_{j} P_{j}\right)}=\frac{\partial C_{i}(t)}{\partial \epsilon_{j}}
$$

where $P_{j} \quad$ represents an unperturbed field, and $\epsilon_{j}$ is a scaling variable with a nominal value of 1 . The semi-normalized sensitivity coefficient $S_{i j}$ is calculated by the partial derivative of a species concentration, to the scaling variable. This results in the change in the output from $100 \%$ change in the input, with sensitivities carrying a same unit as model output $C_{i}$ (e.g. ppb).

Numerous 3-D methods such as Green's Function Method (GFM) [Hwang, et al., 2003], Automatic Differentiation in FORtran (ADIFOR) [Bischof et al., 1994], Decoupled Direct Method (DDM) [Dunker, 1984; Yang et al., 1997] also known as forward sensitivity, and more recently the Adjoint Method (backward sensitivity) [Cacuci, 1994; Sandu et al., 2005] have been developed, and used to calculate sensitivity coefficients in more efficient ways. GFM is computationally expensive but it is efficient when the number of sensitivity parameters approaches the number of chemical species. ADIFOR automatically follows the sequence of elementary operations in the computer code to calculate the sensitivity coefficients, but it does not take advantage of the existing program structure. Forward and backward sensitivity analysis methods are the two most used approaches which will be explained in details further below. 


\subsubsection{Decoupled Direct Method}

A group of sensitivity analysis techniques that relies on a direct solution to the sensitivity equations is called Decoupled Direct Method also referred to as the Tangent Linear Model (TLM) [Derwent, 2004; Derwent et al., 2001]. For transport related processes (advection, diffusion, deposition, etc.), DDM is one of the most common methods in deriving more efficient sensitivity coefficients, and it is used with the same numerical algorithms. DDM calculates the local sensitivities of pollutant concentrations with respect to a single emission source or a single perturbation to all sources, therefore it is a source-oriented sensitivity analysis technique. The perturbation of a single input is made and propagated forward in time to develop a sensitivity field of the outputs. Initial and boundary conditions and other parameters such as chemical reaction rate constants, dry deposition velocities may also be among the input parameters for most applications. A perturbation in the input parameters (e.g., emissions $\delta E i$ ) results in a perturbation in each predicted concentration. A linearized version of the atmospheric diffusion equation governs the sensitivities to the perturbation [Yang et al., 1997]:

$$
\frac{\partial S_{i j}}{\partial t}=-\nabla \cdot\left(u S_{i j}\right)+\frac{1}{\rho} \nabla \cdot\left(\rho K \nabla S_{i j}\right)+G_{i} S_{i j}+E_{i}
$$

where $S_{i j}$ is normalized sensitivity of species $i$ with respect to the emissions of species $j, \mathbf{u}$ and $\mathrm{K}$ are the same as defined for $\mathrm{ADE}$ (Equation 3-1), $G_{i}$ is the $i^{\text {th }}$ row of the Jacobian of the chemical reaction rates, and $E_{i}$ is the unperturbed emission rate.

Sensitivity equations in DDM are derived directly from the concentration equations in the base model. Sensitivity coefficients at all receptors are computed with 
concentrations simultaneously. Similar to other sensitivity analysis DDM simulations calculates the effects of changes of emissions; however, the method does not involve actually changing any emissions. Instead, using the appropriate differentiation of the model equations, DDM involves calculating derivatives with respect to emissions or other inputs [Dunker et al., 2002]. DDM is a forward and source-oriented method where sensitivity information is integrated forward in time and space from the source to all receptors. In doing so, DDM calculates sensitivity at all receptors to a few parameters.

\subsubsection{Adjoint (Backward) Method}

Adjoint sensitivity analysis efficiently computes the sensitivity of a cost function of interest (defined on the model output) to a large number of model parameters simultaneously. Contrary to the DDM, the adjoint propagates influences on a single receptor or an ensemble of receptors backward in time and space to all sources. As such, the adjoint method is a backward approach for sensitivity analysis and is receptor-based in nature. The method is a powerful and efficient approach to identifying how one receptor-based metric (ozone concentration, exposure, health, etc.) is impacted from different sources, and has particular use in policy applications [Hakami et al., 2006]. In a single run of the adjoint model, sensitivity of ozone concentrations at a given location and time (or an integrated metric such as average over a spatial domain and time interval) can be calculated, with respect to individual sources over the spatial and temporal resolution of the model [Zhang et al., 2008]. What makes the adjoint approach complementary to the forward approach is the efficiency when the sensitivities of a limited number of outputs (a scalar, like a species concentration) are to be calculated with 
respect to a large number of spatially (and temporally) variable input fields (e.g., emissions). This helps in addressing a wide spectrum of questions in a more flexible manner in the context of 3-D atmospheric modeling, as is illustrated in Figure 3-1 below. As can be seen from the graph adjoint method is a receptor-oriented aproach with the particular feature that it can produce informations on sources rather than receptors.

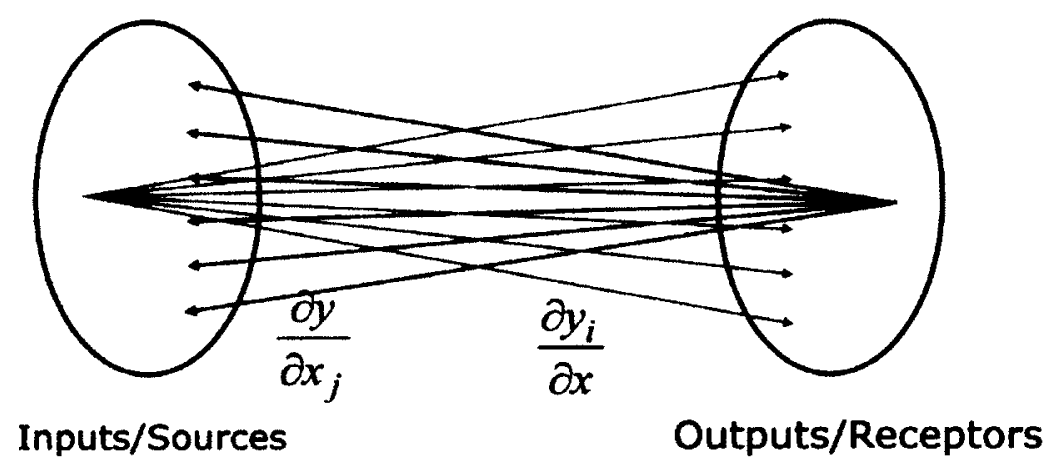

Figure 3-1: Comparison of Forward and Backward (Adjoint) methods; Forward approach shown in red, where the sensitivity of different receptors is compared to a single source vs. Adjoint model, shown in blue which is receptor-oriented, suited for a simulation with more input parameters than responses [Hakami et al., 2007].

To proceed with adjoint analysis, an auxiliary set of equations that include Lagrange multipliers and integration by parts are applied to Equation 3-4, producing adjoint variable, which is the derivatives with respect to the inputs (or in this case, emission of VOCs):

$$
-\frac{\partial \lambda_{i}}{\partial t}=-u \cdot\left(\nabla \lambda_{i}\right)+\nabla \cdot\left(\rho \mathbf{K} \nabla \frac{\lambda_{i}}{\rho}\right)+G_{i}^{T} \lambda_{i}+\phi_{i}
$$

where $G_{i}^{T}$ is the $i^{\text {th }}$ row of the transpose Jacobian (or the transpose of the $i^{\text {th }}$ column of the original Jacobian) of the chemical reaction rates; $\varphi_{i}$ is the forcing term driving the adjoint equation, a similar term to emissions in the $\mathrm{ADE}$, and $\lambda_{i}$ is the adjoint variable for species $i$ which contains sensitivity information about a scalar function $J$, usually referred to as the adjoint cost function (or objective function): 


$$
J=\int_{t} \int_{\omega} g(C, t, \omega) d \omega d t
$$

where $\omega$ is the generalized spatial coordinate, and $\mathrm{g}$ is the local cost function; adjoint variables will be defined such that at each time and location:

$$
\lambda_{i}=\partial J / \partial C_{i}
$$

Then, one can define the forcing term as perturbations in the local cost function injected into the domain at any location and time:

$$
\varphi_{i}=\frac{\partial g}{\partial C_{i}}
$$

For a sensitivity analysis of concentrations, the cost function is simply set to the concentration of the species of concern. Different forms of the cost function for problems of interest in the application of AQMs are discussed in [Hakami et al., 2007; Sandu et al., 2005]. The integration of the adjoint equation will provide us with the sensitivities of the cost function with respect to concentration at any given time and location. Then the gradients of the cost function, with respect to emissions, can be calculated simultaneously:

$$
\frac{\partial J}{\partial E^{n}}=\left(\frac{\partial C^{n+1}}{\partial E^{n}}\right)^{T} \times \frac{\partial J}{\partial C^{n+1}}
$$

where $E$ is emission at the $n$th time-step, and $C$ is the concentration at the final time step of forward simulation. Since ADE (Equation 3-1) and Equation 3-5 are structurally similar together, the adjoint equation can be integrated (for the most part) by the same numerical integration routines as the ADE, with the same CTM structure. The negative sign associated with the time derivative term shows how the adjoint equations are integrated backward in time, and the wind field in the adjoint system is reversed. 
For a system of differential equations, there are two ways of deriving and integrating adjoint equations, known as continuous and discrete. In the continuous approach, Equation 3-5 is discretized, and solved numerically; while in the discrete method, the adjoint of discretized TLM is derived and integrated [Gou, Singh, \& Sandu, 2009]. In view of the fact that discretization and adjoints are not commutative operations different results are obtained in continuous and discrete approach; however, results are expected to be consistent for most practical applications [Sandu et al., 2005]. In a discrete form of the equation, adjoint variables are calculated using the same operator splitting scheme that is used for the integration of concentrations. In this study, an adjoint of the gas-phase CMAQ v4.5.1 model was used where the discrete adjoint was developed for all the processes involved with the exception of horizontal advection for which a continuous adjoint is used [Hakami et al., 2007]. More information about the derivation and integration of adjoint equations can be found elsewhere [Elbern et al., 2000; Hakami et al., 2007; Sandu et al., 2005].

\subsubsection{Prior studies of the adjoint method}

The adjoint method's first appearance in the field of atmospheric science goes back to early 1970 s in atmospheric modeling [Lamb, Chen, \& Seinfeld, 1975], and more extensively in meteorology in the following years [Errico \& Vukicevic, 1992]. However, the first use of the adjoint method in CTMs was in the last decade, where Langrangian models were used by Fisher \& Lary (1995) and Elbern, Schmidt, \& Ebel (1997). The first adjoint of a 3-D Eulerian CTM characterized by chemistry was introduced by Elbern, Schmidt, Talagrand, \& Ebel (2000), and Hendrik Elbern \& Schmidt (1999). The adjoint 
was used for data assimilation of tropospheric gas observations for the European Air Pollution Dispersion Model (EURAD-CTM2). Later on, more CTMs were provided with the development of adjoint application; CHIMERE [Schmidt \& Martin, 2003], IMAGES [Stavrakou \& Müller, 2006], Polair [Mallet \& Sportisse, 2005], the California Institute of Technology urban-scale model [Martien et al., 2006], DRAIS [Nester \& Panitz, 2005], and STEM [ Sandu et al., 2005; Hakami et al., 2006]. More recently, Henze et al. (2007) developed the first adjoint of a CTM that included aerosol dynamics and thermodynamics, the adjoint of global CTM model GOES-Chem. The adjoint of CMAQ model for gas-phase processes, which is implemented in this study, was developed by Hakami et al. (2007).

Most applications of the adjoint method in CTMs have been intended for inverse modeling and data assimilation [Elbern \& Schmidt, 2001; Wang et al., 2001]. Wang et al. (2001) provides the adjoint methodology and data assimilation and applications to atmospheric chemistry. Elbern et al. (2000) investigated four-dimensional variational (4D-Var) techniques to analyze the emission rates of the precursor constituents of ozone. They conclude that NOx emissions could be successfully analyzed for their strength, while for individual VOC emissions regularization techniques are needed to account for known ratios of individual species. Other researchers have used adjoint methods to examine sensitivities to many inputs and parameters. The mathematical foundations of the adjoint sensitivity method, as applied to AQMs were discussed by Sandu et al. (2005), as well as the present computational tools in 3-D context; they used identical twin experiments in the STEM-2kl model for sensitivity analysis. Mallet \& Sportisse (2005) also investigated ozone sensitivities of all emissions over Western Europe using an 
adjoint model. Adjoint version of STEM was used was used by [Hakami, 2005] for inverse modeling of inert carbonaceous aerosols in Asia. They used the same model for sensitivity analysis of NAAQS nonattainment ozone metric in the continental US [Hakami et al., 2006] and showed that simple cap and trade programs may prove inadequate in reaching sought-after air quality objectives. More recently, Zhang et al., (2009) applied adjoint of GEOS-Chem to quantify contributions to ozone concentrations over west coast of the US. The same model was used to evaluate the influences of specific sources of inorganic PM2.5 in the US by Henze et al. (2009). 


\section{Methodology}

\subsection{Overview}

Reactivity Research Working Group (RRWG), as mentioned before, was tasked with studies on the reactivities of organic compounds, including three-dimensional modeling ( e.g., Carter, (2005) and Hakami et al., (2004a)), as well as box model studies (e.g., Carter, (1994)). In previous studies, reactivity metrics were compared for different domains based on a variety of inventories, models, and chemical mechanisms. The major parts of the previous studies were carried out with either stationary box [Carter, 1989, 1994] or single cell trajectory models [Derwent et al., 1998]. These models were colligated with a detailed treatment of chemical reactions, but with a simplified usage of physical processes. For a better implementation of scales, and a better comparison of VOCs in terms of their ozone formation potential, an ensemble measure is desirable. This goal can be met through 3-D modeling, since it provides a range of scales for various conditions, locations, and times. To be able to analyze the VOC impact on ozone in time and space, more realistic grid model studies were applied for Los Angeles [Bergin et al., 1995], New York [Carter et al., 2003], and for southern and central California [Hakami et al., 2004].

Forward sensitivity methods, such as Brute-force or DDM, are source-oriented and provide receptor specific information. While important, forward methods cannot distinguish between impacts from individual sources. In other words, forward methods provide receptor specificity but lack source specificity. The adjoint (backward) 
approach is the opposite. Adjoint sensitivities are propagated from receptors and are therefore receptor-oriented. The adjoint sensitivity field provides source-specific responses of an integrated cost function. Therefore, the adjoint approach lacks receptor specificity but provides source specificity. The two methods complement each other and provide different perspectives and each is more suitable for different types of applications. Since the goal of developing 3-D reactivity scales is to be able to distinguish between different sources, the adjoint seems to be a natural fit for the application. Furthermore, as in adjoint simulations all sensitivities are calculated in one run, adjoint reactivity estimation results in very efficient calculation of 3-D reactivities.

Three distinct questions are explored in this study:

1. The first task is to estimate 3-D reactivity metrics over the North American domain with the application of the adjoint of the CMAQ model. Various aspects of a new backward reactivity metric and the resulting scales need careful consideration. This would provide a continental scale reactivity estimation that has never been accomplished before.

2. The impacts of different base mixtures based on emissions and concentration profiles on the reactivity scales are to be examined.

3. Spatiotemporal consistency of calculated 3-D adjoint metrics is an important policy concern that needs thorough evaluation.

4. The calculated metrics and scales are to be compared with previous box model and forward scales.

The final outcomes are the development of adjoint reactivity metrics and scales and evaluation of their robustness. It should be noted that although "metrics" and "scales" 
are used rather interchangeably here, there is a slightly different definition to each. The calculation of a specific organic compounds' reactivity is called a "reactivity metric", while a "scale" is made up of a set of those metrics, quantitatively representing the compound in the spectrum of comparison to each other [Hakami \& Arhami, 2004]. Metrics are based on one set of attributes (e.g., being based on a single location/time/episode vs. being spatially integrative), while scales have many different sets of attributes.

In this chapter, the model and inputs specifications are explained in detail. Then, we will present the development of the metrics with a new definition, and different aspects of those will be discussed at the end.

\subsection{Modeling Episode and Domain}

The US EPA's CMAQ modelling system was used to simulate the Summer 2007 air pollution episode over North America, for three months (from July to September). The first two days of the 3-month period are considered a "ramp up" period, which is used to remove the effect of initial conditions. This episode was favorable to ozone formation throughout North America, and was chosen because of this to examine the impacts on reactivities. A North American domain was chosen for this study, due to the availability of comprehensive emission inventories and meteorological data for this domain (see Section 4.4). In addition, EPA is willing to update its guidance to the States if new information becomes available [USEPA, 2005], and further extensions might be implemented in near future. This domain is associated with more divergent chemical and 

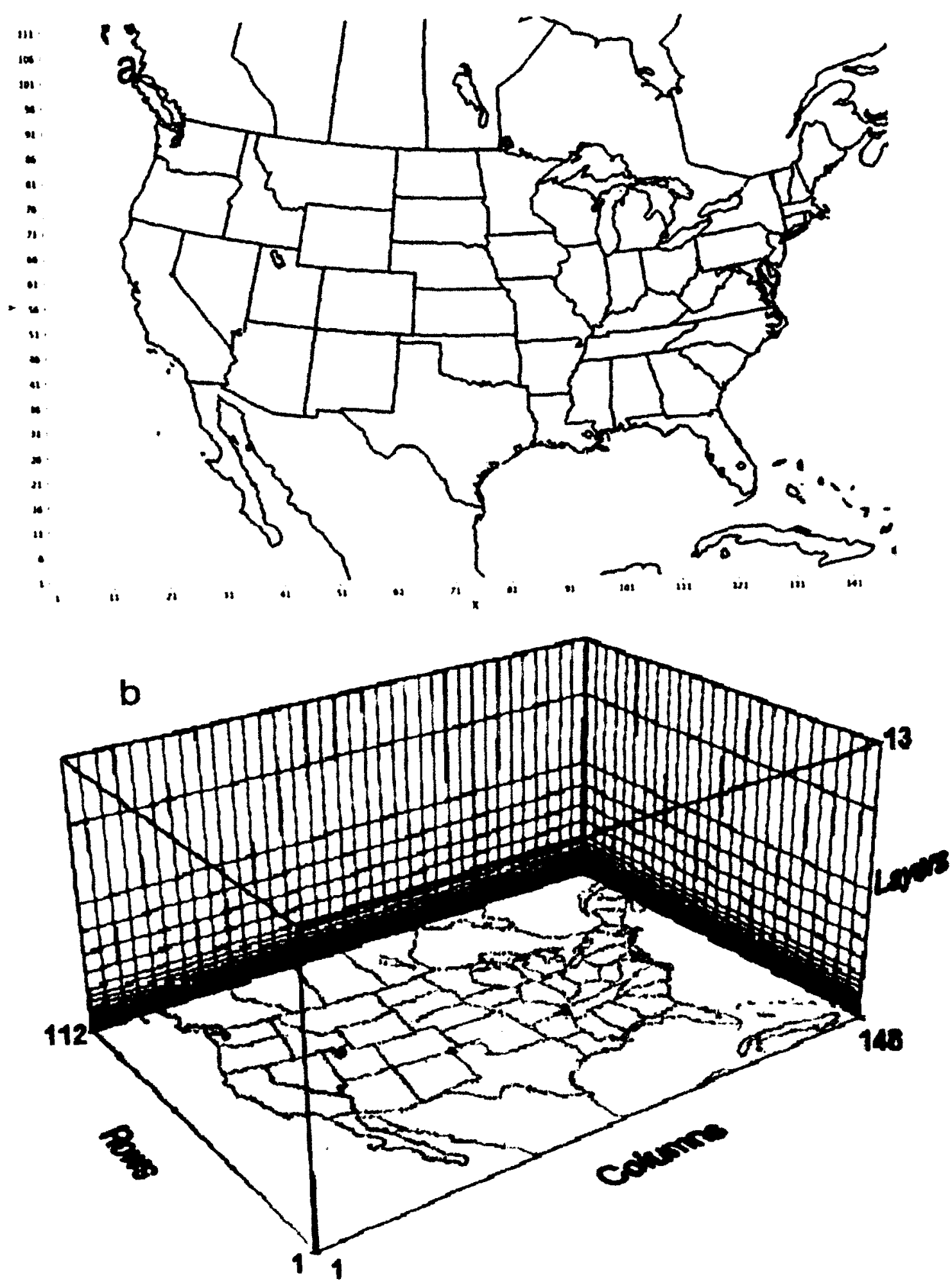

Figure 4-1: Simulation domain covering North America:

a) with a $36 \mathrm{~km}$ horizontal resolution and b) 34 vertical layers. 
meteorological characteristics than in previous studies, since it covers a larger area, and incorporates cities of varying size, rural areas, mountainous valleys, and coastal regions.

The modeling domain, being a Lambert conformal projection of North America, has a 36-km resolution horizontal uniform grid (148 columns and 112 rows) covering most of Canada and contiguous United States (see Figure 4-1 above). The terrainfollowing hydrostatic pressure vertical coordinate resolves 34 layers for vertical extension of the domain [NCAR, 2010]. The layers closest to the surface are shallow, and become coarser at the top of the model. The dynamics of the atmosphere and the emissions for the duration of the episode are the inputs for the CMAQ model. A suite of programs for conducting the simulations of atmospheric and land processes are installed in CMAQ, and will be discussed further below.

\subsection{The Models-3 Platform}

Three-dimensional chemical transport models that use simulated meteorological forcing can be used to study past pollutants' behaviour, and to examine the impacts of pollution reduction strategies. They simulate the emissions, transport, and chemical transformations of gases and particles in the troposphere, while General Circulation Models (GCMs) focus on simulating overall atmospheric dynamics (such as winds and atmospheric circulations). In addition, CTMs accurately represent the entire cycle for the sspecies of interest, including fluxes, chemical production/loss, and deposition [Jacob, 1999].

The CMAQ Eulerian model version 4.5.1, gas-phase (used in this study) is a part of Models-3 platform and third generation air quality model widely used in North 
America and across the world. CMAQ simulates the emissions, transport, and chemical transformations of individual model species (i.e. gas-phase mechanism species, aerosols, non-reactive species, and tracer species) in the troposphere, using numerical integration techniques. The results are temporal and spatial distributions of the concentrations of multiple air pollutants (gaseous and aerosol) on a variety of scales [Byun \& Ching, 1999]. It is also used in modeling of acid deposition, visibility, and fine particulate matter in the troposphere for regulatory analysis, policy analysis, and scientific investigation [Byun \& Schere, 2006]. Similar to other photochemical transport models, CMAQ was developed to integrate the species conservation equations that governs reactive transport, as explained before with the ADE (Equation 3-1). There are three major components for CMAQ: the meteorological processing model, the emission processing, and the CMAQ Chemical Transport Model (CCTM), all of which are responsible for solving or producing inputs required to solve the $\mathrm{ADE}$ equation. The overview of the CMAQ modeling framework, along with the flow of data between the modules, is shown in Figure 4-2.

The main input data required to perform simulations are the meteorological parameters, as well as the anthropogenic and biogenic emission data. These parameters and inputs) needed by CMAQ come from different sources, and can thus have an incompatible format with CMAQ. The output of meteorological and emission models should have the same spatial and temporal resolution as the CMAQ domain, since this is most often set by the user. Numerous pre-processes and conversions need to be performed prior to the use of the equipped data in air quality simulations (see Section 4.4). 


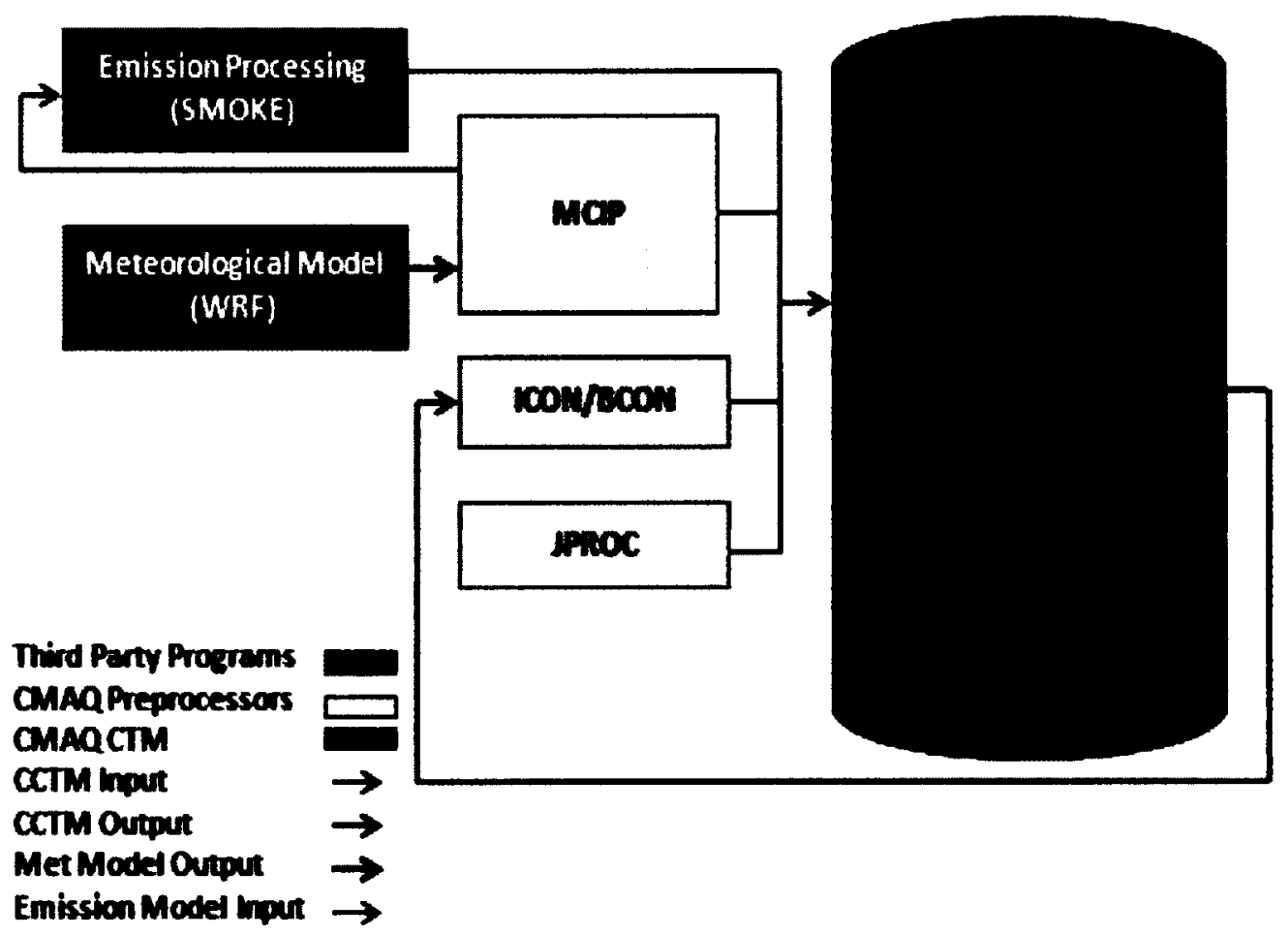

Figure 4-2: The Model-3 CMAQ and CMAQ-ADJ modelling system, CCTM and preprocessors, specifically the version used in this air quality study.

Initial and boundary conditions are other required inputs, as well as the clear sky photolysis reaction rates; these all are needed for CMAQ to be able to simulate the chemical system in the atmosphere. For the beginning of a model simulation, the first time step in a simulation is produced by an initial condition processor (ICON), and is then used as the initial condition by CMAQ. After this, the boundary conditions processor $(\mathrm{BCON})$ is responsible for providing lateral boundary concentrations for the simulation in the domain; the concentrations of all the model species at the boundaries of the domain are introduced as boundary conditions to the CTM. Numerous chemical reactions in the atmosphere are initiated by the photo-dissociation of several trace gases; hence CMAQ needs to compute the photolysis rates of reactions. These rates are 
dependent on the angle of the sun (based on the time of day), the season, and the latitude [Byun \& Ching, 1999], and are generated by the Photolysis Rate Preprocessor, JPROC. To facilitate the implementation of forward and adjoint sensitivity analysis, CMAQ uses chemistry solvers to compute pollutant concentrations and their rate of formation or depletion. The chemical solver used in this model is the Kinetic PreProcessor (KPP) package of Rosenbrock solvers (version 2.2) [Damian et al., 2002] which also includes TLM and adjoint versions. Chemical mechanisms are developed for 3-D air quality models to represent the compounds present in the air and the interactions between them, in a simplified way. CMAQ has a number of different chemical mechanisms used to simulate the gas phase chemistry. Two important mechanisms are the Statewide Air Pollution Research Center, Version 1999 (SAPRC99) photochemical mechanisms [Carter, 1999], of which the gas phase version was used in this study, and the Carbon Bond mechanism (CB05) [Yarwood et al., 2005]. The former mechanism represents chemical compounds for Eulerian modeling in more detail than the latter. The detailed SAPRC-99 chemical mechanism is used as the suggested evaluation method for organic compounds [RSAC, 1999], since it has been developed exclusively for proper representation of VOC species and reactions. Therefore, the SAPRC-99 mechanism was chosen for the reactivity estimations in this analysis.

One of the main processes in a CTM is advection, which is defined as a transport of pollutants by bulk motion of the wind. Another process is turbulent diffusion (horizontal and vertical), described as the dilution and dispersion of pollutants due to the random fluctuation in the wind [Tesche, 1983]. Consequently, the advection process is simulated separately in the vertical and horizontal directions in CMAQ. Piecewise 
Parabolic Method (PPM) is used to simulate the horizontal advection in CMAQ [Colella \& Woodward, 1984]. Only the gas phase processes of CMAQ are discussed here (Table 4-1), and other processes such as cloud formation, particular matter and plume-in-grid model (which are not part of this study) can be found in [Byun \& Ching, 1999; Byun \& Schere, 2006].

Table 4-1 CMAQ model specification

\begin{tabular}{|c|c|}
\hline Model & CMAQ v.4.5.1 \\
\hline Chemistry & SAPRC v.99 \\
\hline Number of Species & 94 \\
\hline Explicit VOCs & 18 \\
\hline Total Emitted VOCs & 28 \\
\hline Number of Chemical Reactions & 30 \\
\hline Chemical Solver & KPP v.2.2 \\
\hline Horizontal Advection & Finite Difference Scheme \\
\hline Advection Scheme & PPM \\
\hline
\end{tabular}

\subsection{Input Generation for CMAQ}

In this section, the processes used to generate meteorological and emissions inputs to CMAQ are explained, done by the Weather Research Forecast (WRF) model, the Meteorology-Chemistry Interface Processor (MCIP), and the Sparse Matrix Operator Kernel Emissions (SMOKE) Modeling system, respectively. This generation was done for the summer 2007 episode described initially. 


\subsubsection{Meteorology Inputs}

\subsubsection{WRF Model}

The Weather Research and Forecasting (WRF) Model is a mesoscale numerical weather prediction model, used to develop the 3-D meteorology fields and provide information on atmospheric research. It is intended mostly for operational weather forecasting, regional climate prediction, air quality simulation, and idealized dynamical studies [NCAR, 2010]. It characterizes multiple dynamical cores, a 3-dimensional variational (3DVAR) data assimilation system, and a software architecture allowing for computational parallelism and extensible systems. The WRF model is suitable for a broad spectrum of purposes, across scales ranging from meters to thousands of kilometres. Assuming a balance between vertical pressure and gravitational forces with no net vertical acceleration, the hydrostatic assumption employed in this model works very well for large scale domains. On the other hand, for resolving the atmospheric dynamics of finer resolutions (such as a regional or urban scale) the compressible non-hydrostatic assumption is better [NCAR, 2010].

The Weather Research and Forecasting model uses North American Mesoscale (NAM) datasets in a GRIB format from the National Center for Environmental Prediction [NCEP, 2005a, 2005b]. WRF is responsible for the meteorological fields, fed to the emission model (SMOKE) and to CMAQ. The modeling domain of WRF used here (version 3.1) covers North America with 165 columns, 129 rows and 34 vertical layers. Thus, the outputs are not in a format that can be used directly with CCTM, and the conversion is processed with the MCIP model to provide the compatible input to CMAQ. 


\subsubsection{MCIP Model}

Since most meteorological models are not built for air quality modeling purposes (e.g. WRF outputs), Meteorology Chemistry Interface Processor (MCIP) acts as a preprocessor for the data [Byun et al., 1999]. The model deals with issues related to data conversion to gridded two- and three-dimensional meteorological data files. MCIP deals with issues related to data format translation, conversion of units of the parameters, diagnostic estimations of parameters not provided, extraction of data for appropriate window domains, and the transformation of meteorological data for different grid and layer structures. Hence, MCIP links meteorological model data from the WRF model with the CMAQ model. To support the multiscale generalized coordinate performance of the CMAQ CTM, MCIP presents suitable dynamic meteorological parameters to allow mass-consistent air quality computations. When the meteorological data from the WRF model are recast with the proposed set of governing equations using MCIP, CTMs can closely follow the dynamic and thermodynamic descriptions of the meteorological data.

In this study, the model used is MCIP $\vee 3.0$. MCIP was extended to the lateral boundaries of the WRF domain ( 165 columns $\times 129$ rows) and trimmed into a smaller domain matching that of the CCTM (148 columns $\times 112$ rows). Moreover, the MCIP model can change, if necessary, the vertical resolution of the meteorological data by "layer collapsing" from high resolution into user-defined vertical resolution. In this work, however, the vertical layers of WRF and MCIP were the same as the required layers in CMAQ. MCIP writes the output data in a transportable binary format (netCDF [UCAR, 2008]) using the Models-3 input/output applications program interface (I/O API) library 
[BAMS, 2005]. Other characteristics and abilities of this model are described elsewhere [Byun et al., 1999].

\subsubsection{Emission Inventories}

\subsubsection{SMOKE Model}

The emissions inputs for CMAQ were generated by the Sparse Matrix Operator Kernel for Emissions (SMOKE, version 2.4) model [CEP, 2006]; it was used to process area, on-road mobile, non-road mobile, and point source emissions. The purpose of SMOKE is to convert the resolution of the emission inventory data to the resolution needed by the CTM. The emissions inventories are typically made up of total annual emissions prepared for each emission source (e.g., stationary, mobile, etc). The air quality models require emission data for each time step (on an hourly basis), in each model grid cell (and in each layer), and for each model species. Consequently, the main purpose of emissions processing is transforming an emission inventory through temporal/spatial allocation and chemical speciation, to achieve the input requirements of the CMAQ.

SMOKE supports various emission sources, such as area-, mobile-, and pointsource emissions processing, and also includes biogenic emissions modeling. Spatially, emissions were allocated by surrogates such as population, land use, and land cover [CEP, 2006]. Since non-road emissions are assigned to moveable sources that are not on roadways (e.g. garden equipment, construction vehicles), they function better when built into the area sources category. SMOKE can also simulate both criteria and toxic emissions data inventories. SMOKE can process criteria gaseous pollutants (e.g. carbon 
monoxide, volatile organic compounds, etc), particulate matter (PM10, PM2.5, etc), and toxic pollutants (e.g., benzene, formaldehyde, etc).

Table 4-2: Monthly average emissions over the domain ( $K$ tonnes per day)

\begin{tabular}{|c|c|c|}
\hline & NOx & VOC \\
\hline Jul-07 & $\mathbf{8 8 2}$ & 9536 \\
\hline Aug-07 & 875 & 8722 \\
\hline Sep-07 & 794 & 5876 \\
\hline
\end{tabular}

In this study, SAPRC 99 was used to speciate the emission profiles, and it is based on source category [Carter, 1999]. The SAPRC-99 includes 72 species, 235 chemical reactions and 30 photolytic reactions. Biogenic emissions from trees, plants, and crops were also processed by the Biogenic Emissions Inventory System (BEIS), version 3.12. Emission projections used in this study, which are a function of changes in emission rates, as well as the growth/decline in population, were taken from the emission inventories of 2007 from National Emissions Inventory (NEI) [US EPA, 2009].

The total emissions of VOCs and $\mathrm{NO}_{\mathrm{x}}$ for the period of three months, and for each episode, are shown in Figure 4-3 and Table 4-2, respectively. Meteorologically, July was very favorable to ozone formation, while August and September were less conductive, and resulted in moderate ozone concentrations over the domain. As expected, emissions of VOCs and $\mathrm{NO}_{\mathrm{x}}$ have significant values over large urban cores, and lower levels in other areas where industries and major cities are not present (Figure 4-3). Regions influenced by point sources, as a result of high industry population (e.g. Texas, Philadelphia, San Francisco Bay area) tend to have much higher VOC emissions than other areas where $\mathrm{NO}_{\mathrm{x}}$ emissions are in the same range, comparable over the domain, and have less variation from industrial to urban regions. 


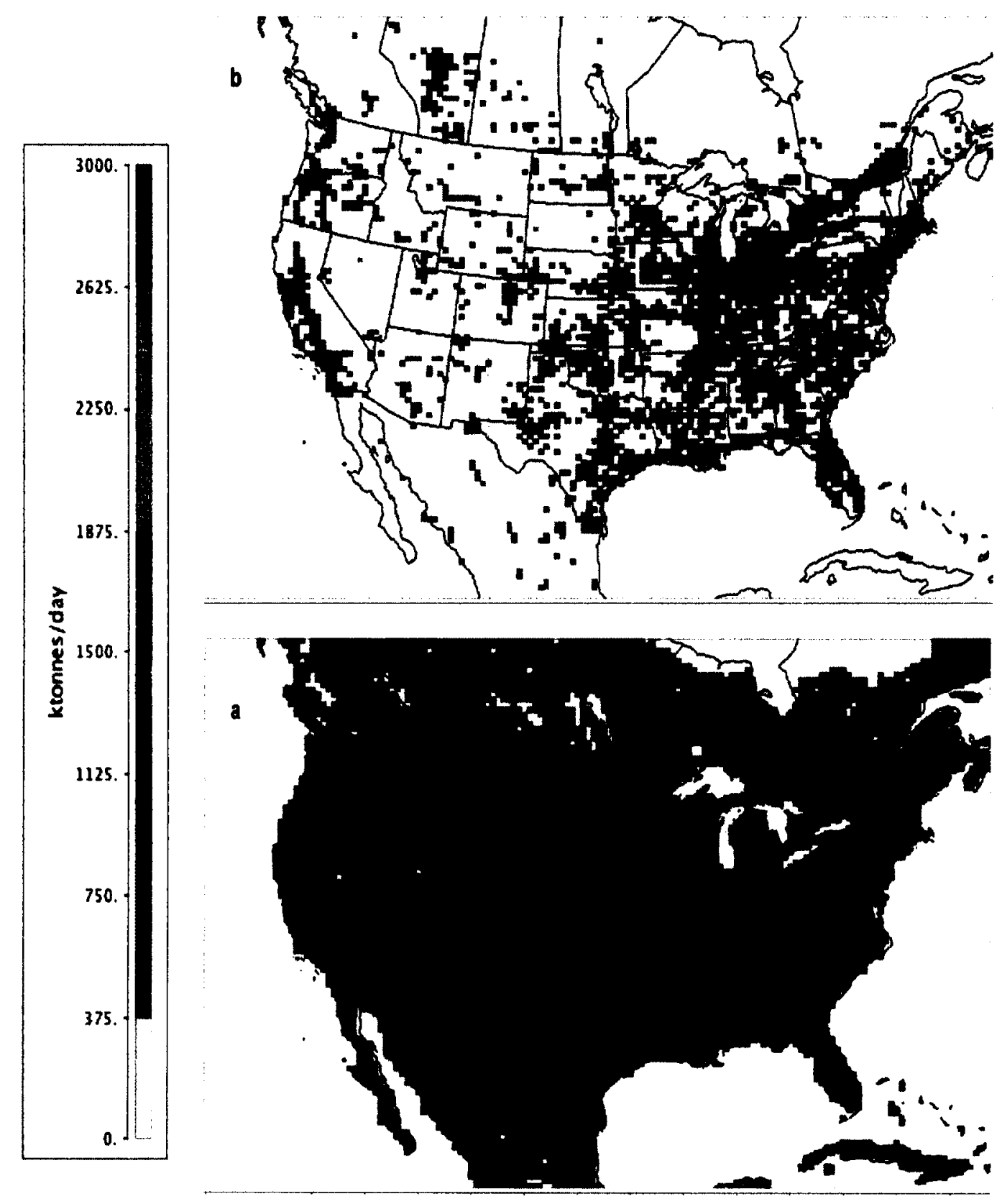

Figure 4-3: Total emissions over the episode of three months for each grid (tonnes/d) a) VOC b) NOx (x10) 


\subsection{CMAQ Performance Evaluation}

To be able to rely on computer modeling results, simulations should be compared against observation data, or results generated from a highly evaluated performance model [Byun \& Ching, 1999]. CMAQ has been extensively evaluated in many other modeling studies [Arnold \& Dennis, 2006; Eder \& Yu, 2006; Smyth et al., 2006]. To assess the predictive capabilities of the CMAQ platform, the resulting concentrations should be compared to the corresponding observed data. For inventories used in this research, the evaluation was done by a colleague in the same research group, and the complete results are discussed in more detail in that work [Mirzajani, 2011]. Since the same emission profiles were used in this study, the procedure was not repeated, and the findings from that study are referenced here.

The observed values used for evaluation were from urban, suburban and rural monitoring stations, collected on an hourly basis. A summary of statistics for ozone performance of the gas-phase CMAQ used in backward sensitivity analysis for the duration of the episode across Canada and the Unites States are presented in Table 4-3. Two different thresholds were considered to first disregard the nighttime predictions as

they usually contribute to poor estimation (below $40 \mathrm{ppb}$ ), as well as only addressing higher ozone levels closer to standard regulatory values $(60 \mathrm{ppb})$. Overall, the daytime ozone concentration is overestimated (positive MNB), while an underestimation is associated with high ozone concentration (negative MNB) [Mirzajani, 2011]. Normalized error is low throughout the simulation period, and the bias is also at a reasonable level. The overall Mean Normalized Bias and Mean Normalized Error for the duration of the 
study over the US and Canada were in an acceptable range, as suggested by EPA, of $\pm 15 \%$ and $\pm 35 \%$, respectively [US EPA, 1991].

Table 4-3: Ozone Performance Statistics [Mirzajani, 2011]

\begin{tabular}{|l|l|l|l|l|}
\hline \multirow{2}{*}{ Threshold } & \multicolumn{2}{|c|}{ Canada } & \multicolumn{2}{c|}{ United States } \\
\hline MNB & $6.69 \%$ & $-5.85 \%$ & $9.20 \%$ & $-2.97 \%$ \\
\hline MNE & $20.06 \%$ & $16.20 \%$ & $18.75 \%$ & $13.30 \%$ \\
\hline
\end{tabular}

\subsection{Reactivity Calculation Methodology}

Three-dimensional reactivity assessment is conducted here by implementing backward sensitivity analysis (adjoint method) in a widely acceptable CTM (CMAQ). As stated before, adjoint is capable of capturing the effects of the VOC emissions on the average or total amount of ground-level ozone (depending on how the metric is defined) formed in the modeling domain.

\subsubsection{Adjoint Calculations}

In order to efficiently investigate how VOC emissions from different locations impact the air quality, which is measured by 8 -hour standard ozone concentration in this report, knowledge of the emissions at each of the locations, and their contribution to air pollution is required. Adjoint (backward) sensitivity analysis, as discussed in Chapter 3, is one of the better options to show how a model output defined in a single grid cell or across the domain is affected due to a perturbation in numerous inputs. It is important to note the theoretical difference between prior 3-D reactivity studies, i.e. forward 
sensitivity (e.g. DDM) and the backward sensitivity used in current work. In one forward sensitivity run, the derivative of all receptors with respect to one single source can be calculated, whereas the sensitivity of a receptor or a cost function (a function of receptors such as average, maximum, root square, etc.) with respect to all inputs can be calculated in one single backward sensitivity run. While forward approaches provide spatially and temporally distributed sensitivity information about receptors, backward analysis provides the structurally same information about sources. In that sense, forward and backward methods are in fact complementary as they address different aspects of the question.

The focus of this study is on differentiating between individual sources of organic compounds in terms of their potential influence on ozone concentrations. Therefore, adjoint sensitivity analysis is the natural choice for this study. Unlike the forward simulation, the adjoint analysis is initiated at the final time step, and is traced backward from the change in ozone concentrations to the initial emissions (Equation 3-5). The results of this analysis are the adjoint variables, which allow us to see the sensitivity of ozone concentrations to concentrations of different species at various locations and times in a proficient manner. Adjoint variables are then extended to calculate adjoint gradients, i.e. sensitivity of the cost function with respect to emissions, using Equation 3-9. The results are the same as perturbing the emissions by equal amounts for each pollutant, and yet fewer simulations (in some cases just one single run) are required. The adjoint variables are set to zero initially, and are updated at each time step by a local derivative of the cost function with respect to concentration (forcing term). Details of the derivation 
of the adjoint equations are beyond the scope of this work, and related information can be found in Appendix A and elsewhere [Hakami et al., 2007; Sandu et al., 2005].

\subsubsection{Adjoint Cost Function}

Adjoint analysis can be carried out for an integrated metric (in space and/or time) over receptors, times, model columns, or species instead of one single point. This metric is referred to as the adjoint cost function, i.e. defined as any desirable function of concentrations that deal with air quality. For sensitivity analysis of concentrations, the adjoint cost function (Equation 3-8) is set to the concentration of species of concern at a specific location or time (e.g. average ozone, ozone related mortality, 8-hour maximum ozone, exposure, etc). Therefore, the adjoint method is not capable of providing detailed information on individual receptors. From a theoretical point of view, the adjoint cost function can be defined over a smaller area or even a single grid cell. However, it would be prohibitively expensive to calculate sensitivities of each individual receptor as each cost function will require a new set of adjoint calculations. This thesis focuses on the sensitivity of ozone concentration change in North America, and so the domain-wide average of the 8-hour maximum ozone level is defined as the adjoint cost function (i.e. the metric the sensitivity of which is being calculated). This means that the calculation of the local gradient of the domain-wide average of daily maximum 8-hour averages is done for each day and in each grid cell, with respect to all emission sources across the domain. As explained in Section 3.3.2, the local cost functions are then integrated over time and space to get the overall cost function. The nationwide metric is the scalar cost function the sensitivity of which is to be calculated in adjoint analysis. The environmental goal 
(cost function) can also be calculated as the domain-wide average maximum 8-hour ozone concentration for only critical grids where this average is higher than $60 \mathrm{ppb}$. This value is chosen to reflect the lower end of the proposed EPA national ambient ozone standards [US EPA, 2008]. Both definitions of the cost function are considered in the current work.

\subsubsection{Absolute Incremental Reactivities}

The sensitivities of ozone resulting from Equations 3-4 and 3-5 are the absolute incremental reactivities of organic compound $i$, and implemented as $I R_{i}$ in former equations $(2-1: 2-6)$. For previous 3-D reactivity assessments where a forward approach was used, sensitivities were calculated on a source-based analysis that provides receptor specificity:

$$
I R_{f-i}=\frac{\partial C_{o_{3}}(x, y, t)}{\partial E_{i}}
$$

whereas for the adjoint or backward method, the corresponding IR values are defined in a receptor-based approach with source specificity:

$$
I R_{b-i}=\frac{\partial J}{\partial E_{i}(x, y, t)}
$$

where $x, y, t$ specify location and time for the emission sources (backward) or ozone receptors for target species $i . J$ is the cost function of interest, and $C_{O 3}$ and $E_{i}$ are as explained before, concentration of ozone and emissions. Adjoint values (reactivities) can be written for any time step of interest (every day, every hour, etc.). Here, the values correspond to the total of the sensitivities for each day, and for each VOC. The reactivities are computed in relation to equal amounts of individual emitted VOCs (unit 
of mass), in order to readily compare their reactivities. The 'mass' addition approach, in preference to the mole approach is useful in emission reduction strategies, as it provides insight on how many grams of emission need to be reduced in order to lower ozone to a certain level. As explained in Section 2.4 to be able to easily compare the ozone formation potential of compounds of interest to each other, incremental reactivities are normalized to a standard base mixture.

\subsubsection{Base Mixture Specification}

The incremental reactivities of certain VOCs are weighted based on their mixing ratios in the atmosphere, and represent a base organic mixture using Equation 2-6. To be able to represent a standard assessment of relative reactivity, the composition of the base mixture is chosen from a policy perspective; whereas scientifically it is either based on ambient air measurements, or on the total input of anthropogenic emissions to an airshed model [Carter, 2005]. In this work both of the base mixture scenarios have been considered to evaluate their differences. The first scenario uses the total anthropogenic emissions from all of the sources presented in the domain to generate a base mixture profile. The second scenario, meanwhile, is setting base mixture VOC compositions based on their atmospheric concentrations. The correlated values (or compositions) are driven from concentration profiles coming from the forward run of CMAQ module (solving $\mathrm{ADE}$ equation). Base mixture compositions are calculated from either concentrations or emissions such that:

$$
y_{i}=\frac{\sum_{d} \sum_{h} \sum_{x, y} Q_{i}}{\sum_{i} \sum_{d} \sum_{h} \sum_{x, y} Q_{i}}
$$


where $Q$ is representing either emissions or concentrations and $d$ and $h$ are counters for simulation days and hours, respectively. Considering the stated scenarios, the results have been divided in to two different categories:

1. The Total Emissions for each VOC, for all the days in the episode of summer $2007(d=92)$ during daylight hours $(h=10 A M-6 P M$ local time $)$ are added over the domain $\left(x^{*} y=148^{*} / 12\right)$, and their compositions are calculated by the division of emissions for each VOC (i) over the total emissions of VOCs. This group will be referred to as the "emission-based" compositions.

2. The concentrations of each VOC for all the days in the episode (again during daylight hours) are summed over the domain. This number is then divided by the total concentrations of all the VOCs of target, and will result in "concentrationbased" compositions.

The compositions of species in the base mixture and their carbon number are shown in Table 4-4. Note that the numbers are averaged over the domain, and values are based on moles of VOC per moles of total anthropogenic emissions (mole fraction), or in the case of ambient air measurements, total of concentrations. Note that in Table 4-4, Isoprene and Terpenes, the two species that mostly contribute to biogenic emissions, has not been included in the emission-based scenario; while they have been considered in the calculation for concentration-based compositions. The reason is that in the case of emissions the profile of concern is the anthropogenic profile over which we have control. On the other hand, the other scenario corresponds to the concentrations of species after being emitted in to the air and reacting with other species (already existed in the atmosphere), which also includes the two stated compounds. 
Table 4-4: Composition of base mixture in terms of mole fraction (mol VOC/mol Base Mixture)

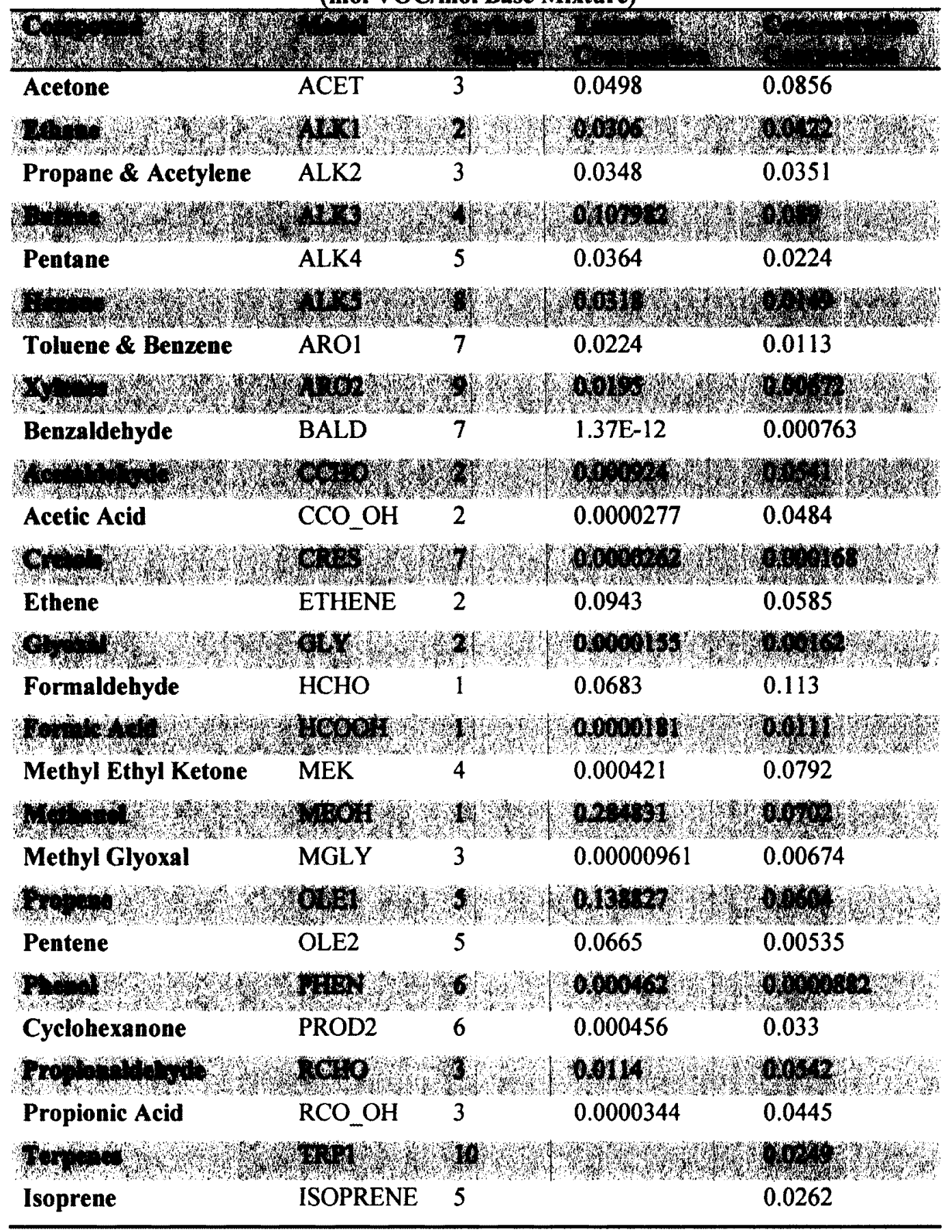


Owing to the fact that the VOC-based controls are to be implemented in each location, the stated base mixtures (emissions and concentrations) can be also characterized and calculated at each location separately. A "location-wise" composition is defined in a case where emissions (or concentrations) of each VOC for all the days in a grid cell are summed and divided by the total VOC emissions (or concentrations):

$$
y_{i, x, y}=\frac{\sum_{d} \sum_{h} Q_{x, y, i}}{\sum_{i} \sum_{d} \sum_{h} Q_{x, y, i}}
$$

Whereas before, compositions were calculated for the domain, and a constant number for each VOC for the whole domain were presented (Table 4-4). The numbers for locationwise compositions is specific to each location, and the fractions obtained $\left(y_{i, x . y}\right)$ represent the composition of each species in that specific grid cell over the length of the simulation period. The contribution of each VOC in the base mixture, derived as explained above, are illustrated and compared in Figure 4-4 and Figure 4-5. Overall, the greatest contribution to the total moles of emissions is Methanol with $28 \%$ and the alkenes with $25 \%$. Following those is the olefins with a $21 \%$ involvement in VOC emissions. On the other hand, these results are different when looking at concentration, as alkenes have a major effect $(22 \%)$, and Formaldehyde has the second greatest with $12 \%$ (Figure $4-5$ ). The relative reactivities are then calculated using a base mixture of interest through Equation 2-4. Relative values are available for each day and location in the simulation episode. This has the advantage of giving us a spatial, as well as temporal coverage of RIRs. Therefore, each day is treated as a single episode, and the scale defined should be a valid representation of these relative values. 


\subsubsection{Development of Reactivity Scale}

There are various approaches that can be used to derive a global reactivity scale, depending on the quantification of the perturbed amount of ozone. Due to the variable nature and dependence of 3-D reactivities on perturbations in emissions, translating these values into a single measurement of ozone formation is more complicated compared with the pioneer studies in box model scales. Considering a large domain (such as North America in the current work), each airshed may exhibit diverse behaviour, as a result of being subjected to various environmental conditions. From the policy point of view, it is favourable to find a single measure of ozone formation potential to be able to compare different performances of various VOCs with respect to each other. Some of the previously calculated scales are inspired by the box model definitions, known as single point metrics (e.g. MIR-3D and POIR-3D) by Hakami et al., (2004). In contrast, multipoint metrics are based on a number of points, integrated over some period of time, and contributes to the spatial distribution in 3-D results (e.g. population/spatially-weighted average). The application of adjoint analysis gives us the ability to calculate any kind of scales with respect to the emitters of a domain, with a single model run. This application renders a greater specificity of sources, which is very beneficial in VOC-substitution strategies since the regulations are set on sources versus receptors.

The Median Relative Incremental Reactivity is the scale defined as the median of daily relative reactivities in the simulation for each location. Each calculated median value (for each species and grid cell) represents the relative reactivity of a day which is the median value in the series of available days (with significant base mixture reactivity) in the episode of 90 days of summer 2007. Final results that are compared with similar 
studies are reported again as the domain-wide median of these values. Note that cells over water were not included in the analysis.

This scale is somewhat similar to Peak Ozone Incremental Reactivity (POIR) as explained in Section 2.4.2, since we are using the maximum 8-hour ozone as the cost function. This will force the adjoint variables to contain sensitivities with respect to maximum ozone in an episode. The key difference is that the scale defined in the current work is associated with a spatial distribution over the domain. It can also be argued that similar to the Regional Average Ozone [Carter et al., 2003], explained in Section 2.4.2, a mean of day to day relative reactivity values could have been chosen for a representation of the metric in a grid cell. However, a mean value of a data set is influenced by outlier data (very large or very small) while the median value is more robust; considering the large domain in current work the number of outlier data is significant. Also a median value is more often used and understandable to the public than other alternative values resistant to outliers such as trimmed mean. This leads to a total of four sets of results (emission/concentration-based and constant/location-wise base mixtures) that are shown and compared in Chapter 5. 


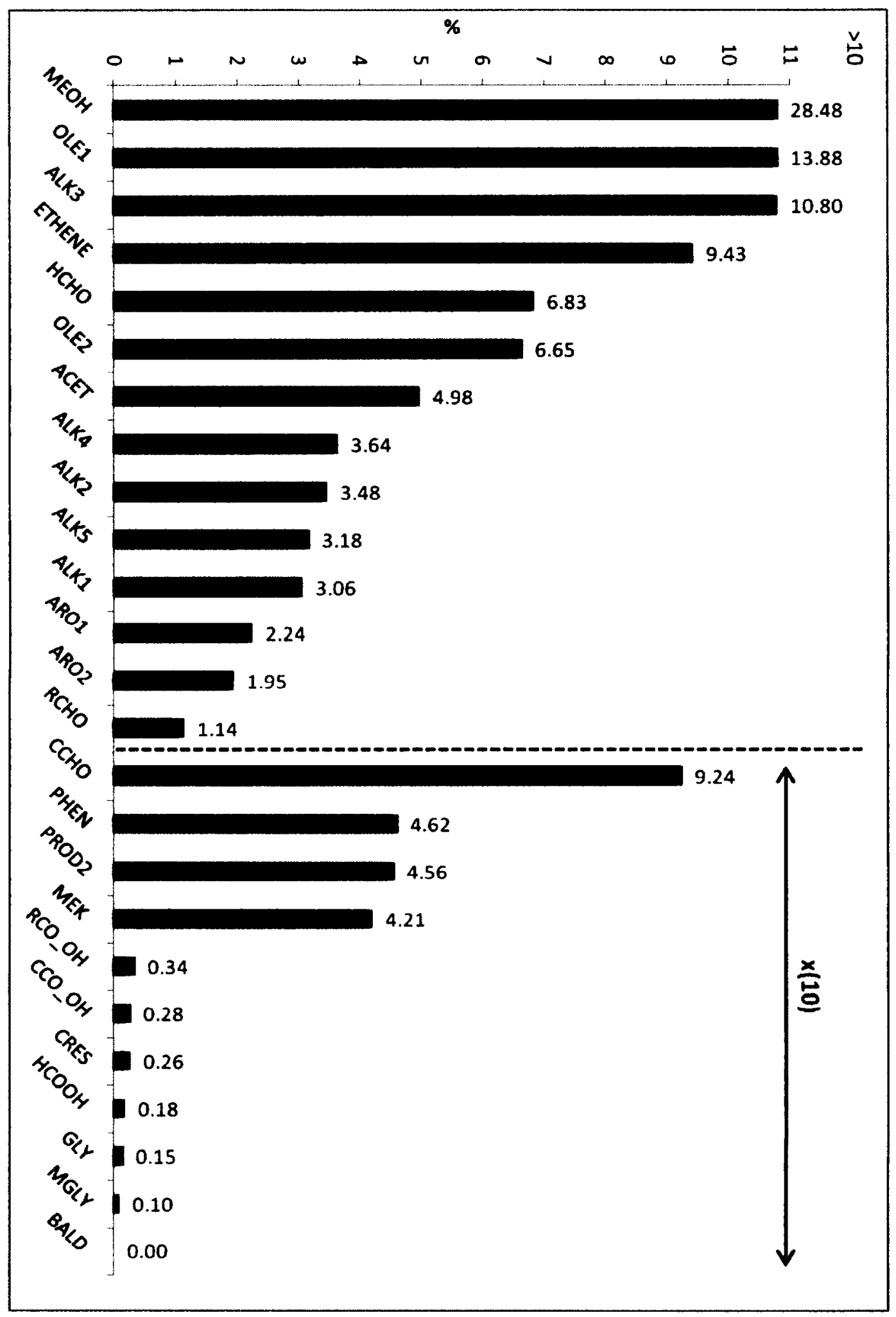

Figure 4-4: Contribution of each particular VOC to the base mix ture derived from emissions 


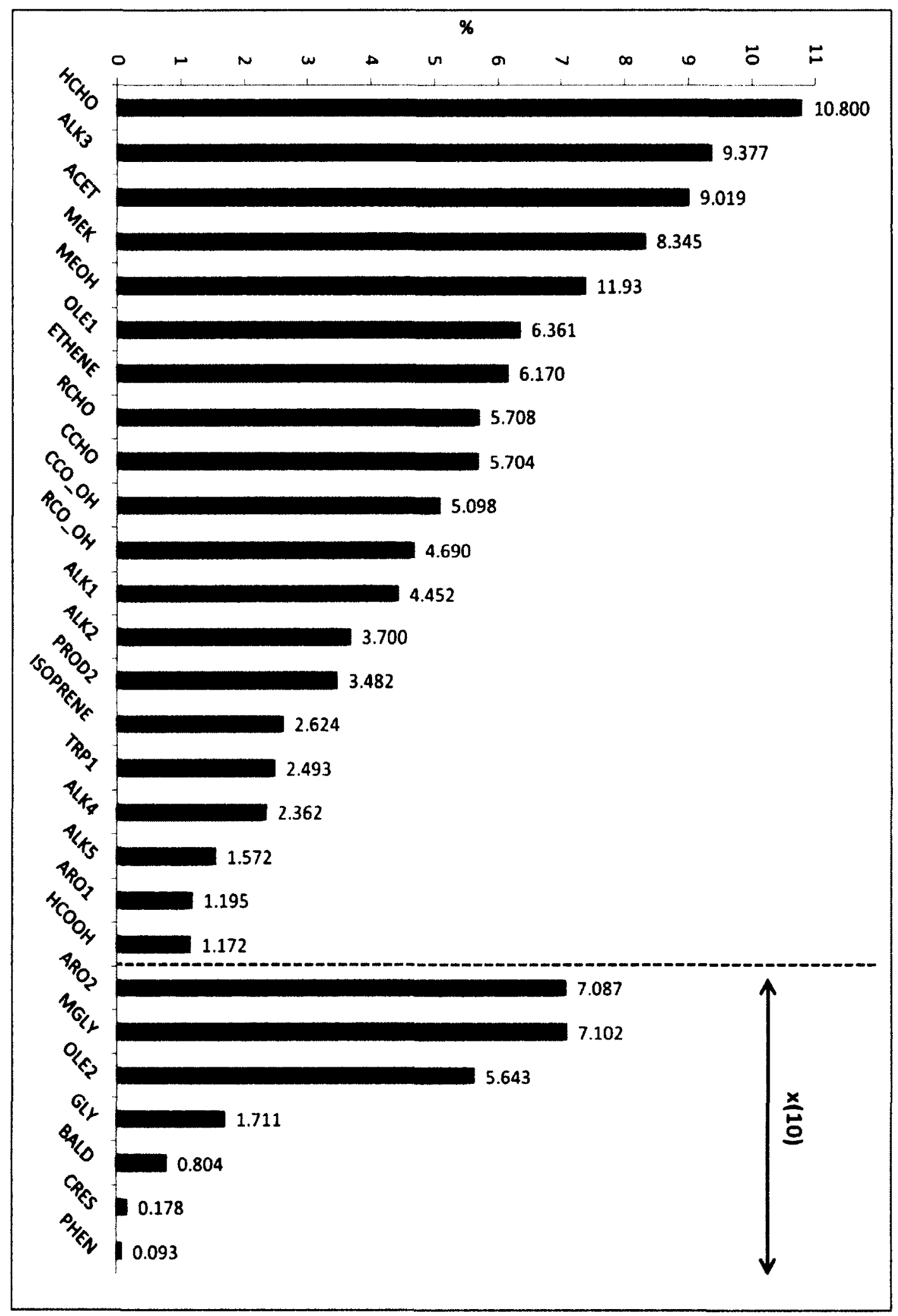

Figure 4-5: Contribution of each particular VOC to the base mixture derived from concentrations 


\section{Results and Discussion}

\subsection{Overview}

As stated earlier, the core purpose of this study is to evaluate three-dimensional reactivities of organic compounds, and their individual impact on ozone formation over North America. Incremental reactivities were quantified with respect to the structure of the latest air quality standard, the local maximum 8-hour average ozone. To achieve this objective the receptor-oriented adjoint sensitivity analysis approach was used, where the sensitivities of $\mathbf{8}$ hour ozone metric to the emissions of individual VOCs were calculated over the domain. Reactivities were calculated with respect to the total amount of anthropogenic VOCs, as opposed to the total amount of organic emissions, to represent the portion of emissions that can be targeted for ozone control policies. The expected improvement through this approach is that specific information on source, or emitters of pollutants, would become readily available to policy-makers. The previous chapter described the details of calculation and derivation of the metrics, while the results obtained from this approach are presented in this chapter.

\subsection{Ozone Profile over the Domain}

The geographical extent of the simulated surface ozone mixing ratio throughout the domain is shown in Figure 5-1a to 5-1c. Emission profiles generated with SMOKE and CMAQ v4.5 were used to carry out a CMAQ forward calculation. Concentration fields of ozone over the targeted domain were created, as well as the checkpoint files 
needed for the backward run. The spatial plots are shown for a typical day in July, August, and September. Meteorological conditions favoring ozone formation such as higher temperature profiles and biogenic VOC emissions (Table 4-2) are considerably higher in August episode, resulting in high ozone concentrations during this episode. The results are associated with low concentrations of ozone in major cities on both the east and west coast of the US and Canada (including cities such as Los Angeles, New York and Vancouver) which corresponds to $\mathrm{NO}_{\mathrm{x}}$ inhibited areas. High ozone concentrations in the southeast of US is most likely due to elevated levels of biogenic emissions of VOCs in that area (Figure 4-3), which causes higher $\mathrm{VOC} / \mathrm{NO}_{\mathrm{x}}$ ratios $\left(\mathrm{NO}_{\mathrm{x}}\right.$-limited regime).

\subsection{Absolute Incremental Reactivities}

Adjoint variables, as explained before, are the output of the model found from solving Equation 3-5. These values hold information about the sensitivity of the selected metric, e.g. the maximum 8 hour average ozone, with respect to VOC emissions at every location and time [Hakami et al., 2007]. Subsequently, the sensitivities to the emission sources at each grid cell are considered to be the incremental reactivities of VOCs. The sensitivities are normalized to the unit of mass of emissions in each grid over the land. Therefore, the effect (absolute reactivity) of VOCs on the targeted metric would be equal to the sensitivity value in that grid multiplied by the perturbation.

The spatial distribution of reactivity of selected VOCs on the maximum local 8hour average ozone for a typical day in the middle of summer, are shown in Figure 5-2a to 5-2d. The values, as explained before, are integrated over the grid cells in the receptor area of North America. A wide range of variability, as expected, is illustrated in the 
graphs (Figure 5-2). Depending on the locations and the species, reactivities can cover a range of few orders of magnitudes. Note the different scaling for each species in the caption of Figure 5-2, which shows the different order of reactivity values for each species and their ranking with respect to each other. One should consider the population density, forest coverage (biogenic emissions), urban cores, etc., when analysing sensitivity results. For instance, in the western United States (such as the Los Angeles area), with high population density and mostly urban areas, there is an association with high $\mathrm{NO}_{\mathrm{x}}$ and low VOC emissions leading to lower VOC-NO ratios (VOC-limited), and therefore large sensitivity to VOCs. Whereas, expected $\mathrm{NO}_{\mathrm{x}}$-limited regions which tend to be further from urban cores with lower population and/or significant forest cover (e.g. Fresno) correspond to lower reactivities of VOCs. Overall, because of the nature of sensitivities, downwind of $\mathrm{NO}_{\mathrm{x}}$-rich plumes where emissions of $\mathrm{NO}_{\mathrm{x}}$ or both $\mathrm{VOC}$ and $\mathrm{NO}_{\mathrm{x}}$ are highest (e.g. Texas), higher levels of reactivities are calculated.

It can also be seen that different compounds affect ozone concentrations to a different extent. In the series shown in Figure 5-2, Ethene is the most reactive species, Methanol has the least effect on ozone formation, and Isoprene is showing negative sensitivity (consuming ozone). For the sake of comparison, incremental reactivities of Ethene averaged for each month of the summer 2007 are also shown in Figure 5-3. A great deal of variability is also observed over the time of the simulation as well. As expected, because September is associated with lower ozone levels, higher reactivities can be seen over the domain. To achieve a scale that provides insight into the collective behaviour across the domain and episode relative reactivities are introduced [Hakami et al., 2004a; Hakami et al., 2004b]. 


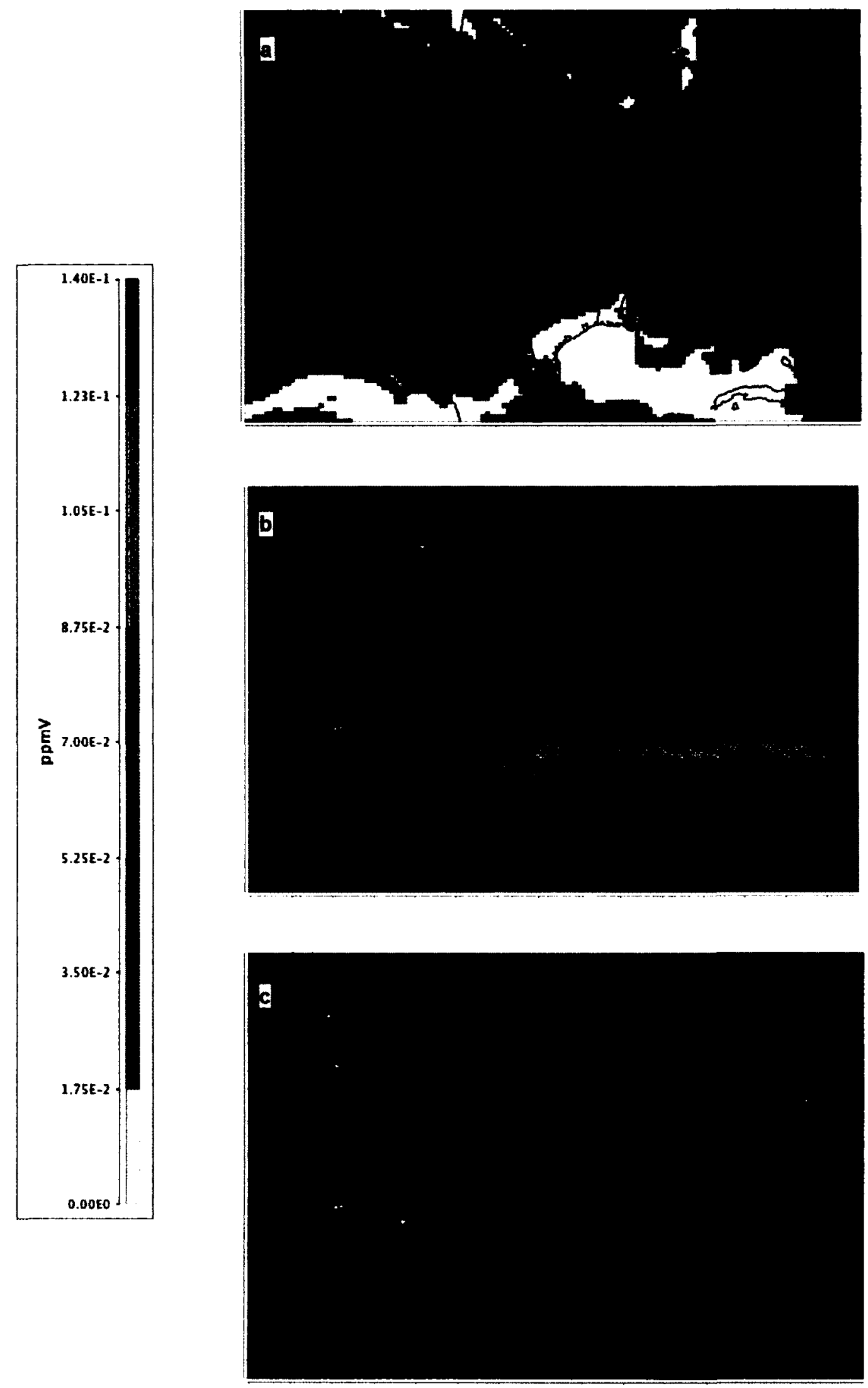

Figure 5-1: 03 concentration at 12:00 GMT over the domain for the middle of:

a) July, b) August, and c) September in summer 2007 


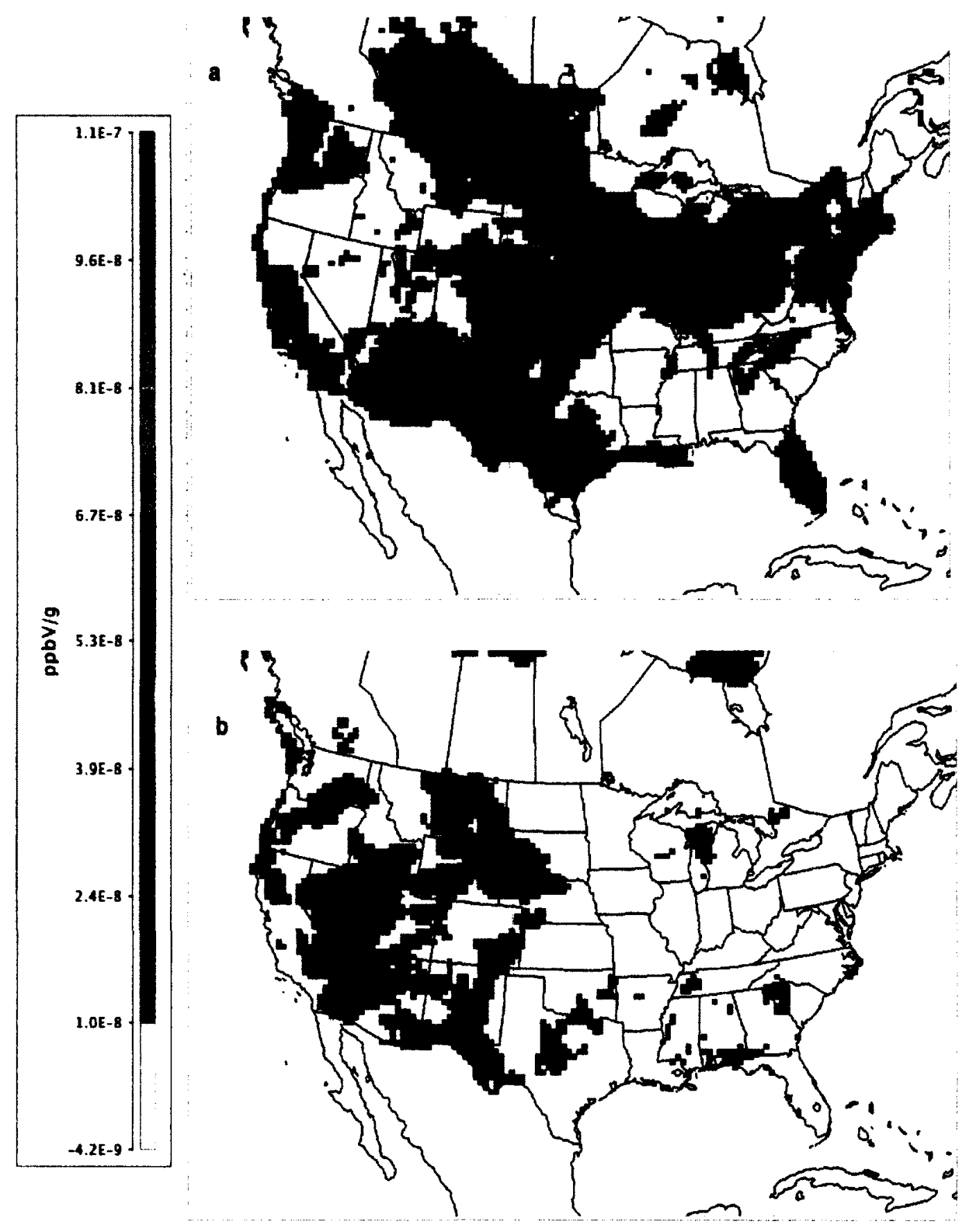

Figure 5-2: Adjoint sensitivites of maximum 8h-averge ozone (absolute VOC reactivities) for the middle of summer 2007 for: a) Ethene $(\times 0.3)$, b) Isoprene $(\times(-1))$, c) Formaldehyde and d) Methanol $(\times 4)$ 


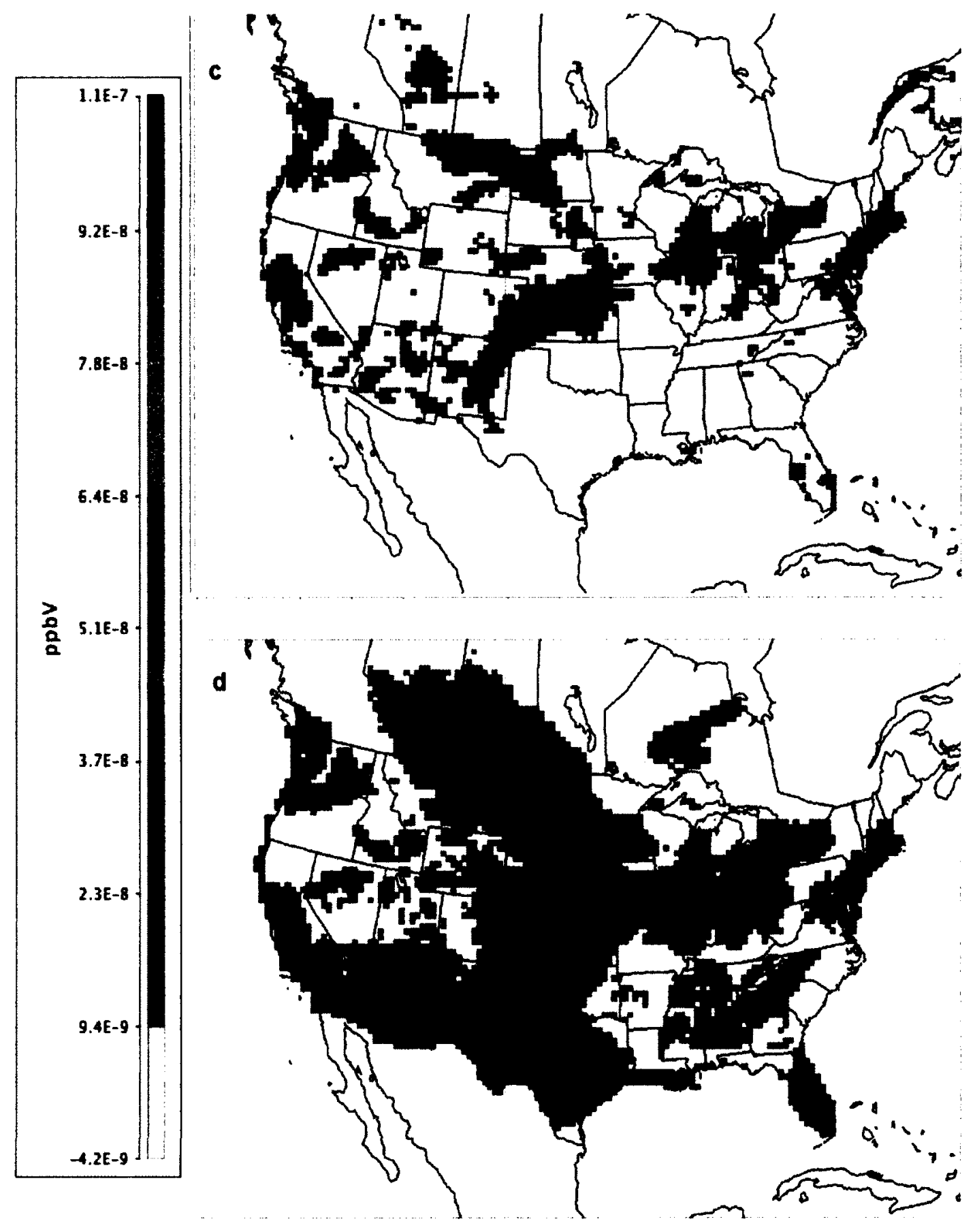

Figure 5-2: (cont'd) 


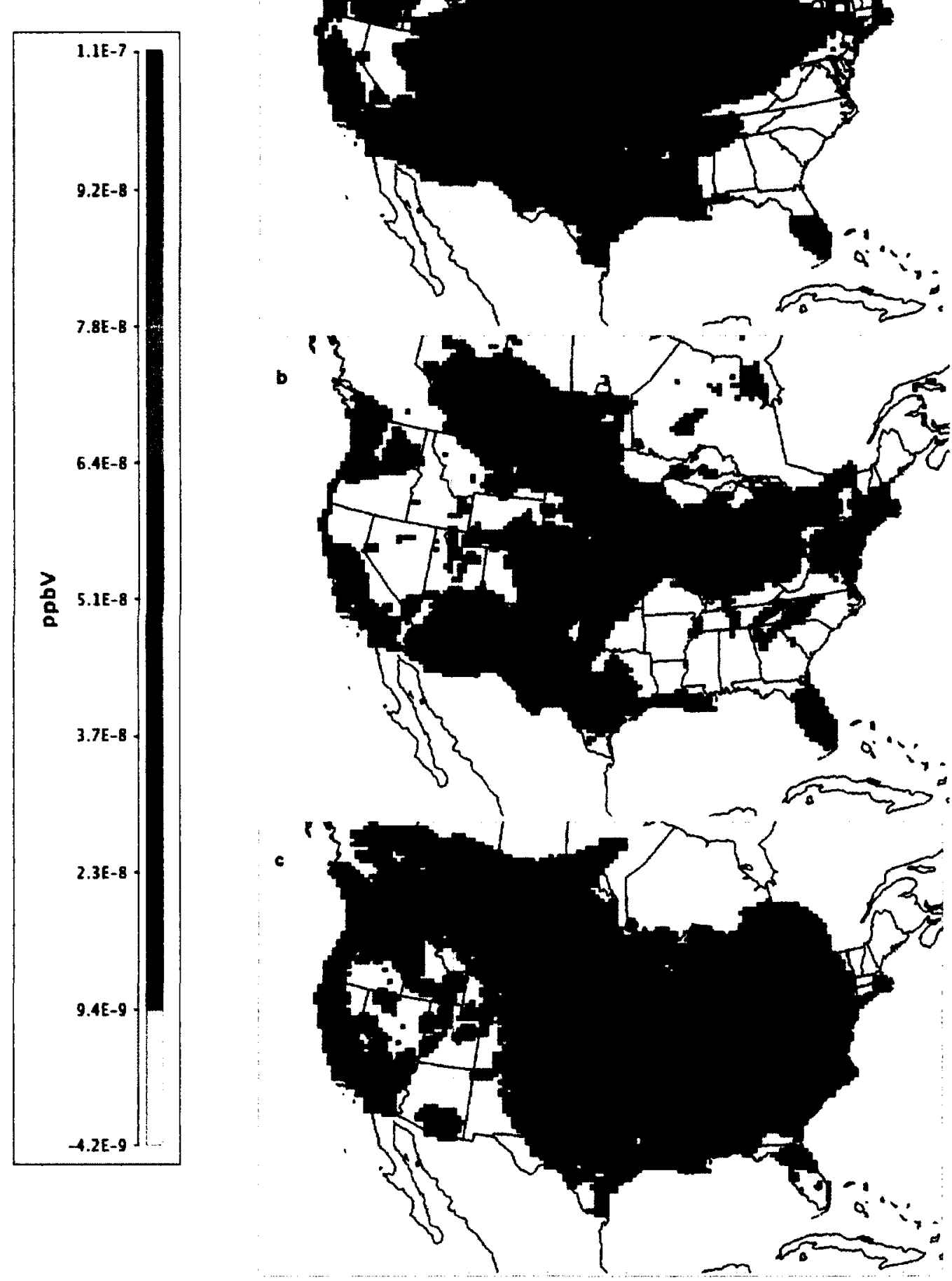

Figure 5-3: Adjoint absolute incremental reactivities of Ethene integrated over 30 days of a) July, b) August, and c) September, results are averaged for each month. 


\subsection{Relative Reactivities}

From an emission reduction policy perspective, using reactivities relative to a standard base mixture is more insightful, compared to absolute reactivities of VOCs. Absolute reactivities are normalized to a base mixture to capture the variation correlated with them. The objective in this normalization is to provide an overall picture that is free of spatial and temporal behaviour in $3 \mathrm{D}$ reactivities. Previous research has shown that RIRs have significantly lower variability than IRs and are better behaved and more consistent [Hakami et al., 2004a; Czader et al., 2008]. As explained before, to be able to serve this rationale, relative reactivities in this study are governed by Equation $2-4$ and are relative to a base mixture which is representing the anthropogenic emission of actual compounds. The relative reactivities for each day are calculated as the absolute reactivity of that compound divided by the absolute reactivity of the base mixture for that day. For post processing, cells and days with insignificant (negative or very small) base mixture reactivity were not considered in the calculations. The reason is that, in Equation 2-4, small amounts of base mixture in the denominator will cause misleading or erroneous results. Consequently, VOC controls, in these regions and these episodes, have little impact on ozone formation, rendering reactivity-based controls of little consequence.

The relative reactivities of selected organic compounds are shown in Figure 5-4a to $5-4 d$ for a typical day in the middle of August 2007. Spatial distribution of relative reactivities show variability from one location to the other, however, the range is at a much lower level than the absolute values. It can be seen that different compounds affect the ozone concentration to a different extent; however, the 8-hour integrated reactivities of the compounds are fairly similar and follow the same pattern. 

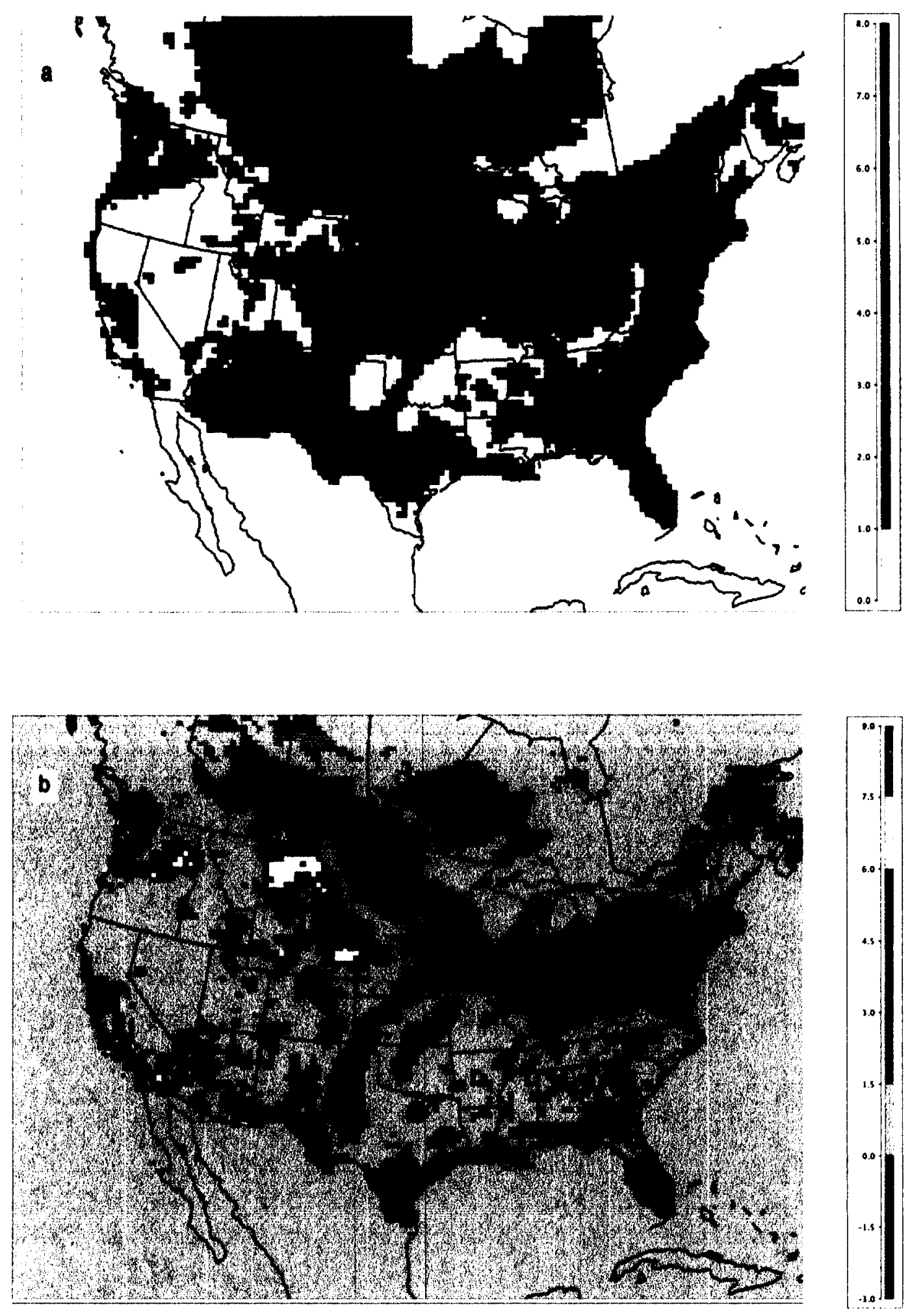

Figure 5-4: Adjoint relative reactivities in the middle of summer 2007 for: $a)$ Ethene $(\times 0.5), b)$ Isoprene, c)Formaldehyde, and d)Methanol $(\times 10)$ 

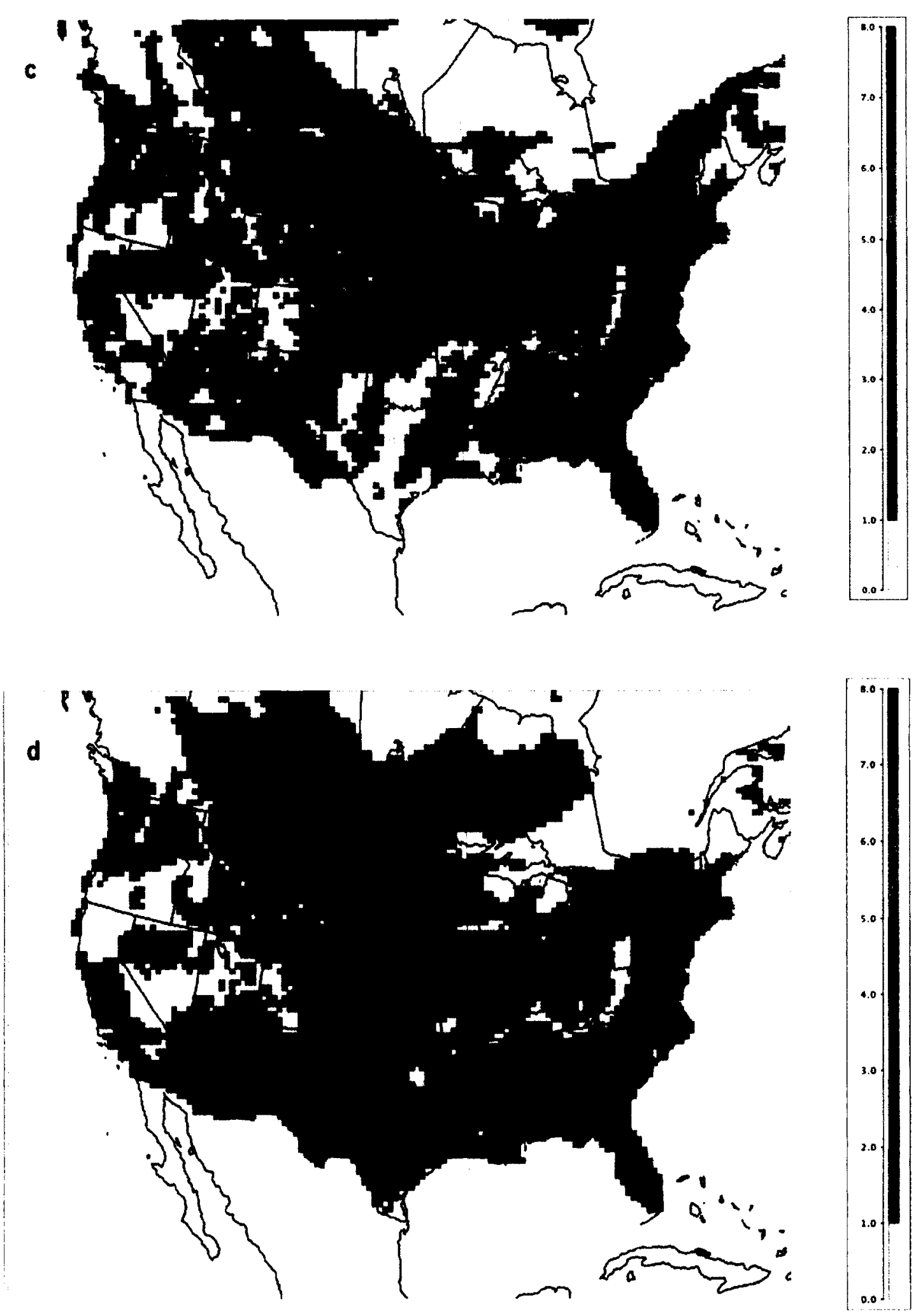

Figure 5-4: (cont'd) 
It is important to note that since the reactivities are normalized (to that of a base mixture), a relative reactivity of "1" will mean the same regardless of the episode in which the calculation were done. It is also important to remember that the relative reactivities present relative importance of each individual emission source across the domain (i.e. emissions of each grid cell) to the standard ozone metric in the receptor area of North America.

\subsection{Median Relative Reactivity (MRR) Scale}

Adjoin sensitivity information give us the ability to get a domain-wide coverage of the scale which is showing the contribution of each location to the overall ozone concentration (cost function). Here, the daily median of relative incremental reactivity of VOCs was calculated for each grid, so as to be able to compare the reactivities of VOCs in that location and in other regions as well as over the episode.

The Median Relative Reactivities (MRR) for the 92 days of summer in each location are shown in Figure 5-5 to 5-9. The upper panel graphs present median values, whereas the standard deviation from the median (for all the daily values at that location) is illustrated in the lower series. Days with base mixtures higher than the $90 \%$ threshold were counted for each location. This means that base mixture reactivities for each location are sorted over the domain, and the lower 10 percent of the days are excluded from the analysis. The threshold has only been put on the number of days in a grid cell, and not on the locations so as to get a complete coverage of VOC reactivities everywhere. Note that only the most common organic compounds are shown, and a comprehensive 
graphical coverage of all the VOCs existing in the emission profile can be found in Appendix B.

Given the significant temporal and spatial variability in absolute reactivities, the MRR scale is reasonably constant over the domain, and as seen from the lower panels, most of the compounds show a very small day-to-day deviation from the scale. It is crucial to realize that one of the most important applications of reactivity-based regulatory policies is use of reactivity scales to predict the effects of the substitution of one type of VOC for another [Carter, 2005]. If a perfect global reactivity scale were to be chosen, it should have been the same in all cells and over all the episodes, for a single VOC. The reason is that, when substituting a VOC for another, an appropriate reactivity adjustment should result in no changes in any of the cells. That is not the case in reality, since as seen in figures 5-5 to 5-9; relative impacts also vary from location to location, or from time to time, and this causes disparities in developed scales as well. It is indeed difficult to point out the exact nature of these inconsistencies but the overall magnitude of the impact depends on a numerous factors including transport and chemistry as explained in previous chapters. It can be argued that the variation might come from the higher sensitivity of the 8-hour average ozone in North America to major urban centres. Among these cities Los Angeles and Vancouver in the west coast, Houston, Calgary in the center, and New York, and Toronto in the eastern part of the domain can be easily distinguished. More interesting is the diversity of the contribution of emissions in these regions to the overall ozone levels; the emissions on the west coast are playing a more visible role in integrated ozone over the domain rather than other locations (with high levels of emissions as well). This is probably due to the period of residence of those emissions in 


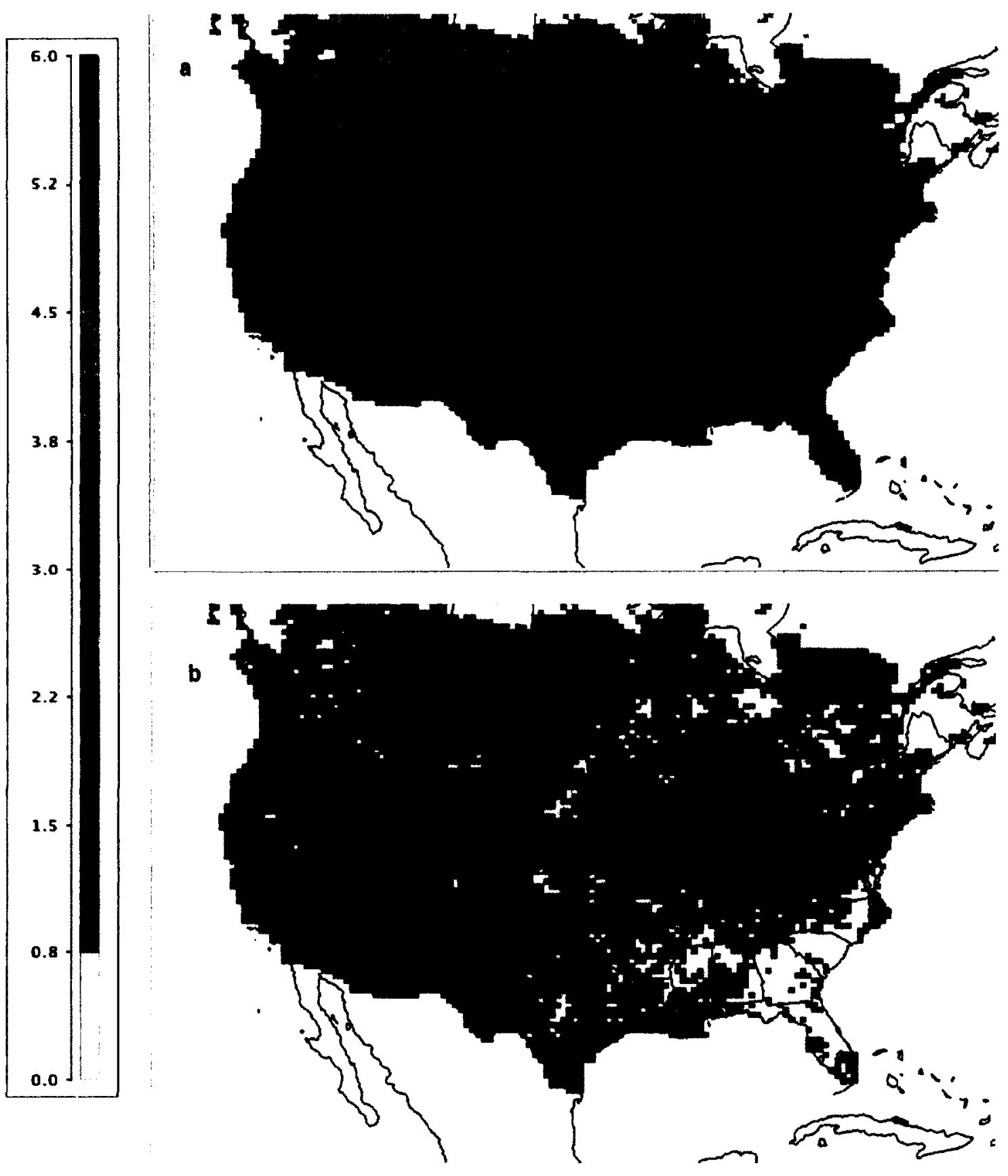

Figure 5-5: Median metric relative reactivities of Ethene for each location: a) median value, and b) standard deviation 


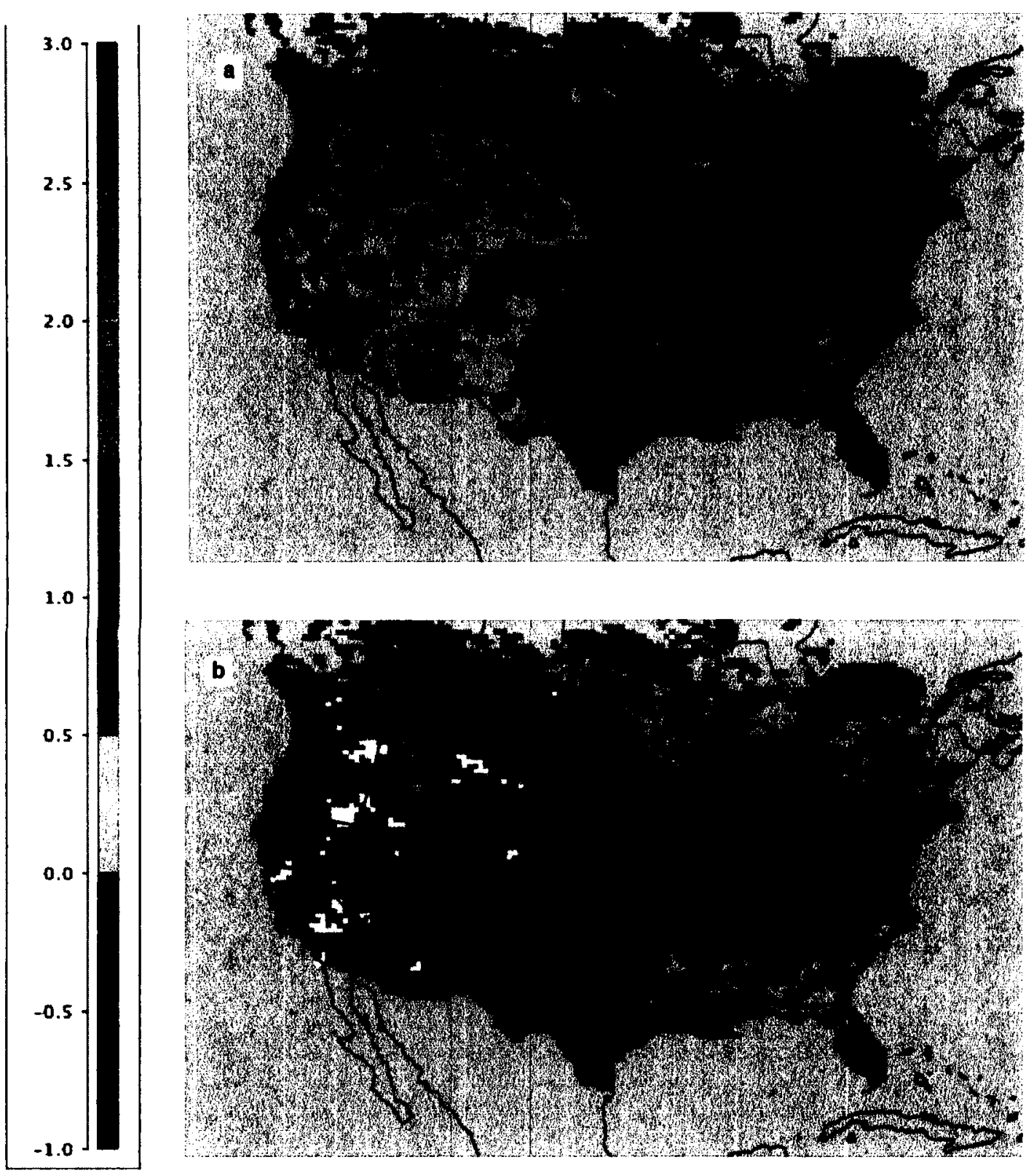

Figure 5-6: Median metric relative reactivities of Isoprene for each location: a) median value, and b) standard deviation 

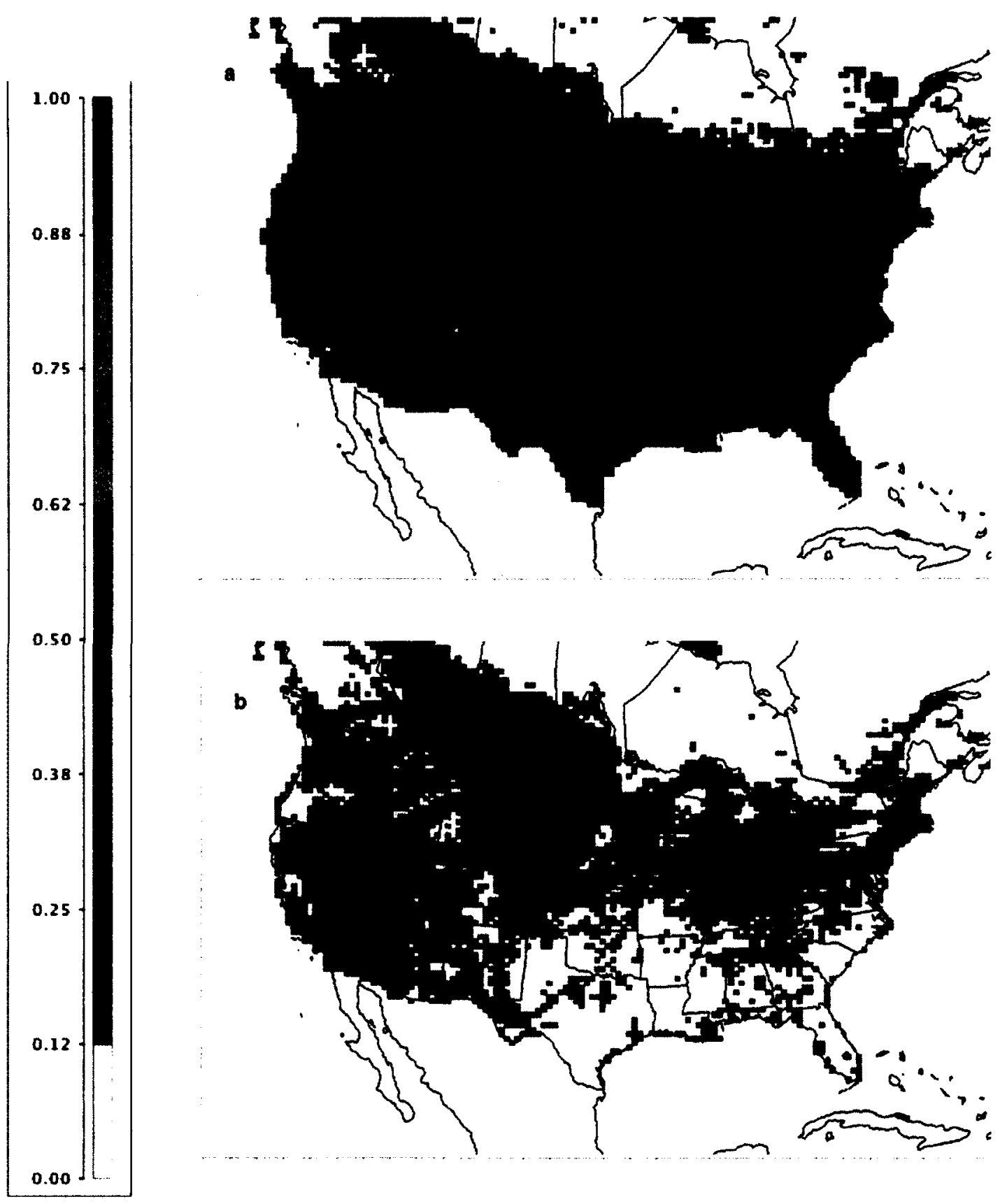

Figure 5-7: Median metric relative reactivities of Formaldehyde for each location: a) median value, and b) standard deviation 

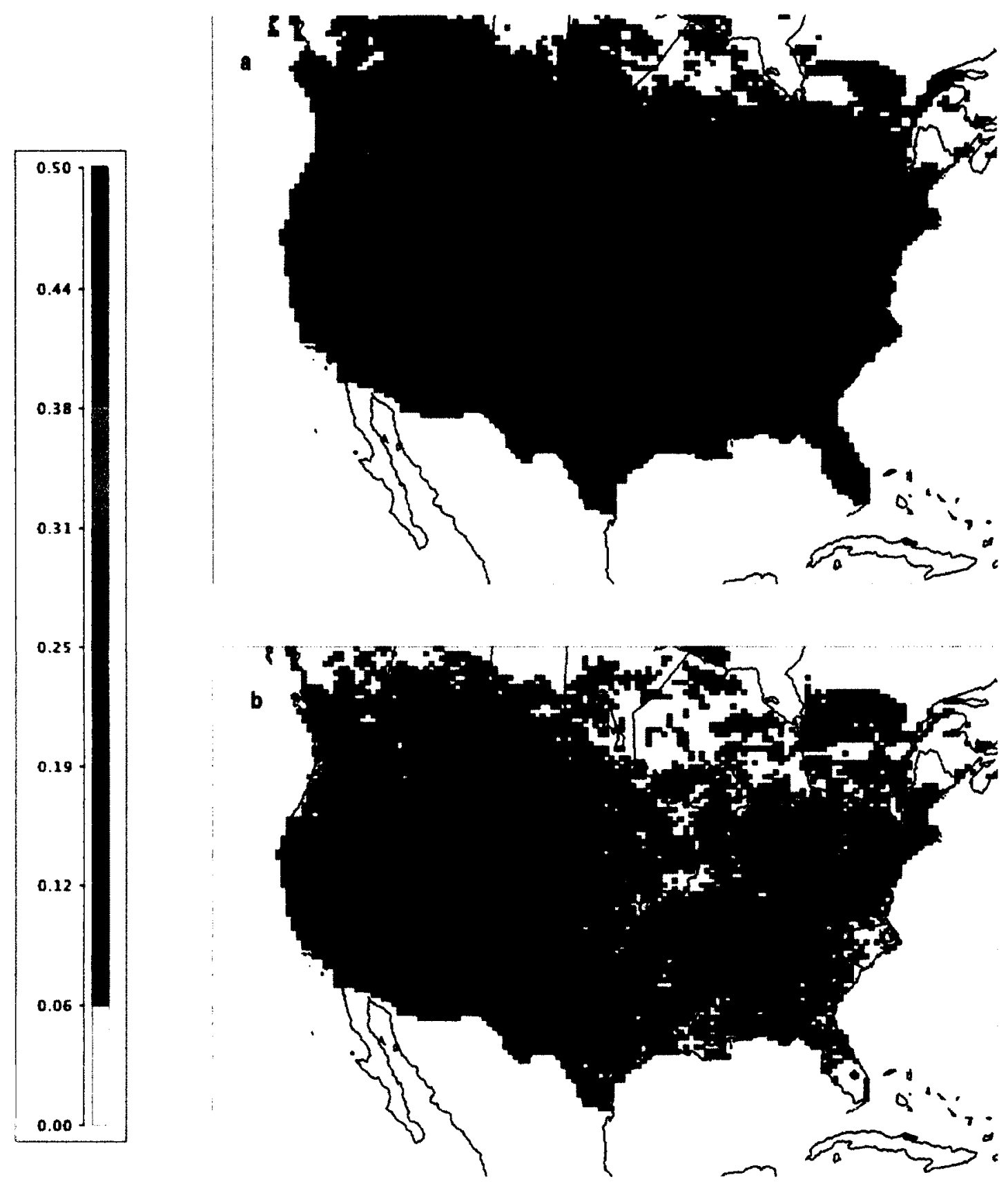

Figure 5-8: Median metric relative reactivities of Methanol for each location:

a) median value and b) standard deviation 

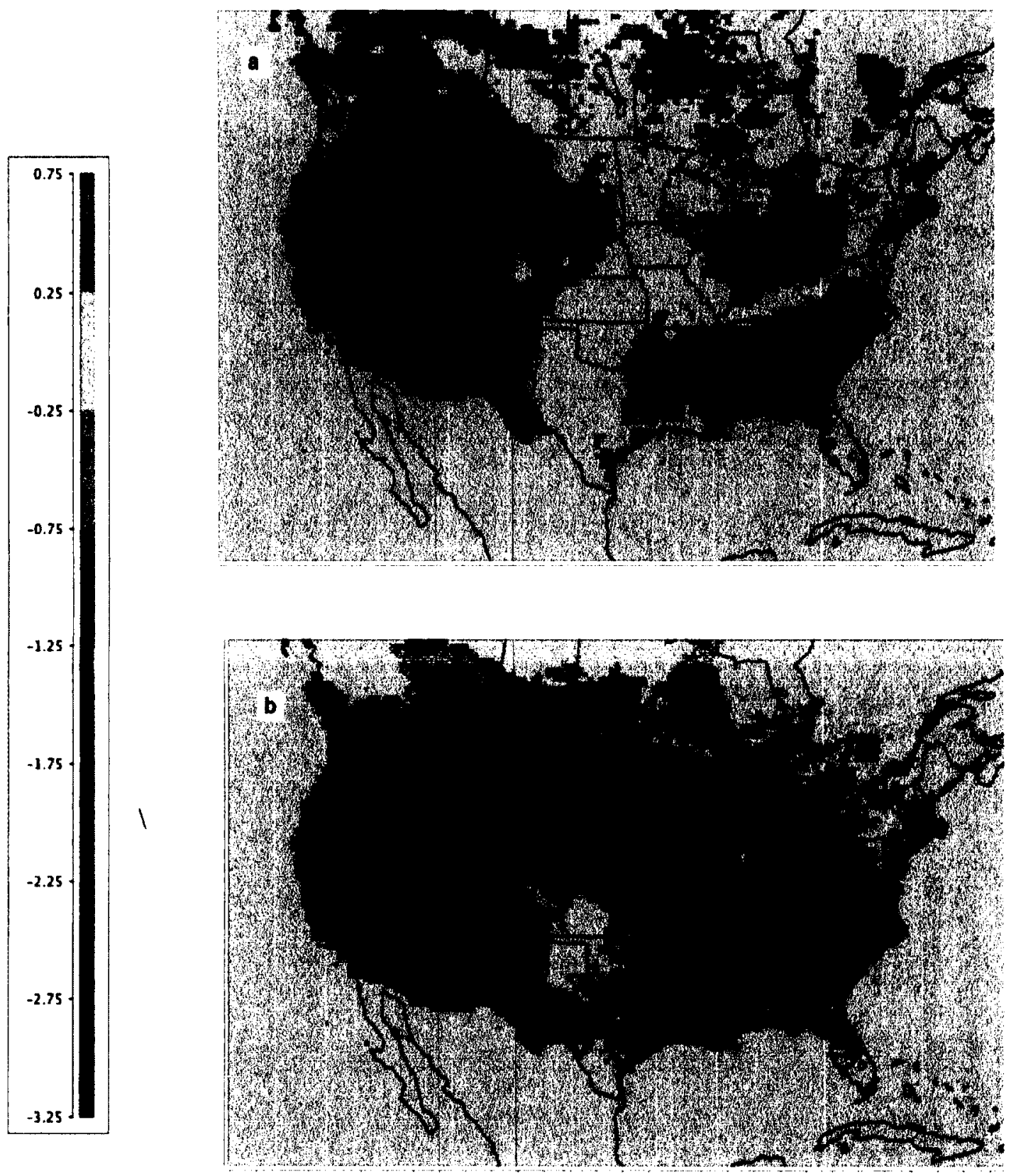

Figure 5-9: Median metric relative reactivities of Lumped Aromatics (ARO1) for each location a) median value, and b) standard deviation 
the domain; the typical wind pattern coming from west to east cause a longer stay of the emitted species from the western Unites States in the whole domain, and consequently a greater contribution to the overall air quality. This is particularly true for VOCs that have a longer atmospheric lifetime and can spend a longer period over the domain when emitted in the west. In any case, relative reactivities provide the means for comparing different compounds relative rankings with respect to each other as also shown in previous studies.

In these sets of graphs (Figure 5-5 to 5-9), the scales are not similar as spatial consistency is the main concerns rather than inter-species comparison. For instance, Methanol (Figure 5-8) has a much lower order of reactivity in comparison to a more reactive species such as Isoprene (Figure 5-5), or Ethene (Figure 5-7). The figures are to some extent consistent over the domain, and it can be concluded that the median scale is a robust metric for comparing the ozone formation potential of organic compounds.

All of the scales presented in the prior studies, including those calculated in box model [Carter, 1994] or the Eulerian models [Carter et al., 2003; Hakami et al., 2004] are domain-wide measurements of relative reactivities; meaning that there is one value for the scale for each species over the domain. By means of the stated advantage of the adjoint method, local scales can also be obtained, leading to calculation of the location specific median scale for each grid cell. Having a spatial distribution of the scale enables us to compare different locations with different conditions. However, it is important to realize which factors should be compared, which is dependent on the base mixture used. In this context, since the MRR scale in this section was derived using a constant 
composition over the domain, comparing RIR values of a single VOC for different location seem appropriate for applications with regulatory purposes.

Figure 5-10 and 5-11 show the daily MRR for ten specific locations in the modeling domain (Vancouver, Phoenix, Los Angeles, Calgary, Houston, New York, Toronto, Detroit and Atlanta). Sites have been chosen to reflect several major urban areas (VOC-limited) in different parts of the domain. Four higher reactive species are shown in Figure 5-10 (Ethene, Isoprene, n-Butane and Formaldehyde), and three lower reactive ones are illustrated in Figure 5-11 (Acetone, Methanol and Carbon Monoxide). Among these different cities Atlanta receives large biogenic emissions, rather than being locally affected by anthropogenic emissions as for most of the cities in Southeastern United States. Because of abundance of biogenics, the chemical regime in these locations is invariably NOx-limited resulting in smaller absolute reactivities. As also seen in the spatial distribution of the MRR scale of different VOCs, different cities correlate well with each other and cover a narrow range of variability. It is expected that local reactivity metrics show higher variability than the domain-wide relative metrics. However, considering the large domain in which this study was carried out and various meteorological conditions of each location, the median reactivities of different sites are somewhat consistent and show low day-to-day variability (standard deviation) compared to each other. 
5.0

3.0

2.0

1.0

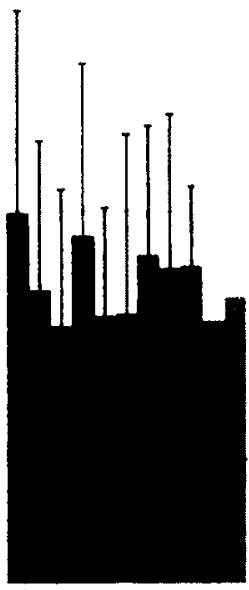

Ethene

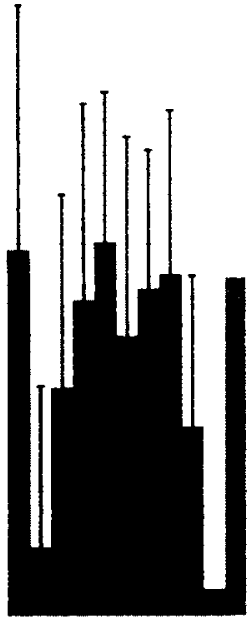

Isoprene

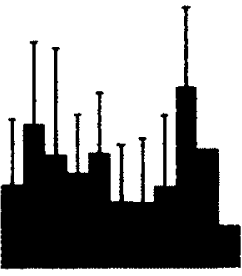

n-Butane

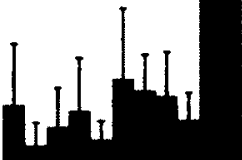

Formaldehyde

Figure 5-10: Local MRR of high reactivity compounds for different sites over the domain, and comparison with MIR and MOIR

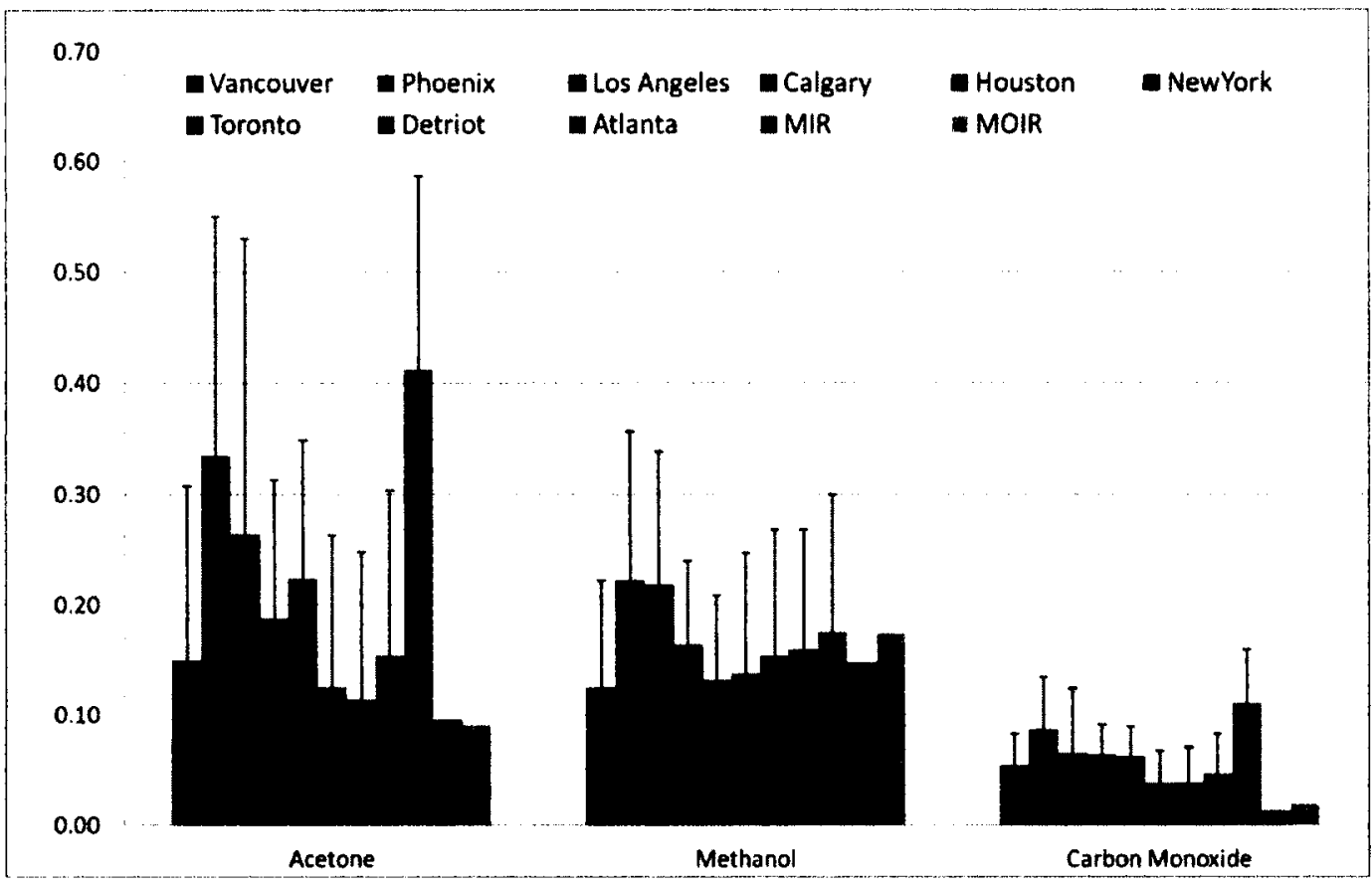

Figure 5-11: Local MRR of low reactivity compounds for different sites over the domain, and comparison with MIR and MOIR 
In this section, it was explained how calculated VOC reactivities showed variations with the environment. For emission reduction purposes, one reactivity scale needs to be derived for each VOC, across the domain. This scale is calculated again as the median of the reactivities from all locations. Figure 5-12 gives a ranking of volatile organic compounds according to their domain-wide median MRR. Ethene and n-Butane have the highest rankings for the compounds considered in this study. Formic Acid, Carbon Monoxide and Banzaldehyde (BALD), as expected, show very low reactivities and even a negative behaviour for BALD. Aromatics, Cresols, and Phenols also show overall negative sensitivities to ozone formation, which is mostly due to their reaction with $\mathrm{NO}_{\mathrm{x}}$ resulting in low reactivity products. These negative values are consistent with previous reactivity studies [Hakami et al., 2004a; 2004b;Carter, 2005].

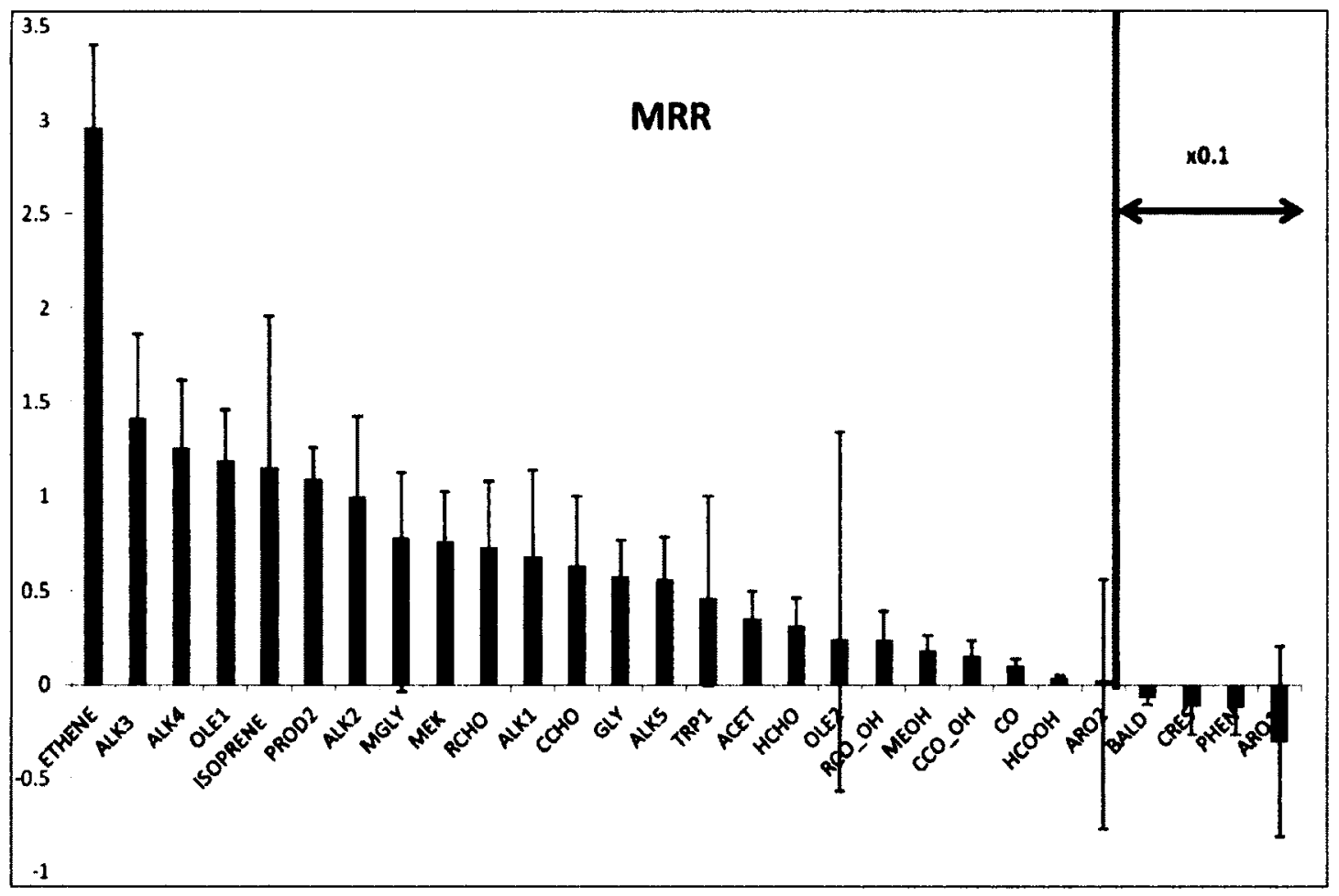

Figure 5-12: Domain-wide median of MRR for the VOCs in this study 


\subsection{Comparison of Results with the MIR scale}

The most widely used reactivity scale in the United States is the MIR scale developed by Carter using the SAPRC chemical mechanism in a box model. This scale was calculated for a great number of VOCs with a box model for the air mixture composition derived based on chemical conditions representing only 39 cities in the United States. As explained in Section 2.4.1, MIR is calculated for conditions that are the most sensitive to organic compounds' emissions, or that have the greatest impact on ozone formation ( $\mathrm{NO}_{\mathrm{x}}$-inhibited regime, or urban core area). This is the reason that MIR is a widely-used scale in several reactivity-based regulations in California [CARB 1993, 2000]. The SAPRC mechanisms, and thus the MIR values, have been updated from SAPRC90 [Carter, 1994b] to SAPRC99 [Carter, 1999] and most recently to SAPRC$\mathrm{C} 07$ [Carter, 2010].

Calculated regional model reactivities (median values) are to some extent consistent with box model reactivities of Carter's scales (2003), as shown in Figure 5-13. The reactivities of Carter are derived from the same mechanism, and they are relative to the same base mixture used in this work, so as to conduct a fair assessment. It can be seen that, although there are differences, the results are correlated, and in most cases both models predict the same reactivity rankings with some notable discrepancies. Slower reacting species have a propensity to higher relative reactivities when placed in to a 3-D model, most likely due to having a longer time of reacting in the atmosphere. Also, 3-D reactivities have in general a subdued inter-species variability compared to box model scales. This is again consistent with previous studies of forward 3-D reactivities. 
The calculated reactivities of aldehydes and Isoprene are much lower than the corresponding reactivities obtained from the box model. However, these results are not unexpected (also noted by Hakami et al., [Hakami et al., 2004a; Hakami et al., 2004b]) since the highest variations of reactivities with a change of the environment (across the domain or multi-day scenario) were found for these species (Figure 5-13). 3-D modelling accounts for the carryover of the species that provide a source for radicals (e.g. photolysis of ozone) into following days. Consequently, this sustained source of radicals makes for a less radical-limited regime, and so this makes the radical producing organics (e.g. aldehydes) less reactive than in the box model simulations. The box model scales for olephins are also significantly higher compared to the regional modelling (although alkenes show good agreement), while Acetone is somewhat lower. Figure 5-14 shows the comparison of median reactivities with MIR, when the four compounds of highest variability were removed from the analysis. This improved the agreement between the corresponding reactivities.

In general, 3-D scales are usually lower than box model values for more reactive species (with the exception of Ethene), and about the same or higher for less reactive compounds. By and large, reactivity scales correlate well with box-model values and some variations are reasonable. This discrepancy can be attributed to the diverse meteorological conditions that metrics were calculated in, different reactivity quantification, and different versions of chemical mechanisms employed in the simulations. 


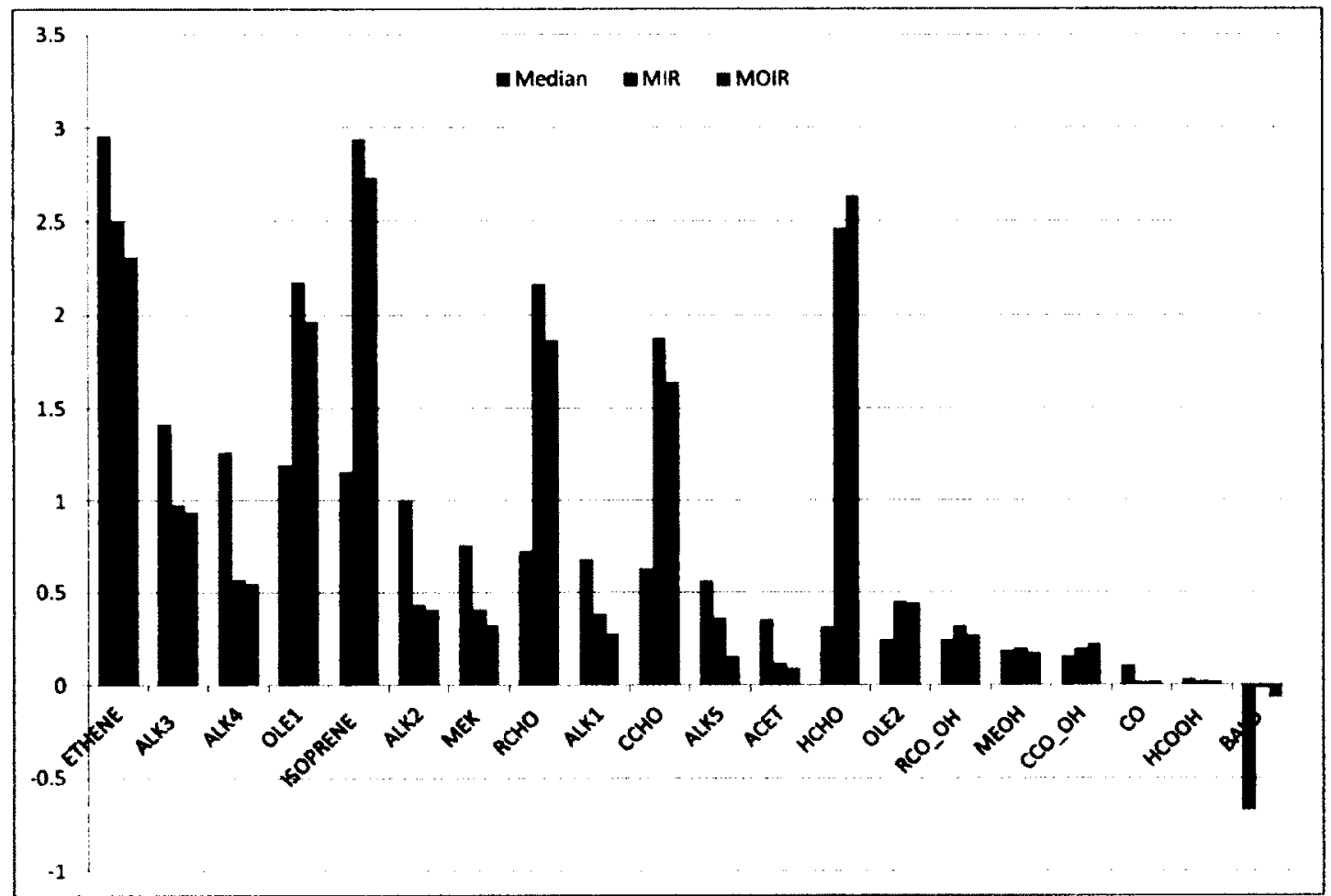

Figure 5-13: Comparison of relative box model MIR scale (Carter 2003) and 3-D adjoint MRR.

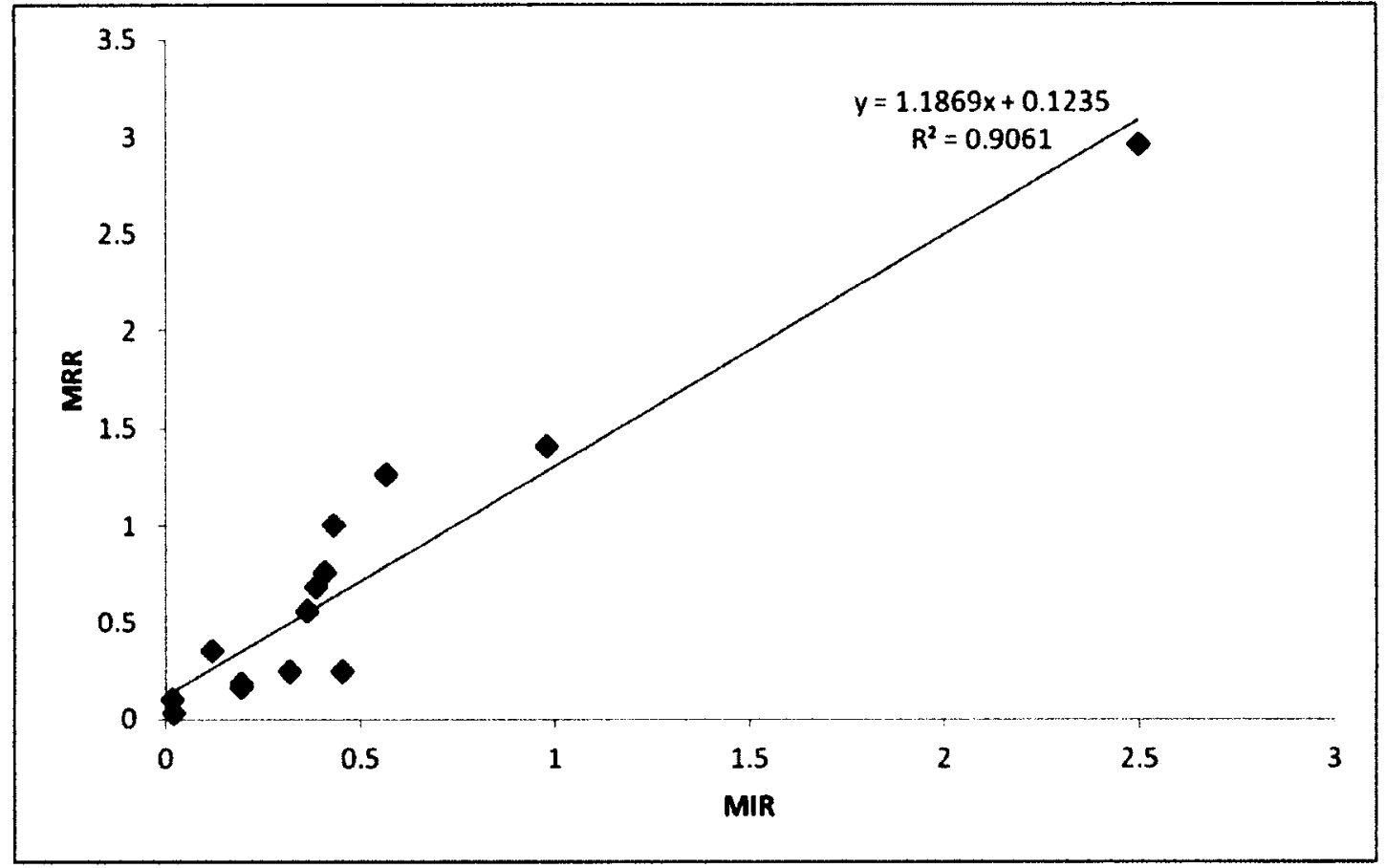

Figure 5-14: Comparison of MIR and MRR. Isoprene and aldehydes (HCHO, RCHO CCHO) were removed from the list of species. 
Note that all the calculations above are showing values corresponding to emission-based constant (domain-wide) compositions. A similar procedure has been performed for concentration-based and location-wise scenarios stated in Section 4.6.2; the spatial plots were to a great extent similar to the above figures (Figure 5-5 to 5-9), and the differences (if any) were more visible in the final summary scales when comparing the domain-wide measures. Therefore, the related numbers for concentration-based as well as the location-wise scenario is shown in Appendix B, and the final results are discussed below.

\subsection{Local Base Mixture MRRs}

In view of the fact that VOC-based controls are implemented for each industry in a specific urban or industrial area, evaluating the ranking of organic compounds and their reactivities specific to the location, where substitution is happening, might be of a greater virtue for regulatory purposes. As observed in the previous sections, relative reactivities tend to behave differently from location to location because of diverse meteorological conditions. Considering this fact, VOCs might behave differently relative to each other when placed in to a different meteorological and geographical situation. To address this issue, a localized base mixture composition has been developed in this work, to be able to target the specific circumstances of a location. Compositions of anthropogenic emissions for each location were derived, so each grid cell has its specified compositions of base mixture. Figure 5-15 shows the comparison of median relative reactivity over the domain between the scenarios of constant compositions and location-wise compositions for selected compounds. Although the results presented in previous reactivity studies were specific to the modeled domain and episode, it was concluded from those evaluation that 
the scales exhibit a fairly consistent behaviour over a regional domain or an episode [Carter et al., 2003; Hakami, Harley, et al., 2004]. It can also be seen in Figure 5-15 that except for a few points, the two scenarios correlate very well with each other. This shows that the median relative reactivity derived from a domain-wide base mixture is very similar to a scale which was driven specifically for that location, and most likely a good representation of VOC reactivities in each grid cell.

The statement is supported in Table 5-1. The ranking of organic compounds are evaluated in each of the sites of interest, and the change in ranking is compared to the domain-wide median of MRR values with constant base mixture over the domain for each location. Note that the MRR numbers are extracted from Figure 5-12 and the changes are relative to the scenario where MRRs are derived with a composition of base mixture characterized for each grid cell. The numbers are demonstrating the change in the levels for each VOC when moving from the location-wise scenario to the constant composition scenario. A wide range of changes in rankings can be seen, meaning that there is a significant change when comparing MRRs of VOCs over the domain rather than explicit to a grid cell. This can be concluded that temporal consistency is more achievable, and so regional variation (error bars in Figure 5-12) might be significant, and consistency over such a large domain may no longer be valid. This is likely due to diverse meteorological conditions of each region, such as wind flow, temperature, existence of water, and population. It can also be concluded that when considering the domain-wide median of MRRs, the rankings get closer to those of previous studies [Carter, 1999]. 

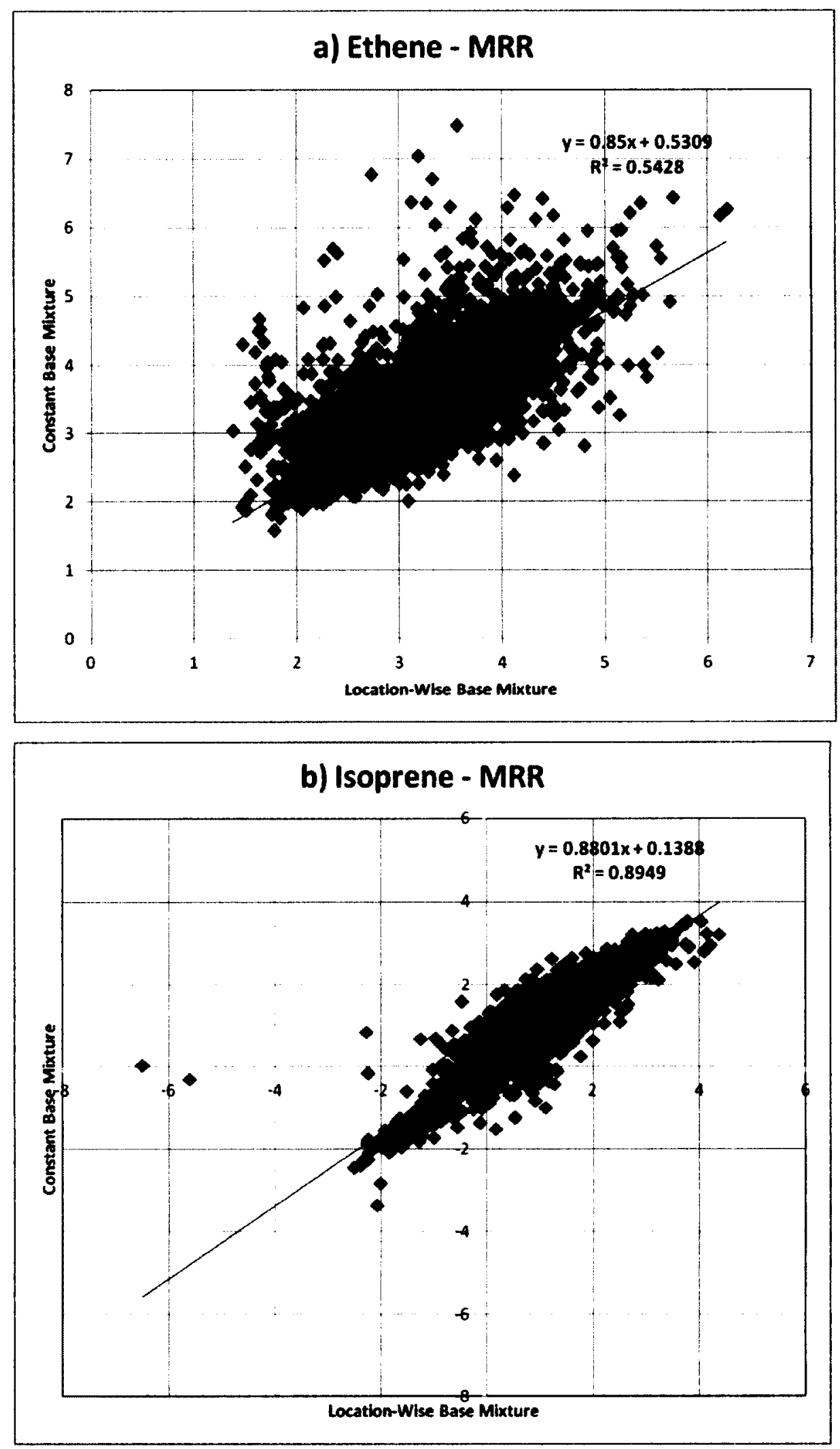

Figure 5-15: Comparison of median relative reactivities between constant base mixture and locationspecific base mixture for: a) Ethene, b) Isoprene, c) Formaldehyde, and d) Methanol 

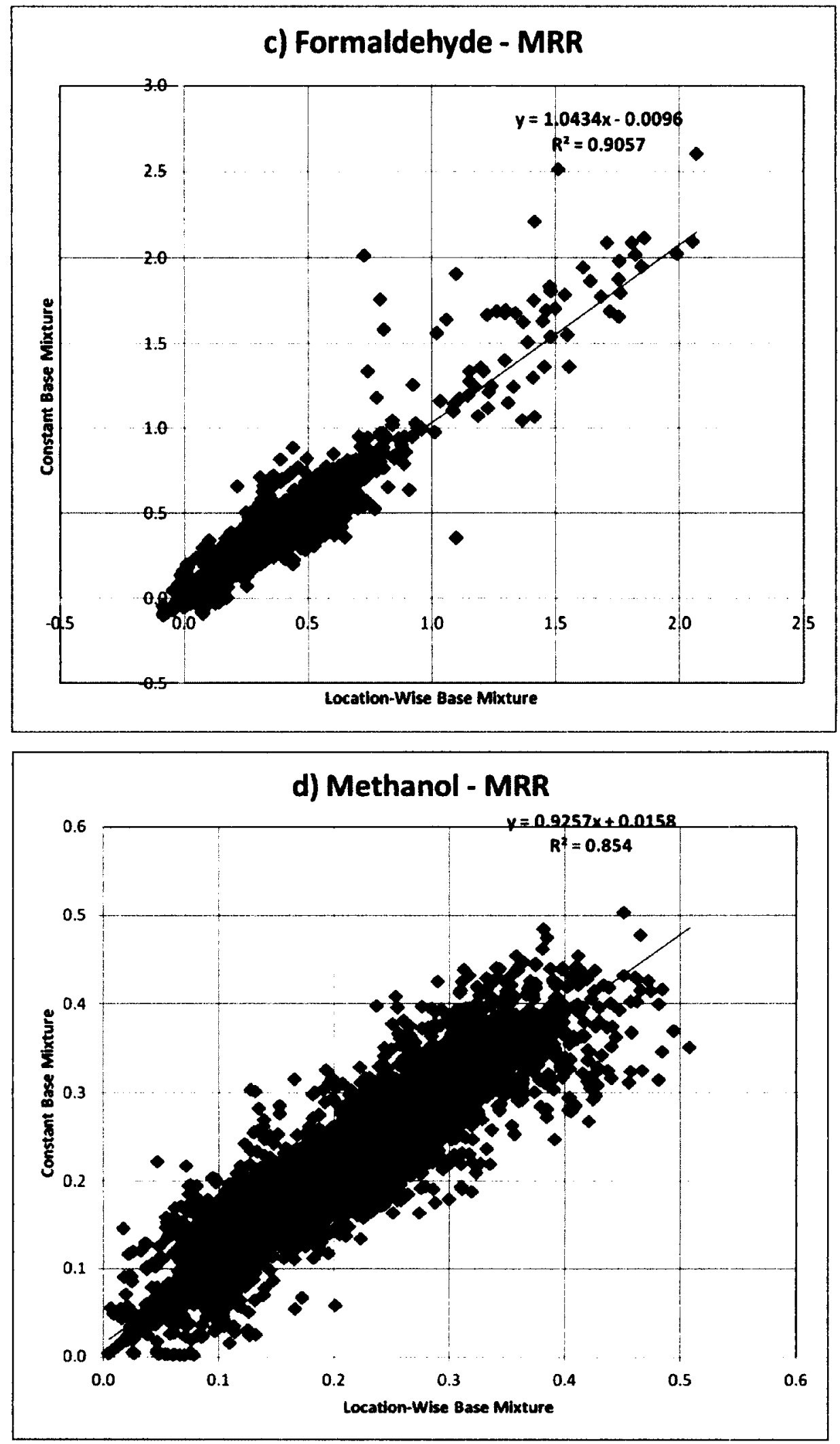

Figure 5-15: (cont'd) 
Table 5-1: Change in the rank of VOCs' location-specific median in comparison with the corresponding: A) domain-wide median and B) daily median

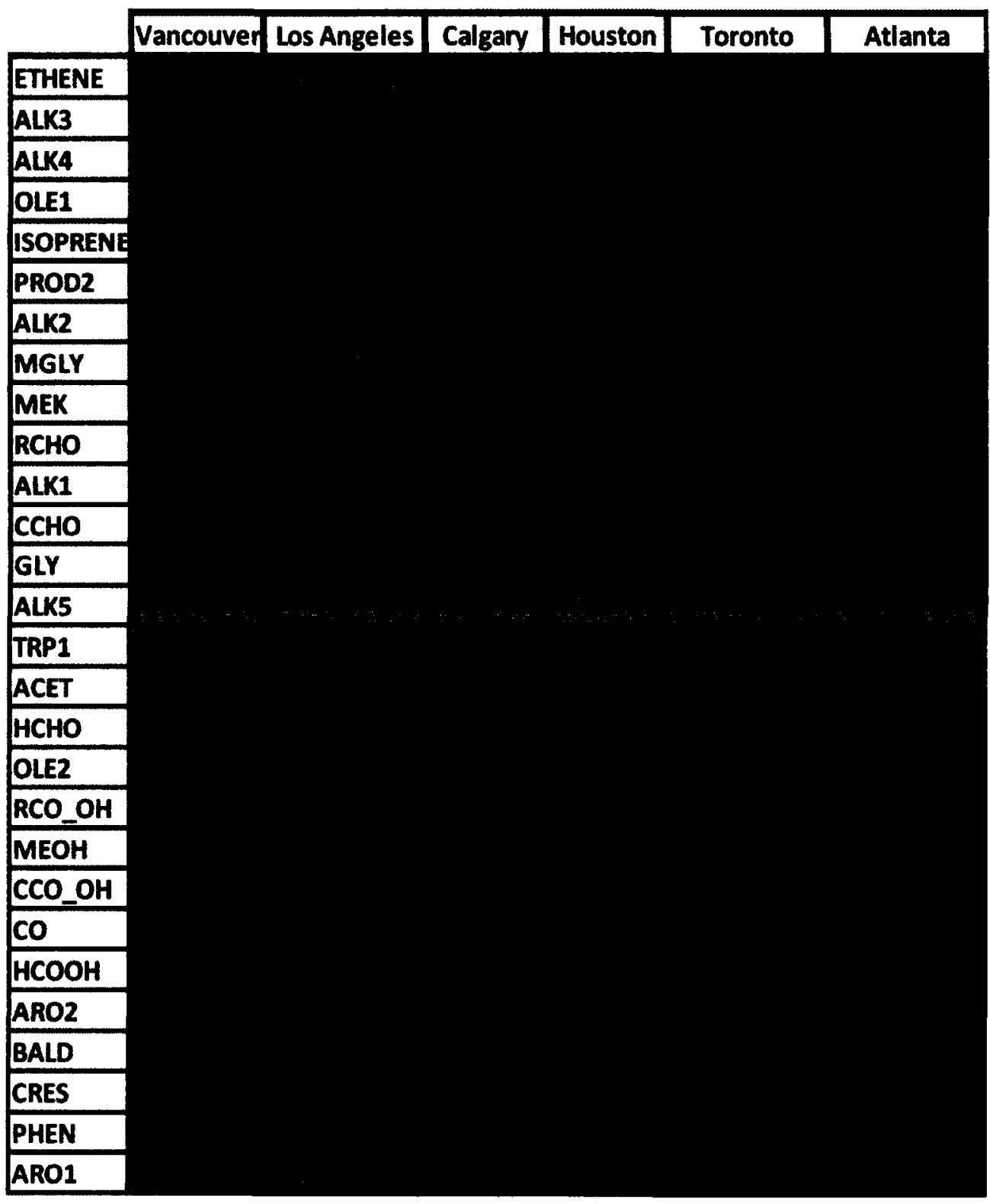




\subsection{Non-Attainment Scale}

As of the end of 2004 a large fraction of population in the U.S. was in some degree of nonattainment with respect to the 8-hour national ambient air quality standard for ground-level ozone [US EPA, 2011]; the standard was last updated to 75ppbv. To simulate these nonattainment conditions and evaluate the sensitivities of these areas to emissions of VOCs everywhere, the nationwide cost function was set in a way to account only for grid cells that are not meeting the standard; however, to allow a margin for the uncertainties in the model and inputs (and consequent errors in model predictions) and for future reductions in the standard (with the proposed range of $60-70 \mathrm{ppb}$ ), we used a value of $60 \mathrm{ppbv}$. Figure 5-16 is comparing the median values derived for non-attainment with the case where there is no threshold on the calculations of the sensitivity of the ozone levels.

The calculated non-attainment scales tend to give lower relative values in comparison with the no-threshold case. This is mostly due to the shifted focus of contributions of locations where ozone is more of a problem (closer to MIR conditions). In those areas VOC react more quickly and so the time of their stay in the atmosphere is reduced and so does their ability of ozone production. Rankings have not changed between the two scenarios except for ARO2 which correspond to the lowest reactive compound in the group (hence more relative reactivity). Generally, the two scenarios correlate very well each other and it can be concluded that the median relative reactivity can also be implemented with a fairly good agreement in the locations with severe ozone concentrations. 


\subsection{Concentration-Based Reactivities}

Reactivity measurements for all the above mentioned results are based on the base mixture with emission-based compositions. Considering the fact that concentrations of VOCs are the determining factors in defining the chemical state of the atmosphere, it is also reasonable to use concentration profiles for definition of the base mixture. Concentrations of organic compounds were derived from forward results of CMAQv4.5. As explained in Section 4.6.2, compositions were derived from summing the concentration of each species and dividing by the total concentrations of VOCs (Table 44). The same procedure was conducted for calculating the relative reactivities and MRR as well; since the results were to some extent similar, only final results are discussed here.

Figure 5-17 illustrates the ranking of VOCs with respect to median reactivities derived by concentrations across the domain. Both of the scenarios considered so far are also compared (the emission-based and concentration-based scenarios). The rankings are the same in both scenarios; however, it can be seen from Figure 5-17 that the concentration-based base mixture is inclined to give slightly higher reactivities for organic compounds. This is explained by the fact that the concentration-based composition of the base mixture provides for a slightly less reactive mixture than emission-based profile. Note that standard deviation is generally smaller for emissionbased, therefore, use of emission-based base mixture seems to be preferable. Overall, the emission-based and concentration-based scenarios correlate very well together. 


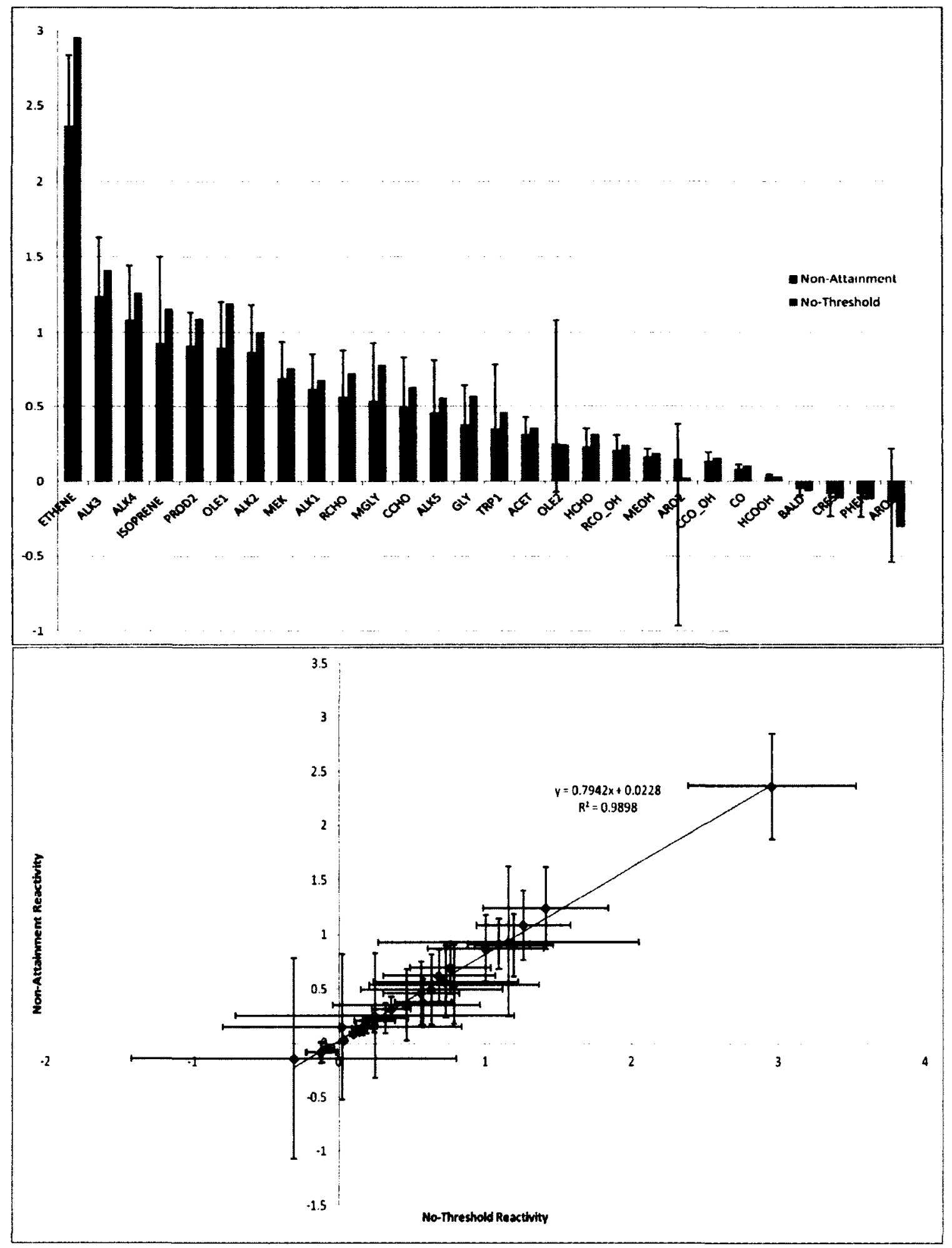

Figure 5-16: Comparison of Non-Attainment median relative reactivity with the case when there is no threshold over the domain. 


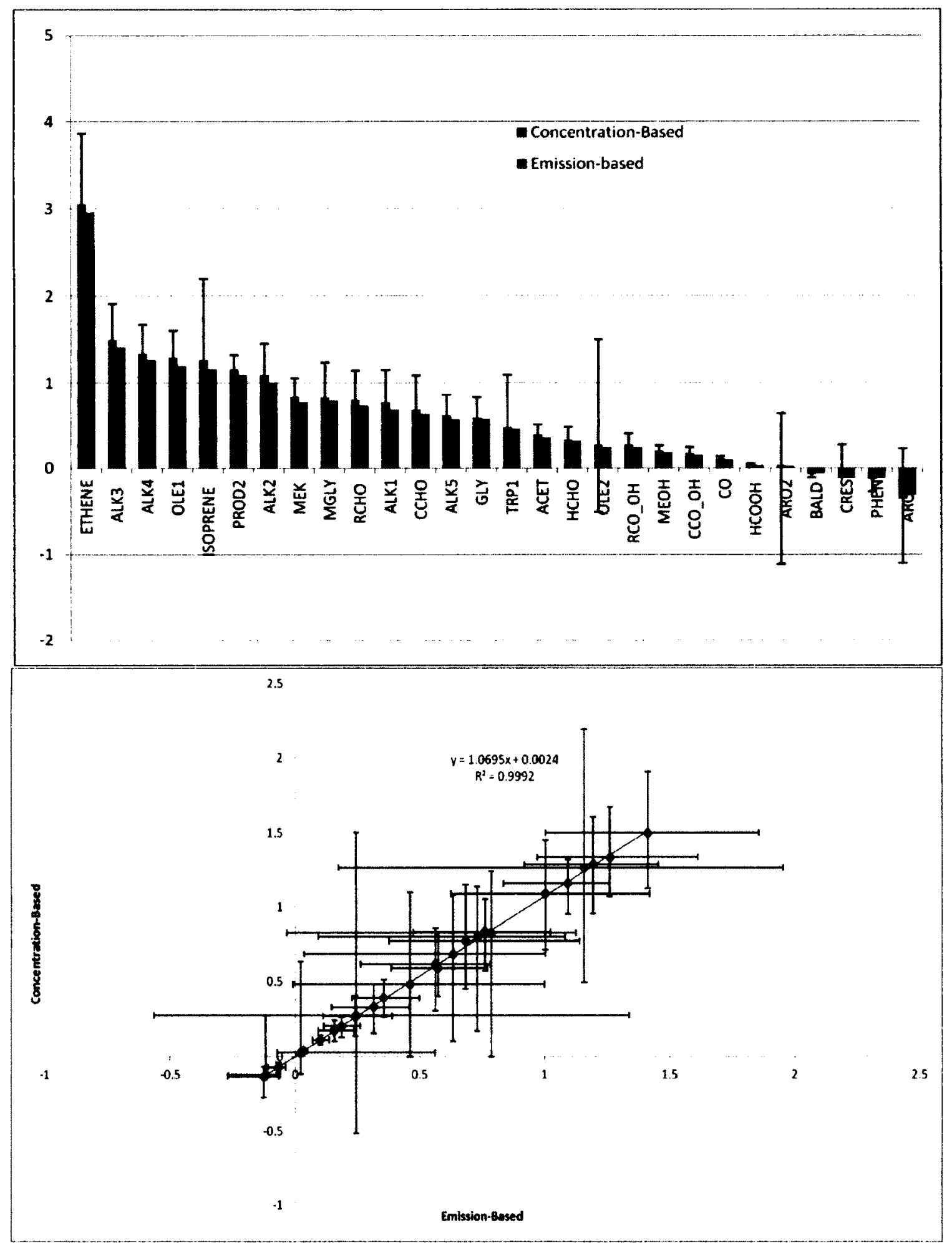

Figure 5-17: Comparison of emission-based and concentration-based composition of base mixture scenarios. 


\section{Conclusions and Future Work}

Three-dimensional relative reactivities of volatile organic compounds were quantified using CMAQ-ADJ for the 8-hour average standard, for everywhere, and also for non-attainment locations over the North American domain during the summer of 2007. Adjoint sensitivity analysis was shown to be effective for calculating the ozone formation potential of VOCs with respect to each source of emission across the domain. Equal amounts (on a mass basis) of each species were injected into the sensitivity field, and the absolute incremental reactivities of different compounds were calculated. To capture the variability of absolute values for different organic species, or the same species at different locations and times, reactivities were normalized to a base mixture and consequently relative reactivities were quantified for each VOC. By means of the adjoint method, new metrics and scales were defined for characterization of VOCs at each location and domain-wide.

First and foremost, it was consistently found that relative reactivities have less day-to-day and domain-wide variability than absolute reactivities for the modeled episode and domain. There is considerable change in rankings of VOCs when comparing the daily metric to the domain-wide metric. This emphasizes the fact that a domain-wide scale would probably not be a good representation of organic reactivities. Providing such scales would need further research into classification of the regions so that more spatially uniform scales that are closer to classical definitions of box model MIR and/or MOIR can be developed. Such classification can be based on the chemical regime or characteristic of the location (e.g., urban or rural). More interestingly, it was inferred from spatial 
distributions that the emissions coming from west coast of United States are most likely playing a more influential role than other areas due to a longer time of residence in the domain. It was also inferred that the conditions correlated with less biogenics and more radical-limited environments result in higher reactivities for those more reactive VOCs that are important sources of radicals. In contrast, the multi-day analysis in this study shed light on the fact that reactivity-based replacements might become less effective than that suggested by box model scales.

Furthermore, the 3-D results compare well for most species with the box model; however, important differences were also revealed between the two. There is a tendency for the 3-D model to give higher relative reactivities for the low reactivity species, because they have more time to react. The reason for more frequent negative sensitivities of some of the low reactivity compounds compared to the box model and forward 3-D reactivity studies is somewhat less clear and needs to be investigated. It is possible that the choice of base mixture (in previous studies exclusively based on 39 urban areas and not a larger domain such as of the current work) may have had skewed the overall scales.

Finally, comparison between the definition of the ozone cost function in two selected scales of non-attainment and no-threshold cases produced similar results. Nonattainment scale was associated with a slightly lower range most likely due to the more influence from radical limited areas. This is of particular policy significance as these points are typically those that drive the regulatory process. Similarly, reactivities calculated from the concentration-based base mixture correlated very well with that of emission-based scales. 
These findings suggest that developing robust reactivity scales need further research. But our results also indicate that the adjoint method provides a natural fit for quantifying 3-D reactivity scales. This also requires simulations over longer periods (multi-year episodes), use of higher resolution, and improved inventories. It should also be noted that unlike concentrations, evaluation of simulated sensitivities in 3-D models is difficult, since the direct comparison with observations are not possible as atmospheric sensitivities are difficult (or impossible) to measure. Furthermore, various effects of several subsystems or numerical schemes on sensitivity calculations make it difficult to perform any comparison with indirect inferences of sensitivities. The non-controlled environment of reactions in real world challenges the reliability of well-tested chemical mechanisms against experimental data or analytical solutions which are done within a simplified and isolated performance framework.

It is crucial to realise that this research has been conducted to demonstrate the adjoint analysis as a scientifically robust and flexible tool to numerically quantify reactivities of VOCs with respect to different emitters across the domain. There is no intention of drawing definitive policy conclusions from the results discussed earlier, especially since only three months of Summer 2007 were presented here. Possible ways to address the limitations stated in previous paragraph and potential topics for future research that can improve our understanding of volatile organic compounds' reactivities are discussed further below:

- Chemical mechanism used in this study was SAPRC99 since it is the version available for CMAQ-ADJ. In future work more up-do-date version of SAPRC (SAPRC07) should be used. 
- For modeling of photochemistry with a detailed chemical mechanism in urban/regional scale, a finer grid resolution is required than those of the current work. However, switching from a coarser resolution (continental-scale) would come at a higher computational cost. Computational limitations notwithstanding, the impact of grid resolution on 3-D reactivity scales need to be investigated.

- The results shown are specific to the period July $1^{\text {st }}$ to September $30^{\text {th }}, 2007$. Ozone regimes change from one year to another and as such, inter-annual variability of reactivity scales should be explored in a multi-season simulation.

- The analysis in this research is focused on 8-hour average ozone standards. Adjoint can be adapted for investigation of other functional targets of ozone, e.g., population exposure or associated health risks such as mortality. Such end-metrics are valuable in an integrated approach toward combined nationwide analysis. 


\section{REFERENCES}

Arnold, J. R., \& Dennis, R. L. (2006). Testing CMAQ chemistry sensitivities in base case and emissions control runs at SEARCH and SOS99 surface sites in the southeastern US. Atmospheric Environment, 40(26), 5027-5040. doi:10.1016/j.atmonsenv.2005.05.055

Atkinson, R. (1994). Gas-Phase Tropospheric Chemistry of Organic Compounds. Journal of Physical and Chemical Reference Data, Mongraph N(Supplement 4), 1-216. doi:10.1016/j.atmosenv.2007.10.068

Atkinson, R. (2000). Atmospheric chemistry of VOCs and NOx. Atmospheric Environment, 34(V).

Baron Advanced Meteorological Systems (BAMS). (2005). The EDSS/Models-3 V/O API. Retrieved June 4, 2012, from http:/www.baronams.com/products/ioapi/

Bell, M. L., Dominici, F., \& Samet, J. M. (2005). A Meta-Analysis of Time-Series Studies of Ozone and Mortality With Comparison to the National Morbidity, Mortality, and Air Pollution Study. Epidemiology, 16(4), 436-445. doi:10.1097/01.ede. 0000165817.40152 .85

Bergin, M. S., \& Russell, A. (1998). Effects of chemical mechanism uncertainties on the reactivity quantification of volatile organic compounds using a three-dimensional air quality model. Environmental science \&amp; 32(5), 694-703. Retrieved from http://pubs.acs.org/doi/abs/10.1021/es9704489

Bergin, M. S., Russell, A., \& Milford, J. B. (1995). Quantification of Individual VOC Reactivity Using a Chemically Detailed, Three-Dimensional Photochemical Model. Environmental science \& technology, 29(12), 3029-37. doi:10.1021/es00012a021

Bergin, M. S., Shih, J.-S., Krupnick, A. J., Boylan, J. W., Wilkinson, J. G., Odman, M. T., \& Russell, A. (2007). Regional air quality: local and interstate impacts of $\mathrm{NO}(\mathrm{x})$ 
and SO2 emissions on ozone and fine particulate matter in the eastern United States. Environmental science technology, 4l(13), 4677-4689. Retrieved from http://www.ncbi.nlm.nih.gov/pubmed/17695914

Bischof, C., Carle, A., Khademi, P., \& Mauer, A. (1994). The ADIFOR 2.0 system for the automatic differentiation of Fortran 77 programs. IEEE Computational Science and Engineering, 3(ANL-MCS-P981-1194), 1-33. doi:10.1109/99.537089

Byun, D. W., \& Ching, K. S. (1999). Science Algorithms of the EPA Models-3 Community Multiscale Air Quality (CMAQ) Modeling System. Retrieved from http://www.epa.gov/AMD/CMAQ/000_cover_exec.pdf

Byun, D. W., Pleim, J., Tang, R., \& Bourgeois, A. (1999). Meteorology-Chemistry Interface Processor (MCIP) for Models-3 Community Multiscale Air Quality (CMAQ) Modeling System. Washington DC US Environmental Protection Agency Office of Research and Development.

Byun, D. W., \& Schere, K. L. (2006). Review of the Governing Equations, Computational Algorithms, and Other Components of the Models-3 Community Multiscale Air Quality (CMAQ) Modeling System. Applied Mechanics Reviews, 59(2), 51. doi:10.1115/1.2128636

CEP Sparse Matrix Operator Kernel Emissions. (2006). SMOKE v2.6 User's Manual. Carolina Environmental Program. Retrieved June 7, 2012, from http://www.smokemodel.org/version2.6/SMOKE_v26_manual.pdf

Cacuci, D. (1994). On the application of the adjoint method of sensitivity analysis to problems in the atmospheric sciences. Retrieved from http://redalyc.uaemex.mx/redalyc/pdf/565/56507103.pdf

California Air Resources Board (CARB). (1990). Proposed Regulations for LowEmission Vehicles and Clean Fuels -- Staff Report and Technical Support Document. Retrieved from 
http://www.arb.ca.gov/msprog/levprog/cleandoc/cleancomplete_lev-ghg_regs_1210.pdf

California Air Resources Board (CARB). (2000). Initial Statement of Reasons Proposed Amendments to the California Regulation for Reducing Emissions from Consumer Products.

Canadian Council Of Ministers Of The Environment. (2000). Canada-wide standards for Particulate Matter (PM) and Ozone. City.

Capps, S. L., Hu, Y., \& Russell, A. (2010). Assessing near-field and downwind impacts of reactivity-based substitutions. Journal of the Air Waste Management Association $1995,60(3), 316-327$.

Carter, W. P. L. (1989). Computer modeling study of incremental hydrocarbon reactivity. Environmental science \&amp; technology, 23(7), 864-880. Retrieved from http://pubs.acs.org/doi/abs/10.1021/es00065a017

Carter, W. P. L. (1994a). Environmental Chamber Studies of Atmospheric Ozone Formation from Selected Biogenic Compounds. Retrieved from http://www.cert.ucr.edu/ carter/pubs/terptalk.pdf

Carter, W. P. L. (1994b). Development of ozone reactivity scales for volatile organic compounds. Journal of the Air Waste Management Association, 44, 881-899. Retrieved from http://www.cert.ucr.edu/ carter/absts.htm

Carter, W. P. L. (1999). Documentation of the SAPRC-99 Chemical Mechanism for VOC Reactivity Assessment. Assessment (Vol. 1, p. 329). Retrieved from http://www.engr.ucr.edu.oca.ucsc.edu/ carter/pubs/s99doc.pdf

Carter, W. P. L. (2005). Calculation of Reactivity Scales Using Regional Models (pp. 149). Retrieved from http://www.cert.ucr.edu/ carter/RRWG/metrics.pdf 
Carter, W. P. L. (2009). Research on Atmospheric Chemical Mechanisms and VOC Reactivity (pp. 1-18). Retrieved from http://www.cepema.usp.br/wpcontent/uploads/2009/12/Paper_Research-on-Atmospheric-Chemical-Mechanismsand-VOC-Reactivity_WPL-Carter.pdf

Carter, W. P. L. (2010). Development of a condensed SAPRC-07 chemical mechanism. Atmospheric Environment, 44(40), 5336-5345. doi:10.1016/j.atmosenv.2010.01.024

Carter, W. P. L., \& Atkinson, R. (1987). An experimental study of incremental hydrocarbon reactivity. Environmental science technology, 21(7), 670-679.

Carter, W. P. L., Pierce, J. A., Malkina, I. L., Luo, D., \& Long, W. D. (1993). Environmental Chamber Studies of Maximum Incremental Reactivities. Pollution Research, (59166).

Carter, W. P. L., Tonnesen, G., \& Yarwood, G. (2003). Investigation of VOC Reactivity Effects Using Existing Regional Air Quality Models. Environmental Research.

Cohan, D. S., Hakami, A., Hu, Y., \& Russell, A. (2005). Nonlinear response of ozone to emissions: source apportionment and sensitivity analysis. Environmental science technology, 39(17), $\quad 6739-6748 . \quad$ Retrieved from http://www.ncbi.nlm.nih.gov/pubmed/16190234

Colella, P., \& Woodward, P. R. (1984). The Piecewise Parabolic Method (PPM) for gasdynamical simulations. Journal of Computational Physics, 54(1), 174-201. doi:10.1016/0021-9991(84)90143-8

Czader, B. H., Byun, D. W., Kim, S., \& Carter, W. P. L. (2008). A study of VOC reactivity in the Houston-Galveston air mixture utilizing an extended version of SAPRC-99 chemical mechanism. Atmospheric Environment, 42(23), 5733-5742. doi:10.1016/j.atmosenv.2008.01.039 
Damian, V., Sandu, A., Damian, M., Potra, F., \& Carmichael, G. R. (2002). The kinetic preprocessor KPP-a software environment for solving chemical kinetics. Computers \& Chemical Engineering, 26(11), 1567-1579. doi:10.1016/S0098-1354(02)00128-X

Dennis, R., Byun, D. W., Novak, J., Galluppi, K. J., Coats, C., \& Vouk, M. A. (1996). The next generation of integrated air quality modeling: EPA's Models-3. Atmospheric Environment, 30(12), 1925-1938.

Derwent, R. G. (2004). Evaluation and Characterisation of Reactivity Metrics (pp. 1-17). Retrieved from http://www.narsto.org/sites/narsto.org/files/usepa03.pdf

Derwent, R. G., Jenkin, M. E., Saunders, S. M., \& Pilling, M. J. (1998). Photochemical ozone creation potentials for organic compounds in northwest Europe calculated with a master chemical mechanism. Atmospheric Environment, 32(14-15), 24292441. doi:10.1016/S1352-2310(98)00053-3

Derwent, R. G., Jenkin, M. E., Saunders, S. M., \& Pilling, M. J. (2001). Characterization of the reactivities of volatile organic compounds using a master chemical mechanism. Journal of the Air Waste Management Association 1995, 51(5), 699 707.

Dimitriades, B. (1999). Scientific Basis of an Improved EPA Policy on Control of Organic Emissions for Ambient Ozone Reduction. Air \& Waste Managment Association, $\quad 49$ (July), $\quad 831-838 . \quad$ Retrieved from http://www.tandfonline.com/doi/pdf/10.1080/10473289.1999.10463852

Dodge, M. C. (1987). Chemistry of oxidant formation: implications for designing $\begin{array}{llll}\text { effective control } & \text { strategies. } & \text { Retrieved }\end{array}$ http://www.osti.gov/energycitations/product.biblio.jsp?osti_id=6471903

Dunker, A. M. (1984). The decoupled direct method for calculating sensitivity coefficients in chemical kinetics. The Journal of Chemical Physics, 8l(5), 23852393. doi: $10.1063 / 1.447938$ 
Dunker, A. M., Yarwood, G., Ortmann, J. P., \& Wilson, G. M. (2002). Comparison of source apportionment and source sensitivity of ozone in a three-dimensional air quality model. Environmental science technology, 36(13), 2953-2964. Retrieved from http://www.ncbi.nlm.nih.gov/pubmed/12144273

Eder, B., \& Yu, S. (2006). A performance evaluation of the 2004 release of Models-3 CMAQ. Atmospheric Environment, 40(26), 4811-4824. doi:10.1016/j.atmosenv.2005.08.045

Elbern, H., \& Schmidt, H. (1999). A four-dimensional variational chemistry data assimilation scheme for Eulerian chemistry transport modeling. Journal of Geophysical Research, 104(D15), 18583-18. Retrieved from http://www.agu.org/pubs/crossref/1999/1999JD900280.shtml

Elbern, H., \& Schmidt, H. (2001). Ozone episode analysis by four-dimensional variational chemistry data assimilation. Journal of Geophysical Research, 106(D4), 3569-3590. doi:10.1029/2000JD900448

Elbern, H., Schmidt, H., \& Ebel, A. (1997). Variational data assimilation for tropospheric chemistry modeling. Journal of Geophysical Research, 102(D13), 15967-15985. doi: 10.1029/2009JD011953

Elbern, H., Schmidt, H., Talagrand, O., \& Ebel, A. (2000). 4D-variational data assimilation with an adjoint air quality model for emission analysis. Environmental Modelling Software, 15(6-7), 539-548. doi:10.1016/S1364-8152(00)00049-9

Emberson, L. D., Ashmore, M. R., Murray, F., Kuylenstierna, J. C. I., Percy, K. E., Izuta, T., Zheng, Y., et al. (2001). Impacts of air pollutants on vegetation in developing countries. Water Air and Soil Pollution, 130(1-4), 107-118. Retrieved from http://dx.doi.org/10.1023/A:1012251503358 
Environmental Protection Agency US (US EPA). (1991). Guideline for regulatory application of the Urban Airshed Model. Retrieved from http://www.osti.gov/energycitations/product.biblio.jsp?osti_id=6109307

Environmental Protection Agency US (US EPA). (2003). Ozone Transport Commission (OTC) NOx budget program 1999-2002 progress report. Clean Air. Retrieved from http://www.epa.gov/airmarkt/progsregs/nox/otc.html

Environmental Protection Agency US (US EPA). (2005). Revisions to the California State Implementation Plan and Revision to the Definition of Volatile Organic Compounds, $2005 . \quad$ Retrieved from http://www.epa.gov/ttn/oarpg/tl/fr_notices/15311 finalcarb.pdf

Environmental Protection Agency US (US EPA). (2008a). National Ambient Air Quality Standards for Ozone, Final Rule. Federal Register. Retrieved from http:/www.epa.gov/ttn/naaqs/standards/ozone/fr/20080327.pdf

Environmental Protection Agency US (US EPA). (2008b). Clean Air Act. Retrieved from http://www.epa.gov/air/caa/

Environmental Protection Agency US (US EPA). (2011). Health Effects of Ozone in the General Population. Retrieved July 7, 2012, from http://www.epa.gov/apti/ozonehealth/population.html

Errico, R. M., \& Vukicevic, T. (1992). Sensitivity analysis using an adjoint of the PSUNCAR mesoscale model. MonWeaRev, 120, 1644-1660.

Fisher, M., \& Lary, D. J. (1995). Lagrangian four-dimensional variational data assimilation of chemical species. Quarterly Journal of the Royal Meteorological Society, 12I(527), 1681-1704. doi:10.1002/qj.49712152709

Gou, T., Singh, K., \& Sandu, A. (2009). Chemical Data Assimilation with CMAQ: Continuous vs. Discrete Advection Adjoints. (G. Allen, J. Nabrzyski, E. Seidel, G. D. 
Albada, J. Dongarra, \& P. M. A. Sloot, Eds.) (Vol. 5545, pp. 312-321). Berlin, Heidelberg: Springer Berlin Heidelberg. doi:10.1007/978-3-642-01973-9

Hakami, A. (2005). Adjoint inverse modeling of black carbon during the Asian Pacific Regional Aerosol Characterization Experiment. Journal of Geophysical Research, 110(D14), 1-17. doi:10.1029/2004JD005671

Hakami, A., Arhami, M., \& Russell, A. (2004). Further Analysis of VOC Reactivity Metrics and Scales. US Environmental Protection Agency: Retrieved from http://ftp.narsto.org/sites/narsto-dev.ornl.gov/files/Hakami_report2_final.pdf

Hakami, A., Bergin, M. S., \& Russell, A. (2004). Ozone formation potential of organic compounds in the Eastern United States: a comparison of episodes, inventories, and domains. Environmental science technology, 38(24), 6748-6759. Retrieved from http://pubs.acs.org/doi/abs/10.1021/es035471a

Hakami, A., Harley, R., Milford, J. B., Odman, M. T., \& Russell, A. (2004). Regional, three-dimensional assessment of the ozone formation potential of organic compounds. Atmospheric Environment, 38(1), 121-134. doi:10.1016/j.atmosenv.2003.09.049

Hakami, A., Henze, D. K., Seinfeld, J. H., Singh, K., Sandu, A., Kim, S., Byun, D. W., et al. (2007). The adjoint of CMAQ. Environmental science technology, 4l(22), 780717. doi:10.1021/es070944p

Hakami, A., Seinfeld, J. H., Chai, T., Tang, Y., Carmichael, G. R., \& Sandu, A. (2006). Adjoint sensitivity analysis of ozone nonattainment over the continental United States. Environmental science technology, 40(12), 3855-3864. Retrieved from http://www.ncbi.nlm.nih.gov/pubmed/16830553

Henze, D. K., Hakami, A., \& Seinfeld, J. H. (2007). Development of the adjoint of GEOS-Chem. Atmospheric Chemistry Physics, 7(9), 2413-2433. doi:10.5194/acpd6-10591-2006 
Henze, D. K., Seinfeld, J. H., \& Shindell, D. T. (2009). Inverse modeling and mapping US air quality influences of inorganic PM2.5 precursor emissions using the adjoint of GEOS-Chem. Atmospheric Chemistry and Physics, 9(16), 5877-5903. doi:10.5194/acp-9-5877-2009

Hwang, J. T., Dougherty, E. P., \& Rabitz, H. (2003). The Green's function method of sensitivity analysis in chemical kinetics. The Journal of Chemical Physics. Retrieved from http:/www.ipe.uni-stuttgart.de/content/web3/handouts/mrt.pdf

Jacob, D. J. (1999). Introduction to Atmospheric Chemistry. Chemical Reviews (Vol. 103, pp. 4505-8). Princeton University Press. doi:10.1021/cr020463i

Jerrett, M., Burnett, R. T., Pope, C. A., Ito, K., Thurston, G., Krewski, D., Shi, Y., et al. (2009). Long-term ozone exposure and mortality. The New England journal of medicine, 360(11), 1085-1095. Retrieved from http://www.ncbi.nlm.nih.gov/pubmed/19279340

Khan, M., \& Yang, Y. J. (1999). Photochemical reactivities of common solvents: comparison between urban and regional domains. Atmospheric environment, 33(7), 1085-1092. doi:10.1016/S1352-2310(98)00317-3

Kleinman, L. I., Daum, P. H., Lee, J. H., Lee, Y.-N., Nunnermacker, L. J., Springston, S. R., Newman, L., et al. (1997). Dependence of ozone production on NO and hydrocarbons in the troposhere. Geophysical Research Letters, 24(18), 2299-2302.

Lamb, R. G., Chen, W. H., \& Seinfeld, J. H. (1975, October 1). Numerico-empirical analyses of atmospheric diffusion theories. Journal of the Atmospheric Sciences. American Meteorological Society. Retrieved from http://authors.library.caltech.edu/12312/1/LAMjas75.pdf

Lippmann, M. (2002). Health effects of tropospheric ozone: review of recent research findings and their implications to ambient air quality standards. Journal of Exposure Analysis and Environmental Epidemiology, 3(1), 103-129. 
Mallet, V., \& Sportisse, B. (2005). A comprehensive study of ozone sensitivity with respect to emissions over Europe with a chemistry-transport model. J. Geophys. Res, (section 4). Retrieved from http://cerea.enpc.fr/fich/article/mallet_sportissesensitivity_emissions.pdf

Martien, P., Harley, R., \& Cacuci, D. (2006). Adjoint sensitivity analysis for a threedimensional photochemical model: implementation and method comparison. Environmental science technology, 40(8), 2663-2670.

Martien, P., Harley, R., Milford, J. B., Hakami, A., \& Russell, A. (2002). Development of Reactivity Scales via 3-D Grid Modeling of California Episodes (pp. 98-309). Sacramento, CA.

McNair, L., Russell, A., \& Odman, M. T. (1992). Airshed calculation of the sensitivity of pollutant formation to organic compound classes and oxygenates associated with alternative fuels. Journal of the Air and Waste Management Association; (United States), $42: 2$. Retrieved from http://www.osti.gov/energycitations/product.biblio.jsp?osti_id=5447769

Mendoza-dominguez, A., \& Russell, A. (2001). Estimation of emission adjustments from the application of four-dimensional data assimilation to photochemical air quality modeling. Atmospheric Environment, 35(16), 2879-2894. doi:10.1016/S13522310(01)00084-X

Mirzajani, M. (2011). LONG-RANGE TRANSPORT OF OZONE AND ITS PRECURSORS ACROSS US-CANADA BORDER.

Morris, R. E., \& Myers, T. C. (1990). User's guide for the Urban Airshed Model. Volume 1. User's manual for UAM (CB-IV). Retrieved from http://www.osti.gov/energycitations/product.biblio.jsp?osti_id=6166682 
National Center for Environmental Predictions (NCEP). (2005). NAM - NCEP's North American Mesoscale Model. Retrieved June 4, 2012, from http://www.srh.noaa.gov/ssd/nwpmodel/html/nam.htm

National Research Council (NRC). (1991). Rethinking the Ozone Problem in Urban and Regional Air Pollution. Environment International (Vol. 19, p. xxiii, 500 p.). National Academy Press. doi:10.1016/0160-4120(93)90017-C

Nester, K., \& Panitz, H. J. (2005). Sensitivity analysis by the adjoint chemistry transport model DRAIS for an episode in the Berlin ozone (BERLIOZ) experiment. Atmospheric Chemistry and Physics Discussions, 5(5), 8715-8754. doi:10.5194/acpd-5-8715-2005

Predictions, N. C. for E. (2005). NCEP WMO GRIB Documentation. Retrieved June 4, 2012, from http://www.nco.ncep.noaa.gov/pmb/docs/grib2/grib2_doc.shtml

Reactivity Research Work Group. (1999). VOC Reactivity Policy White Paper. Retrieved from http://www.narsto.org/voc_reactivity

Reactivity Research Work Group. (2003). Investigation of VOC Reactivity Assessment with Comprehensive Air Quality Modeling. Retrieved from http://www.narsto.org/sites/narsto-dev.ornl.gov/files/Appendix_D_Modeling.pdf

Russell, A. (1997). Regional Photochemical Air Quality Modeling: Model Formulations, History, and State of the Science. Annual Review of Energy and the Environment, 22(1), 537-588. doi:10.1146/annurev.energy.22.1.537

Russell, A., \& Dennis, R. (2000). NARSTO critical review of photochemical models and modeling. Atmospheric Environment, 34(12-14), 2283-2324. doi:10.1016/S13522310(99)00468-9

Russell, A., Milford, J. B., Bergin, M. S., McBride, S., McNair, L., Yang, Y. J., Stockwell, W. R., et al. (1995). Urban ozone control and atmospheric reactivity of organic gases. Science, 269(5223), 491-495. 
Sandu, A., Daescu, D. N., Carmichael, G. R., \& Chai, T. (2005). Adjoint sensitivity analysis of regional air quality models. Journal of Computational Physics, 204(1), 222-252. doi:10.1016/j.jcp.2004.10.011

Schmidt, H., \& Martin, D. (2003). Adjoint sensitivity of episodic ozone in the Paris area to emissions on the continental scale. Journal of Geophysical Research, 108(D17), 8561. doi:10.1029/2001JD001583

Seinfeld, J. H. (1989). Urban air pollution: state of the science. Science, 243(4892), 745. doi:10.1126/science. 243.4892 .745

Seinfeld, J. H., \& Pandis, S. N. (2006). Atmospheric Chemistry and Physics: From Air Pollution to Climate Change. Atmospheric Chemistry and Physics (Vol. 2nd, p. 1203). Wiley-Interscience. Retrieved from http://www.amazon.com/dp/0471178160

Sillman, S. (1999). The relation between ozone, NOx and hydrocarbons in urban and polluted rural environments. Atmospheric Environment, 33(12), 1821-1845. doi:10.1016/S1352-2310(98)00345-8

Smyth, S. C., Yin, D., Roth, H., Jiang, W., Moran, M. D., \& Crevier, L.-P. (2006). The impact of GEM and MM5 modeled meteorological conditions on CMAQ air quality modeling results in eastern Canada and the Northeastern United States. Journal of Applied Meteorology and Climatology, 45(11), 1525-1541. doi:10.1175\%2FJAM2420.1

Stavrakou, T., \& Müller, J.-F. (2006). Grid-based versus big region approach for inverting $\mathrm{CO}$ emissions using Measurement of Pollution in the Troposphere (MOPITT) data. Journal of Geophysical Research, 111(D15), D15304. doi:10.1029/2005JD006896

Steiner, A., Cohen, R., \& Harley, R. (2008). VOC reactivity in central California: comparing an air quality model to ground-based measurements. Atmospheric, (2), 351-368. Retrieved from http:/hal.archives-ouvertes.fr/hal-00296421/ 
Stroud, C. a., Morneau, G., Makar, P. a., Moran, M. D., Gong, W., Pabla, B., Zhang, J., et al. (2008). OH-reactivity of volatile organic compounds at urban and rural sites across Canada: Evaluation of air quality model predictions using speciated VOC measurements. Atmospheric Environment, 42(33), 7746-7756. doi:10.1016/j.atmosenv.2008.05.054

Tesche, T. W. (1983). Photochemical dispersion modeling: Review of model concepts and applications studies. Environment International, 9(6), 465-489. doi:10.1016/0160-4120(83)90004-1

University Corporation for Atmospheric Research (UCAR). (2008). Unidata NetCDF (Network Common Data Form). Retrieved June 4, 2012, from http://www.unidata.ucar.edu/software/netcdf/

Wang, K. Y., Lary, D. J., Shallcross, D. E., Hall, S. M., \& Pyle, J. A. (2001). A review on the use of the adjoint method in four-dimensional atmospheric-chemistry data assimilation. Quarterly Journal of the Royal Meteorological Society, 127(576, Part B), 2181-2204. Retrieved from http://onlinelibrary.wiley.com/doi/10.1002/qj.49712757616/abstract

Wang, L., Milford, J. B., \& Carter, W. P. L. (2000a). Reactivity estimates for aromatic compounds. Part 2. Uncertainty in incremental reactivities. Atmospheric Environment, 34(25), 4349-4360. doi:10.1016/S1352-2310(00)00206-5

Wang, L., Milford, J. B., \& Carter, W. P. L. (2000b). Reactivity estimates for aromatic compounds. Part 1. Uncertainty in chamber-derived parameters. Atmospheric Environment, 34(25), 4337-4348. Retrieved from http://www.sciencedirect.com/science/article/B6VH3-40X8HC4$\mathrm{C} / 2 / \mathrm{d} 452123 \mathrm{da}$ led2al14a76f5e0695338c6

Wang, W., Bruyère, C., Duda, M., \& Dudhia, J. (2010). ARW Version 3 Modelling System's User Guide, (April). Retrieved from 
http://scholar.google.com/scholar?hl=en\&btnG=Search\&q=intitle:ARW+Version+3

+Modeling+System+User's+Guide\#1

Yang, Y. J., Stockwell, W. R., \& Milford, J. B. (1995). Uncertainties in Incremental Reactivities of Volatile Organic. Environmental Science \& Technology, 29(5), 1336-45. doi: $10.1021 /$ es00005a 028

Yang, Y. J., Wilkinson, J. G., \& Russell, A. (1997). Fast, Direct Sensitivity Analysis of Multidimensional Photochemical Models. Environmental Science \& Technology, 31(10), 2859-2868. doi:10.1021/es970117w

Yarwood, G., Rao, S., Yocke, M., \& Whitten, G. Z. (2005). Updates to the carbon bond chemical mechanism: cb05. North (Vol. 8, p. 246). Retrieved from $\mathrm{http} / / / \mathrm{scholar}$.google.com/scholar?hl=en\&btnG=Search\&q=intitle:UPDATES+TO+ THE+CARBON+BOND+CHEMICAL+MECHANISM:+CB05\#0

Zhang, L., Jacob, D. J., Boersma, K. F., Jaffe, D. A., Olson, J. R., Bowman, K. W., Worden, J. R., et al. (2008). Transpacific transport of ozone pollution and the effect of recent Asian emission increases on air quality in North America: an integrated analysis using satellite, aircraft, ozonesonde, and surface observations. Atmospheric Chemistry and Physics, 8(20), 6117-6136. doi:10.5194/acp-8-6117-2008

Zhang, L., Jacob, D. J., Kopacz, M., Henze, D. K., Singh, K., \& Jaffe, D. A. (2009). Intercontinental Source Attribution of Ozone Pollution at Western U.S. Sites Using an Adjoint Method. Geophysical Research Letters, 36(11). doi:10.1029/2009GL037950 


\section{APPENDIX A:}

\section{CALCULATION OF THE GRADIENTS}

In this section, the calculation of the gradient of a cost function in adjoint model with respect to the model input (e.g. emissions) is discussed in more mathematical details. The gradients are computed employing the adjoint variable. The cost function is shown by character $J$, input vector is represented by $I$, and $\mathrm{C}$ is the concentration vector. Due to the nonlinearity in gas-phase chemistry concentration is a nonlinear function of the input (represented by ADE equation):

$$
C=G(I)
$$

The output is perturbed $(\delta C)$ with any perturbation in each input (e.g., $\delta$ ) [Hakami et al., 2007]:

$$
\delta C=G^{\prime}(\delta I)
$$

where $G^{\prime}$ is the gradient of $G$, and called Jacobian matrix; the gradient is the sensitivities of model output $C$ with respect to the model input $I . G^{\prime}$ also referred to as the tangent linear operator, represents the linear version of G [Wang et al, 200I]:

$$
G^{\prime}=\left[\begin{array}{cccc}
\frac{\partial G_{11}}{\partial i_{1}} & \frac{\partial G_{12}}{\partial i_{2}} & \ldots & \frac{\partial G_{l n}}{\partial i_{n}} \\
\ldots & & & \\
\ldots & & & \\
\frac{\partial G_{m 1}}{\partial i_{1}} & \ldots & \ldots & \frac{\partial G_{m n}}{\partial i_{n}}
\end{array}\right]
$$


How the output $(C)$ changes, is usually the concern; however, recently what is more of a focus is an objective (cost function) dependant of the model output. So $J$ is defined as that scalar cost function, and the perturbation in $J$ is calculated from Equation A-4:

$$
\delta J=\left\langle\nabla_{c} J, \delta C\right\rangle
$$

where $(\ldots)$ is representing an inner product. Substituting Equation A-2 in Equation A-4:

$$
\delta J=\left\langle\nabla_{c} J, G^{\prime} \delta I\right)
$$

Duality principle applied to the inner product, $\left(\langle C, L I\rangle=\left\langle L^{*} C, I\right\rangle\right.$ where $L^{*}$ is transpose of $L):$

$$
\delta J=\left\langle G^{\prime *} \nabla_{\mathrm{c}} J, \delta I\right\rangle
$$

Equation A-7 is showing calculation of the gradient of the cost function $J$ (e.g. average ozone) with respect to the model input $I$ (e.g., emission) [Wang et al, 2001]:

$$
\nabla_{l} J=G^{\prime *} \nabla_{c} J
$$

where the right hand side is gradient of cost function with respect to the input parameters vector; and $G^{\prime *}$ is transpose of Jacobian matrix. 


\section{APPENDIX B:}

\section{SUMMARY OF REACTIVITY RESULTS}

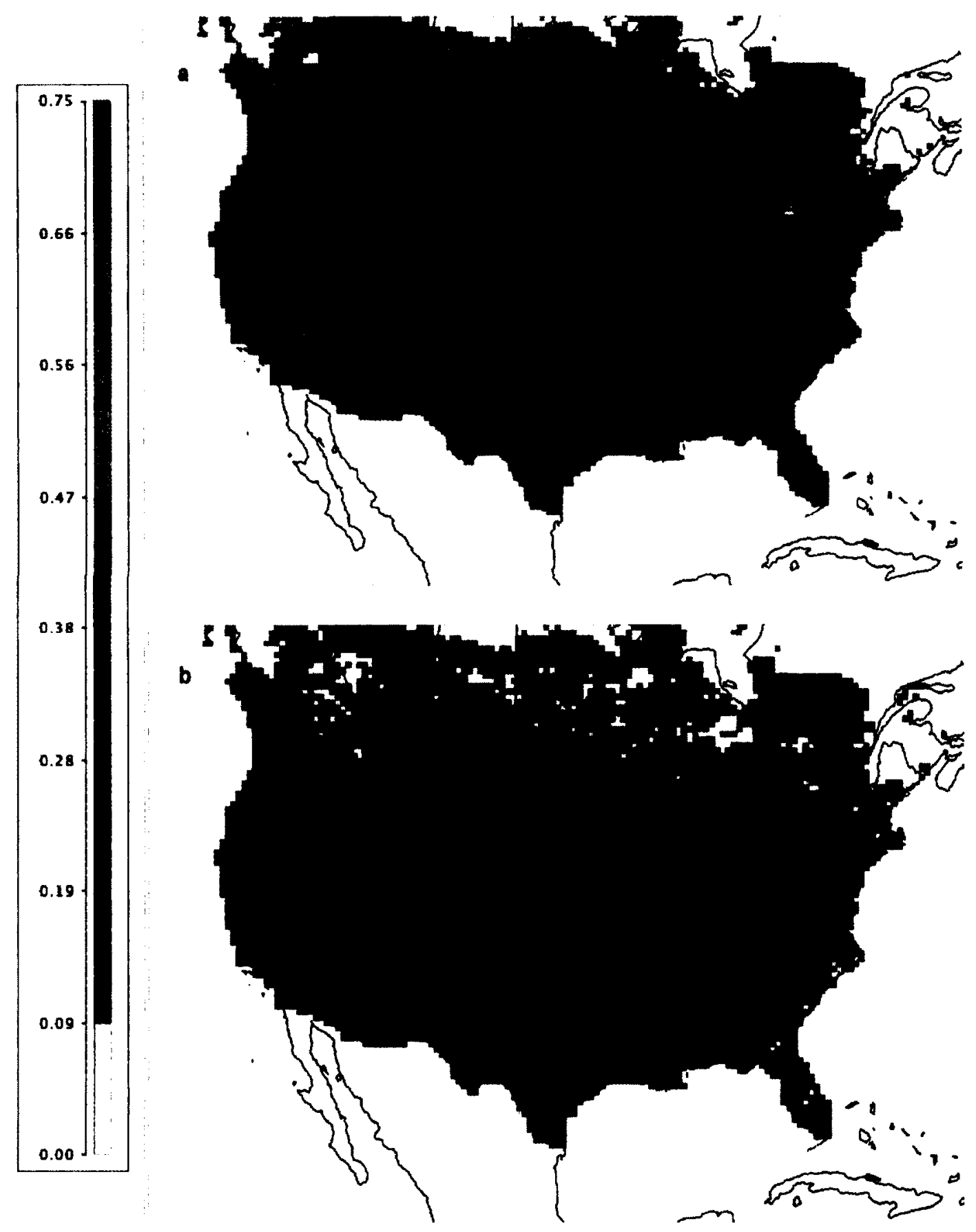

Figure B-1: Median metric relative reactivities of Acetone for each location a) median value b) standard deviation 


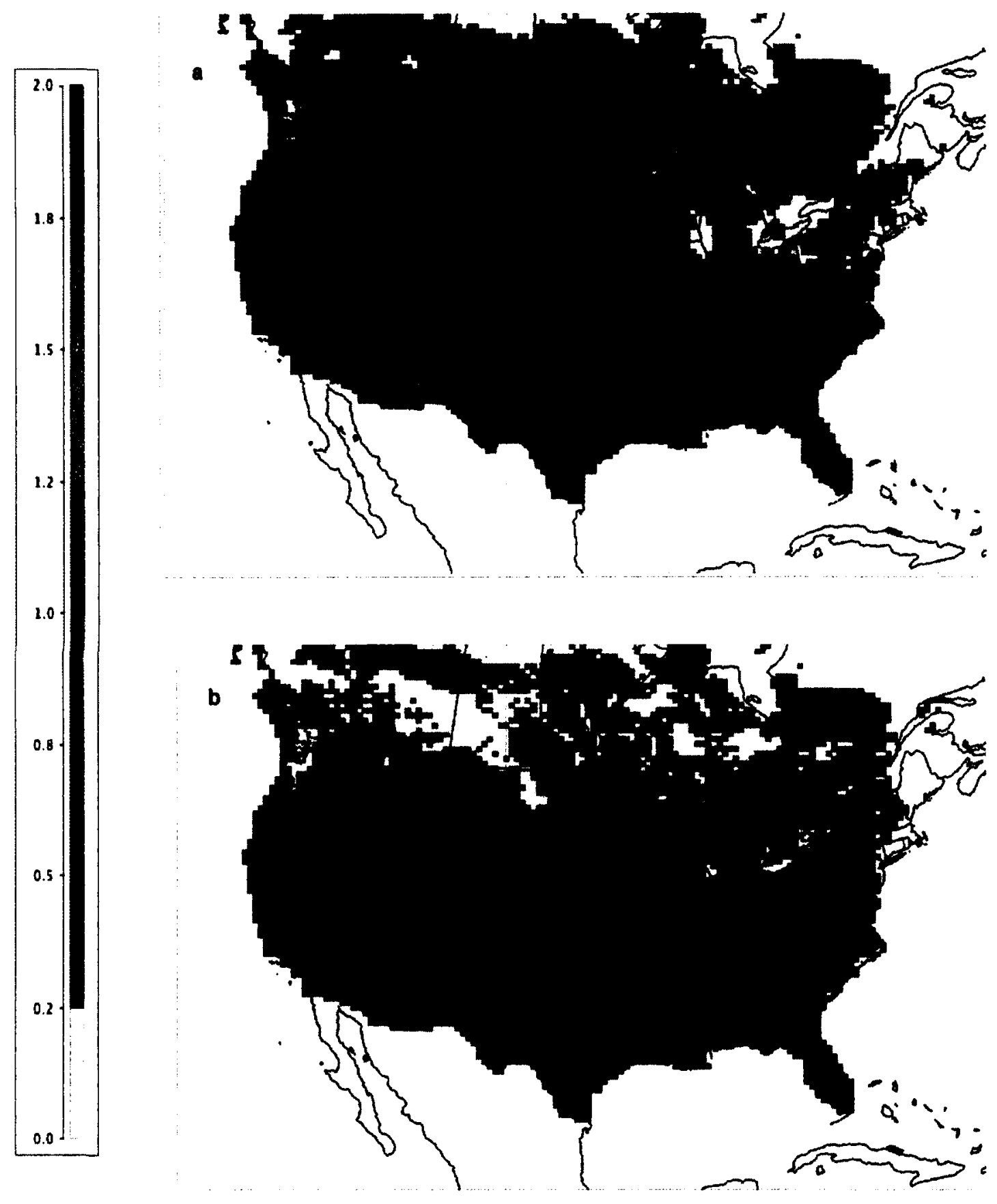

Figure B-2: Median metric relative reactivities of Alkenes for each location a) median value b) standard deviation 


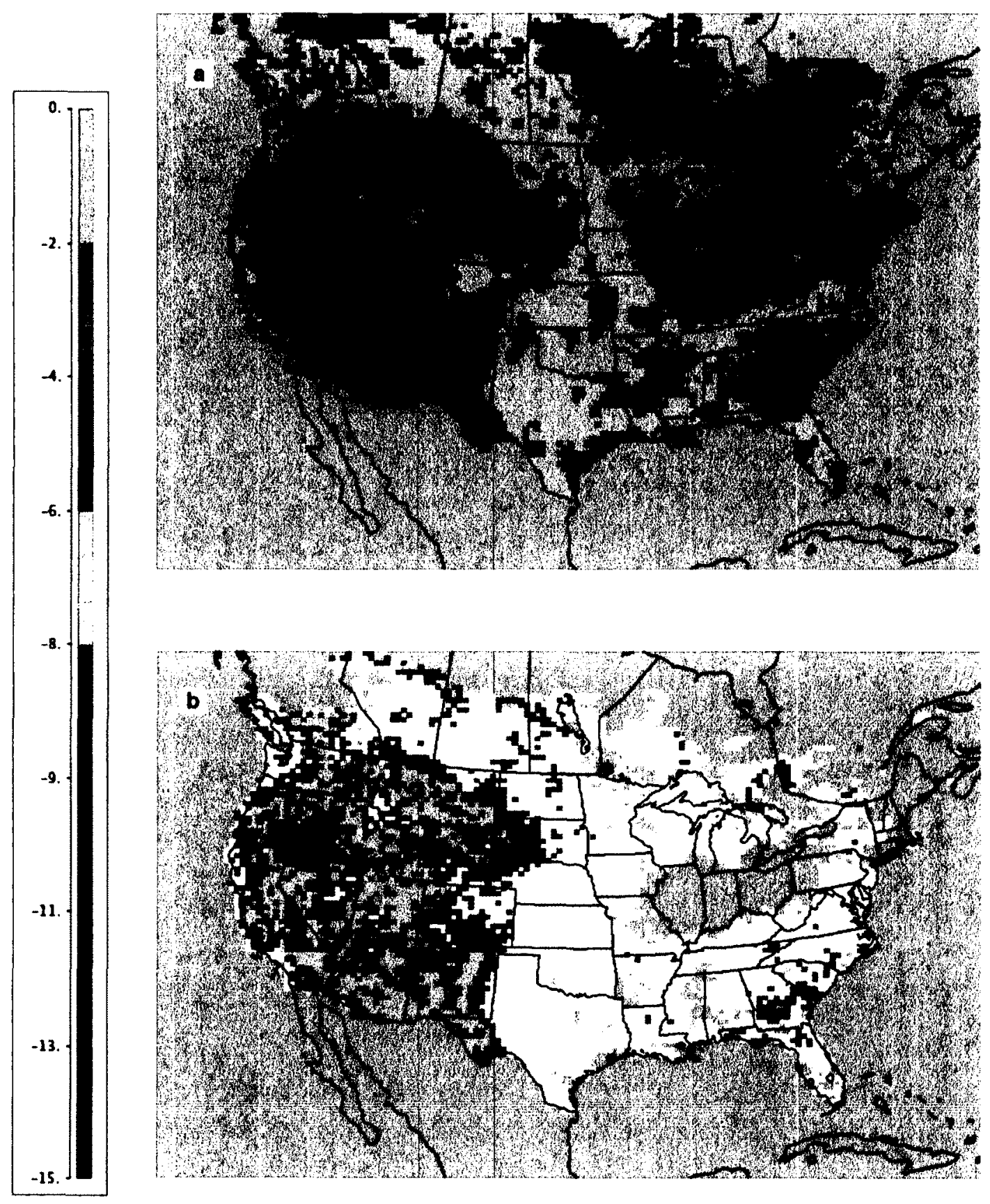

Figure B-3: Median metric relative reactivities of Banzaldehyde for each location a) median value b) standard deviation 

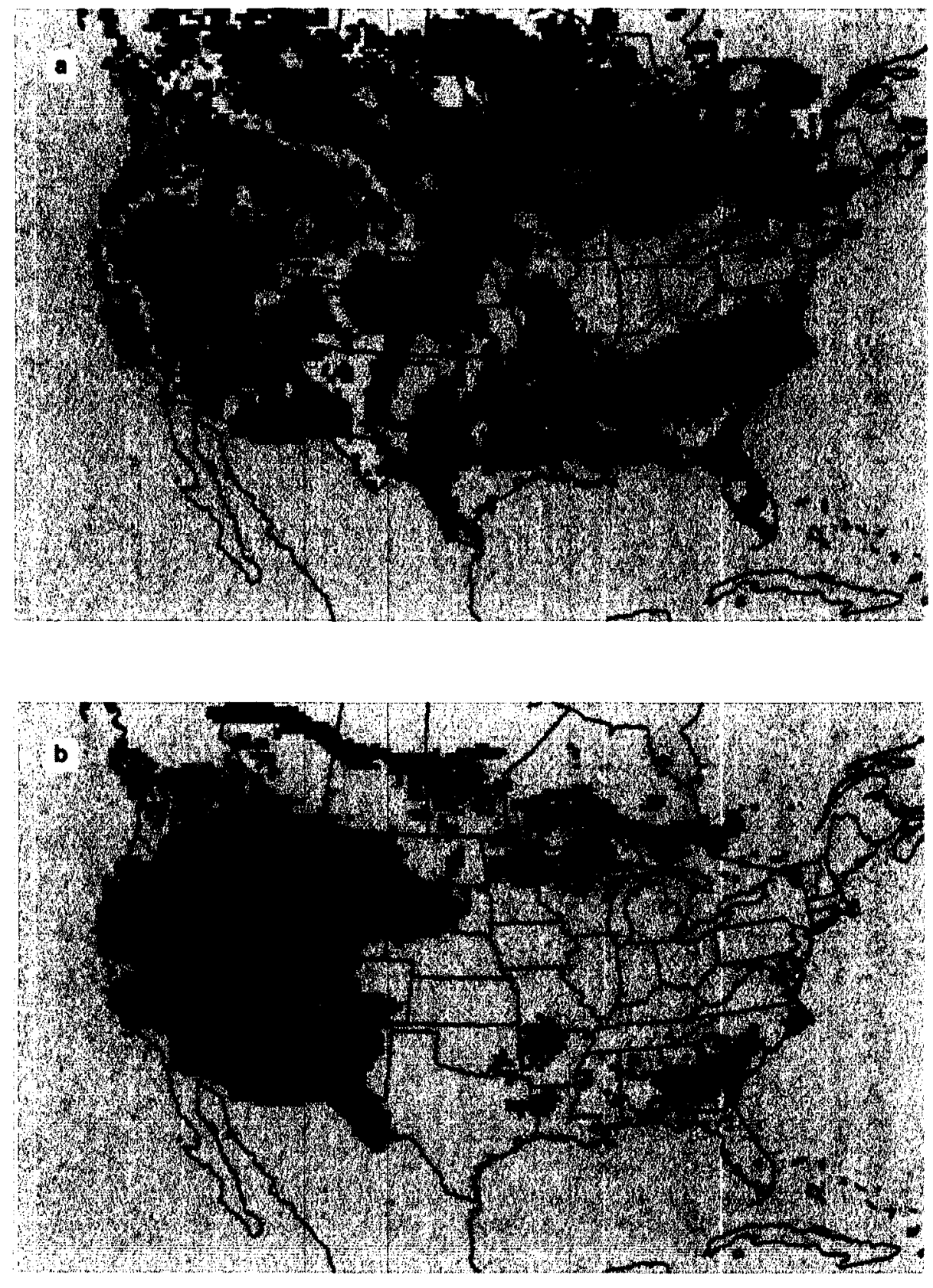

Figure B-4: Median metric relative reactivities of Cresols for each location a) median value b) standard deviation 


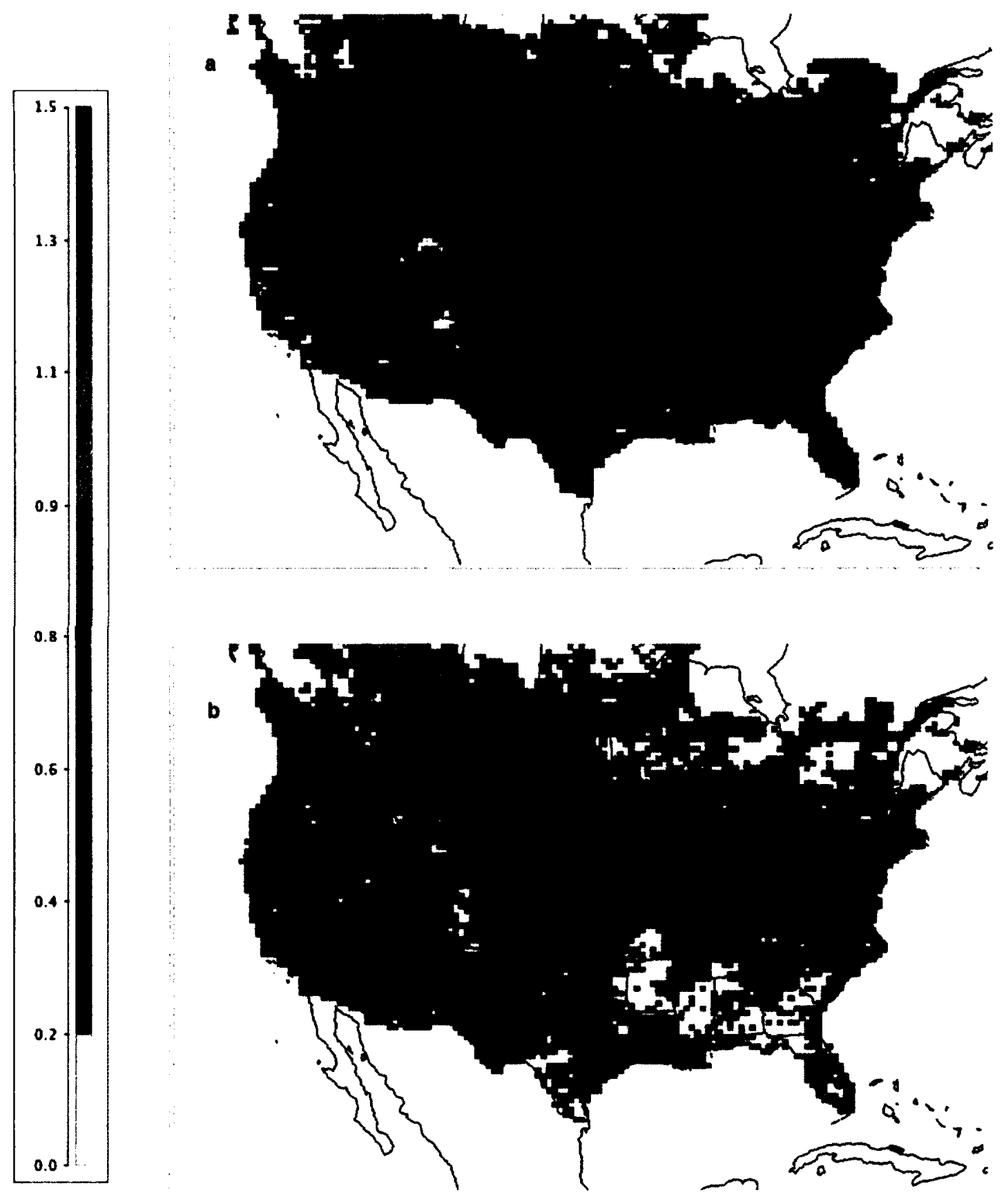

Figure B-5: Median metric relative reactivities of Glyoxal for each location a) median value b) standard deviation 
Table B-1: Median Relative Reactivities of Adjoint and Box Model Values

\begin{tabular}{|l|c|c|c|c|c|c|}
\hline \multirow{2}{*}{ Name } & \multicolumn{5}{c|}{ Adjoint } & \multicolumn{2}{c|}{ Box Model } \\
\hline ACET & MRR & $\begin{array}{c}\text { Standard } \\
\text { Deviation }\end{array}$ & $\mathbf{8 4 \%}$ & $16 \%$ & MIR & MOIR \\
\hline ALK1 & 0.357 & 0.135 & 0.499 & 0.230 & 0.118 & 0.091 \\
\hline ALK2 & 0.685 & 0.382 & 1.141 & 0.377 & 0.385 & 0.278 \\
\hline ALK3 & 1.003 & 0.398 & 1.420 & 0.624 & 0.432 & 0.407 \\
\hline ALK4 & 1.262 & 0.322 & 1.614 & 0.971 & 0.567 & 0.552 \\
\hline ALK5 & 0.563 & 0.260 & 0.784 & 0.263 & 0.363 & 0.155 \\
\hline ARO1 & -0.308 & 1.110 & 0.207 & -2.014 & 0.934 & 0.731 \\
\hline ARO2 & 0.023 & 0.816 & 0.560 & -1.072 & 2.354 & 2.154 \\
\hline BALD & -0.068 & 0.035 & -0.039 & -0.108 & -0.017 & -0.071 \\
\hline CCHO & 0.634 & 0.483 & 1.003 & 0.037 & 1.881 & 1.637 \\
\hline CCO_OH & 0.159 & 0.072 & 0.236 & 0.093 & 0.195 & 0.227 \\
\hline CRES & -0.118 & 0.103 & -0.060 & -0.266 & 0.006 & 0.001 \\
\hline ETHENE & 2.958 & 0.572 & 3.691 & 2.547 & 2.496 & 2.313 \\
\hline GLY & 0.574 & 0.193 & 0.771 & 0.385 & 3.910 & 4.567 \\
\hline HCHO & 0.316 & 0.157 & 0.460 & 0.147 & 2.466 & 2.638 \\
\hline HCOOH & 0.035 & 0.015 & 0.050 & 0.020 & 0.021 & 0.023 \\
\hline MEK & 0.762 & 0.275 & 1.024 & 0.474 & 0.410 & 0.325 \\
\hline MEOH & 0.187 & 0.074 & 0.262 & 0.115 & 0.195 & 0.175 \\
\hline MGLY & 0.786 & 0.580 & 1.127 & -0.033 & 4.457 & 4.990 \\
\hline OLE1 & 1.195 & 0.268 & 1.456 & 0.920 & 2.175 & 1.968 \\
\hline OLE2 & 0.246 & 0.952 & 1.339 & -0.565 & 0.452 & 0.444 \\
\hline PHEN & -0.125 & 0.104 & -0.064 & -0.271 & 0.005 & 0.000 \\
\hline PROD2 & 1.093 & 0.213 & 1.260 & 0.835 & 0.443 & 0.357 \\
\hline RCHO & 0.730 & 0.494 & 1.082 & 0.094 & 2.167 & 1.865 \\
\hline RCO_OH & 0.243 & 0.139 & 0.390 & 0.113 & 0.319 & 0.273 \\
\hline TRP1 & 0.461 & 0.504 & 1.001 & -0.007 & 1.049 & 0.978 \\
\hline ISOPRENE & 1.159 & 0.890 & 1.954 & 0.175 & 2.939 & 2.735 \\
\hline CO & 0.102 & 0.033 & 0.137 & 0.071 & 0.016 & 0.019 \\
\hline
\end{tabular}


Table B-2: Local MRR of selected compounds for different sites over the domain, and BM values

\begin{tabular}{|c|c|c|c|c|c|c|c|c|}
\hline & & Ethene & Isoprene & n-Butane & Formaldehyde & Acetone & Methanol & $\begin{array}{c}\text { Carbon } \\
\text { Monoxide } \\
\end{array}$ \\
\hline \multirow{2}{*}{ Vancouver } & md & 2.98 & 2.95 & 0.67 & 0.47 & 0.15 & 0.12 & 0.05 \\
\hline & st & 1.62 & 1.95 & 0.54 & 0.49 & 0.16 & 0.10 & 0.03 \\
\hline \multirow{2}{*}{ Phoenix } & $\mathrm{md}$ & 2.37 & 0.55 & 1.16 & 0.15 & 0.34 & 0.22 & 0.09 \\
\hline & st & 1.19 & 1.31 & 0.66 & 0.17 & 0.21 & 0.13 & 0.05 \\
\hline \multirow{2}{*}{$\begin{array}{l}\text { Los } \\
\text { Angeles }\end{array}$} & $\mathrm{md}$ & 2.08 & 1.85 & 0.91 & 0.29 & 0.26 & 0.22 & 0.06 \\
\hline & st & 1.09 & 1.54 & 0.87 & 0.32 & 0.27 & 0.12 & 0.06 \\
\hline \multirow{2}{*}{ Calgary } & $\mathrm{md}$ & 2.80 & 2.54 & 0.77 & 0.42 & 0.19 & 0.16 & 0.06 \\
\hline & st & 1.38 & 1.57 & 0.47 & 0.43 & 0.12 & 0.09 & 0.04 \\
\hline \multirow{2}{*}{ Houston } & md & 2.16 & 3.01 & 0.93 & 0.20 & 0.22 & 0.13 & 0.06 \\
\hline & st & 0.87 & 1.20 & 0.49 & 0.14 & 0.13 & 0.08 & 0.03 \\
\hline \multirow{2}{*}{ New York } & $\mathrm{md}$ & 2.18 & 2.26 & 0.54 & 0.69 & 0.13 & 0.14 & 0.04 \\
\hline & st & 1.43 & 1.59 & 0.46 & 0.57 & 0.14 & 0.11 & 0.03 \\
\hline \multirow{2}{*}{ Toronto } & md & 2.65 & 2.64 & 0.53 & 0.59 & 0.11 & 0.15 & 0.04 \\
\hline & st & 1.03 & 1.11 & 0.51 & 0.29 & 0.13 & 0.11 & 0.03 \\
\hline \multirow{2}{*}{ Detriot } & $\mathrm{md}$ & 2.54 & 2.76 & 0.66 & 0.55 & 0.15 & 0.16 & 0.05 \\
\hline & st & 1.23 & 1.30 & 0.58 & 0.36 & 0.15 & 0.11 & 0.04 \\
\hline \multirow{2}{*}{ Atlanta } & $\mathrm{md}$ & 2.56 & 1.53 & 1.47 & 0.35 & 0.41 & 0.18 & 0.11 \\
\hline & st & 0.64 & 1.21 & 0.63 & 0.22 & 0.17 & 0.12 & 0.05 \\
\hline \multirow{2}{*}{ Virginia } & $\mathrm{md}$ & 3.09 & 0.89 & 1.20 & 0.39 & 0.30 & 0.23 & 0.09 \\
\hline & st & 0.99 & 0.90 & 0.76 & 0.15 & 0.23 & 0.11 & 0.04 \\
\hline MIR & - & 2.12 & 0.21 & 0.96 & 2.62 & 0.10 & 0.15 & 0.01 \\
\hline MOIR & - & 2.31 & 2.74 & 0.35 & 2.64 & 0.09 & 0.18 & 0.02 \\
\hline
\end{tabular}


Table B-3: Related values for Concentration-Based and Non-Attainment Scenarios

\begin{tabular}{|c|c|c|c|c|c|c|c|c|}
\hline \multirow[b]{2}{*}{ Name } & \multicolumn{4}{|c|}{ Concentration-based Base Mixture } & \multicolumn{4}{|c|}{ Non-Attainment Metric } \\
\hline & MRR & $\begin{array}{l}\text { Standard } \\
\text { Deviation }\end{array}$ & $84 \%$ & $16 \%$ & MRR & $\begin{array}{l}\text { Standard } \\
\text { Deviation } \\
\end{array}$ & $84 \%$ & $16 \%$ \\
\hline ACET & 0.390 & 0.125 & 0.512 & 0.263 & 0.316 & 0.111 & 0.431 & 0.210 \\
\hline ALKI & 0.771 & 0.351 & 1.150 & 0.447 & 0.621 & 0.239 & 0.857 & 0.379 \\
\hline ALK2 & 1.087 & 0.369 & 1.450 & 0.713 & 0.871 & 0.305 & 1.183 & 0.573 \\
\hline ALK3 & 1.498 & 0.391 & 1.907 & 1.125 & 1.240 & 0.373 & 1.626 & 0.881 \\
\hline ALK4 & 1.334 & 0.299 & 1.669 & 1.070 & 1.083 & 0.316 & 1.442 & 0.811 \\
\hline ALK5 & 0.614 & 0.275 & 0.853 & 0.303 & 0.459 & 0.292 & 0.813 & 0.228 \\
\hline AR01 & -0.356 & 1.165 & 0.220 & -2.110 & -0.142 & 0.927 & 0.212 & -1.642 \\
\hline ARO2 & 0.027 & 0.873 & 0.630 & -1.116 & 0.150 & 0.673 & 0.384 & -0.963 \\
\hline BALD & -0.073 & 0.035 & -0.041 & -0.110 & -0.051 & 0.036 & -0.023 & -0.095 \\
\hline CCHO & 0.682 & 0.490 & 1.080 & 0.101 & 0.494 & 0.321 & 0.833 & 0.191 \\
\hline CCO_OH & 0.171 & 0.068 & 0.238 & 0.103 & 0.135 & 0.067 & 0.192 & 0.059 \\
\hline CRES & -0.125 & 0.103 & -0.063 & 0.270 & -0.083 & 0.098 & -0.039 & -0.236 \\
\hline ETHENE & 3.052 & 0.620 & 3.862 & 2.621 & 2.363 & 0.488 & 2.835 & 1.858 \\
\hline GLY & 0.587 & 0.214 & 0.828 & 0.400 & 0.380 & 0.215 & 0.645 & 0.215 \\
\hline HCHO & 0.328 & 0.164 & 0.482 & 0.154 & 0.231 & 0.139 & 0.352 & 0.074 \\
\hline $\mathrm{HCOOH}$ & 0.038 & 0.014 & 0.050 & 0.023 & 0.030 & 0.015 & 0.041 & 0.012 \\
\hline MEK & 0.831 & 0.242 & 1.052 & 0.569 & 0.694 & 0.240 & 0.938 & 0.459 \\
\hline МЕOH & 0.200 & 0.068 & 0.264 & 0.128 & 0.160 & 0.070 & 0.216 & 0.077 \\
\hline MGLY & 0.825 & 0.618 & 1.237 & 0.000 & 0.539 & 0.363 & 0.929 & 0.202 \\
\hline OLE1 & 1.286 & 0.325 & 1.603 & 0.954 & 0.901 & 0.286 & 1.202 & 0.629 \\
\hline OLE2 & 0.273 & 1.007 & 1.500 & -0.514 & 0.252 & 0.576 & 1.079 & -0.073 \\
\hline PHEN & -0.133 & 0.103 & -0.068 & -0.274 & -0.087 & 0.099 & -0.042 & -0.240 \\
\hline PROD2 & 1.158 & 0.186 & 1.320 & 0.948 & 0.912 & 0.230 & 1.132 & 0.672 \\
\hline RCHO & 0.799 & 0.484 & 1.136 & 0.169 & 0.566 & 0.331 & 0.879 & 0.217 \\
\hline RCO_OH & 0.268 & 0.134 & 0.403 & 0.135 & 0.206 & 0.107 & 0.308 & 0.094 \\
\hline TRP1 & 0.481 & 0.548 & 1.095 & 0.000 & 0.354 & 0.329 & 0.784 & 0.126 \\
\hline ISOPRENE & 1.263 & 0.999 & 2.192 & 0.194 & 0.928 & 0.688 & 1.500 & 0.123 \\
\hline $\mathrm{CO}$ & 0.109 & 0.031 & 0.140 & 0.078 & 0.085 & 0.026 & 0.112 & 0.059 \\
\hline
\end{tabular}

